JOINT TRANSPORTATION RESEARCH PROGRAM

FHWA/IN/JTRP-2009/30

Final Report

SYNTHESIS STUDY: DEVELOPMENT OF AN ELECTRONIC DETECTION AND WARNING SYSTEM TO PREVENT OVERHEIGHT

VEHICLES FROM IMPACTING OVERHEAD BRIDGES

Joseph V. Sinfield

July 2010 


\section{TECHNICAL Summary}

INDOT Research

Technology Transfer and Project Implementation Information

TRB Subject Code: 25-1 Bridges

Publication No.: FHWA/IN/JTRP-2009/30, SPR-3237

July 2010

Final Report

\section{Synthesis Study: Development of an Electronic Detection and Warning System to Prevent Overheight Vehicles from Impacting Overhead Bridges}

\section{Introduction}

Overheight vehicle impacts with bridges are surprisingly common and are of particular concern in areas of Indiana such as the I-65 - I70 merger location in Indianapolis. The damage from collisions can range from minor to severe, and there is evidence that some bridges are impacted multiple times, leading to the potential for cumulative damage effects. With this in mind, there is a clear need to attempt to prevent overheight vehicle collisions with bridges; and this study provides an in-depth examination of the availability and in-field performance of Overheight Vehicle Detection and Warning (OVD\&W) systems that could help address this challenge.

\section{Findings}

The findings of this study indicate that most states have updated their infrastructure to account for overheight vehicles and permanently avoid collisions. The few states that still actively employ overheight vehicle detection and warning systems (OVD\&W) tend to use optoelectronic single- or dual-eye infrared detection systems and report that the devices have decreased the amount of damage occurring to their structures. The initial equipment and installation costs of these systems range from a few thousand to twenty-five thousand dollars based on DOT interviews, and on-going maintenance appears minimal. Overall, considering that the only other completely effective option to avoid overheight vehicle incidents is to raise the height of affected structures, or lower the roadway surface, an (optoelectronic) OVD\&W system is a relatively inexpensive and effective method for decreasing overheight vehicle accident.

\section{Implementation}

The combined insights gained through this study were used to develop a straight-forward decision tool that can be employed by INDOT personnel to identify equipment options to address site specific needs for overheight vehicle protection. This tool and its underlying principles were applied to a test case focused on the I-65 -
I-70 merger location in Indianapolis, IN leading to a preliminary OVD\&W system strategy for that specific location. It is recommended that the sensor characteristics and design decision logic exemplified through this case example be used for future OVD\&W system deployment envisioned in the State. 


\section{Contacts}

For more information:

Prof. Joseph V. Sinfield

Principal Investigator

School of Civil Engineering

Purdue University

West Lafayette IN 47907

Phone: (765) 496-2742

E-mail: jvs@purdue.edu
Indiana Department of Transportation

Division of Research

1205 Montgomery Street

P.O. Box 2279

West Lafayette, IN 47906

Phone: (765) 463-1521

Fax: (765) 497-1665

\section{Purdue University}

Joint Transportation Research Program

School of Civil Engineering

West Lafayette, IN 47907-1284

Phone: (765) 494-9310

Fax: (765) 496-7996

E:mail: jtrp@ecn.purdue.edu 
Final Report

FHWA/IN/JTRP-2009/30

\title{
SYNTHESIS STUDY: DEVELOPMENT OF AN ELECTRONIC DETECTION AND WARNING SYSTEM TO PREVENT OVERHEIGHT VEHICLES FROM IMPACTING OVERHEAD BRIDGES
}

\author{
by \\ Joseph V. Sinfield \\ Principal Investigator \\ Assistant Professor \\ School of Civil Engineering \\ Purdue University \\ Joint Transportation Research Program \\ Project Number: C-36-67VVVV \\ File Number: 9-10-99 \\ SPR-3237

\begin{abstract}
Conducted in Cooperation with the
Indiana Department of Transportation

and the U.S. Department of Transportation

Federal Highway Administration
\end{abstract}

The contents of this report reflect the views of the authors, who are responsible for the facts and the accuracy of the data presented herein. The contents do not necessarily reflect the official views or policies of the Indiana Department of Transportation or the Federal Highway Administration at the time of publication. The report does not constitute a standard, specification, or regulation.

\author{
Purdue University \\ West Lafayette, IN 47906 \\ July 2010
}




\begin{tabular}{|c|c|c|}
\hline $\begin{array}{l}\text { 1. Report No. } \\
\text { FHWA/IN/JTRP-2009/30 }\end{array}$ & 2. Government Accession No. & 3. Recipient's Catalog No. \\
\hline \multirow{2}{*}{\multicolumn{2}{|c|}{$\begin{array}{l}\text { 4. Title and Subtitle } \\
\text { Synthesis Study: Development of an Electronic Detection and Warning System to } \\
\text { Prevent Overheight Vehicles from Impacting Overhead Bridges }\end{array}$}} & $\begin{array}{l}\text { 5. } \text { Report Date } \\
\text { July } 2010\end{array}$ \\
\hline & & 6. Performing Organization Code \\
\hline $\begin{array}{l}\text { 7. Author(s) } \\
\text { Joe Sinfield } \\
\text { Assistant Professor of Civil Engineering. }\end{array}$ & due University & $\begin{array}{l}\text { 8. Performing Organization Report No. } \\
\text { FHWA/IN/JTRP-2009/30 }\end{array}$ \\
\hline \multirow{2}{*}{\multicolumn{2}{|c|}{$\begin{array}{l}\text { 9. Performing Organization Name and Address } \\
\text { Joint Transportation Research Program } \\
\text { Purdue University } \\
550 \text { Stadium Mall Drive } \\
\text { West Lafayette, IN 47907-2051 }\end{array}$}} & 10. Work Unit No. \\
\hline & & $\begin{array}{l}\text { 11. Contract or Grant No. } \\
\text { SPR-3237 }\end{array}$ \\
\hline \multirow{2}{*}{\multicolumn{2}{|c|}{$\begin{array}{l}\text { 12. Sponsoring Agency Name and Address } \\
\text { Indiana Department of Transportation } \\
\text { State Office Building } \\
100 \text { North Senate Avenue } \\
\text { Indianapolis, IN } 46204\end{array}$}} & $\begin{array}{l}\text { 13. Type of Report and Period Covered } \\
\text { Final Report }\end{array}$ \\
\hline & & 14. Sponsoring Agency Code \\
\hline
\end{tabular}

\section{Supplementary Notes}

Prepared in cooperation with the Indiana Department of Transportation and Federal Highway Administration.

16. Abstract

Overheight vehicle impacts with bridges are surprisingly common. The damage from collisions can range from minor to severe, and there is also evidence that some bridges are impacted multiple times, leading to the potential for cumulative damage effects. Thus there is a clear need to attempt to prevent overheight vehicle collisions with bridges.

This Synthesis Study provides a review of solutions that exist to detect and forewarn overheight vehicles and thereby prevent a collision, and specifically examines the breadth of available overheight vehicle detection technologies, the commercial availability of such equipment, and the experience of relevant DOTs with installed and functioning systems.

The findings of this study indicate that most states have updated their infrastructure to account for overheight vehicles and permanently avoid collisions. The few states that still actively employ overheight vehicle detection and warning systems (OVD\&W) tend to use optoelectronic single- or dual-eye infrared detection systems and report that the devices have decreased the amount of damage occurring to their structures. The initial equipment and installation costs of these systems range from a few thousand to twenty-five thousand dollars based on DOT interviews, and on-going maintenance appears minimal. Overall, considering that the only other completely effective option to avoid overheight vehicle incidents is to raise the height of affected structures, or lower the roadway surface, an (optoelectronic) OVD\&W system is a relatively inexpensive and effective method for decreasing overheight vehicle accidents.

With this in mind, this study provides a guide to the site characteristics that influence both sensor selection and overall OVD\&W system design. A simple Equipment Selection Tool is presented to guide system choice, and is demonstrated through a case example centered on the I-65 - I-70 merger location in Indianapolis, IN.

\section{Key Words}

Overheight vehicle, bridge collisions, electro-optical sensors, infrared beam, detection, warning, re-routing

18. Distribution Statement

No restrictions. This document is available to the public through the National Technical Information Service, Springfield, VA 22161
19. Security Classif. (of this report)

Unclassified
20. Security Classif. (of this page)

Unclassified
21. No. of Pages

74 
TABLE OF CONTENTS

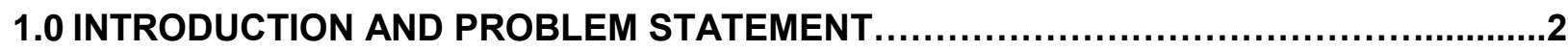

2.0 OBJECTIVES AND SCOPE..................................................................

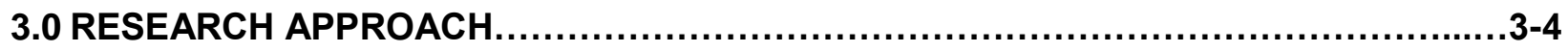

4.0 OVERVIEW OF EXISTING COMMERCIALLY AVAILABLE OVD\&W SYSTEMS...........5-6

4.1 ROADWAY DETECTION WARNING AND RE-ROUTING SYSTEM DESIGNS AND

OPERATING PRINCIPLES....................................................6-14

4.2 COMMERCIAL AVAILABILITY.............................................15-16

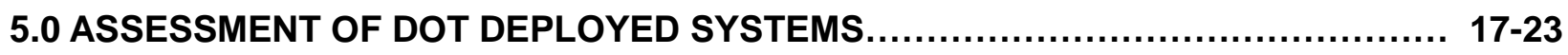

5.1 IDENTIFICATION OF STATES WITH OVD SYSTEMS.........................17-19

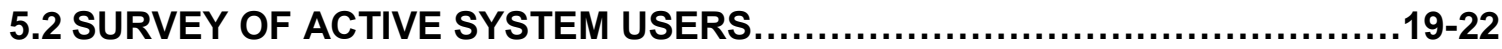

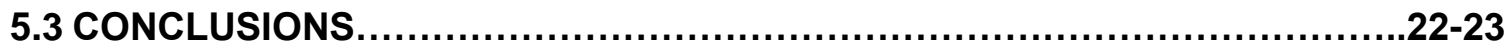

6.0 RECOMMENDATION FOR SYSTEM SELECTION PROCESS $\ldots \ldots \ldots \ldots \ldots \ldots \ldots \ldots \ldots \ldots \ldots \ldots \ldots \ldots \ldots . .23-25$

6.1 OVD\&W SYSTEM SELECTION CONSIDERATIONS ..........................23-24

6.2 OVD\&W SENSOR SELECTION GUIDE......................................24-25

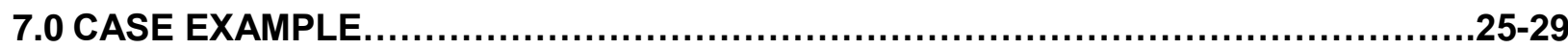

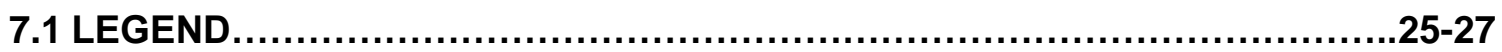

7.2 PREVENTION SIGNS..........................................................27-28

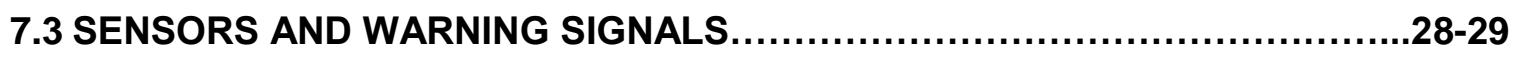

8.0 BENEFITS OF STUDY AND RECOMMENDATIONS FOR USE OF FINDINGS..............30

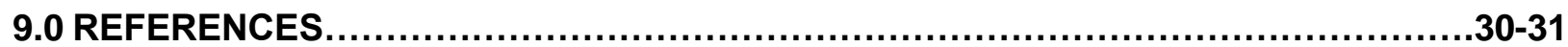

APPENDIX A: Sensor specification sheets by vendor.

APPENDIX B: Vendor contact details.

APPENDIX C: Detailed schematic of I-65 - I-70 merger location in Indianapolis, IN and proposed OVD\&W system deployment plan. 


\subsection{INTRODUCTION AND PROBLEM STATEMENT}

Overheight vehicle impacts with bridges are surprisingly common. An in-depth study conducted by Fu et. al. (2004) in the state of Maryland indicated that "of the 1,496 bridges susceptible to impact by overheight vehicles statewide, 309 (20\%) [had] been struck, [and] $54(4 \%)$ required repairs." Fu et. al. further indicate that a nationwide survey on the subject garnered response from 29 states, and $62 \%$ of these stated that overheight vehicle collisions with bridges are a significant problem. Fu et. al. also point out that few states that actually reported data also track the financial consequences of overheight vehicle impact on bridges. However, for those that did (Kentucky, Mississippi, lowa, Louisiana), the annual average financial impact of vehicle bridge collisions amounted to $\$ 250$ - $\$ 500$ thousand dollars.

The damage from collisions can range from minor to severe, and there is also evidence that some bridges are impacted multiple times, leading to the potential for cumulative damage effects. Fu et. al. (2004) report that for Maryland, about half of the bridges that were known to be struck received only scrapes, about one third sustained minor damage, and slightly less than $20 \%$ required repairs.

While there is little doubt that overheight vehicle collisions result in costly damage, and that preventing these collisions is clearly an issue that must be addressed, it is also apparent that many overheight vehicle collisions with bridges go unobserved and their effects are only discovered at a subsequent time during routine inspections. Thus there is a clear need to not only attempt to prevent overheight vehicle collisions with bridges, but also to monitor susceptible bridge structures and thus alert authorities to a collision that may warrant inspection and repair.

\subsection{OBJECTIVES AND SCOPE}

The objective of this Synthesis Study was to examine and summarize available off-the-shelf solutions that address two challenges associated with the problem of overheight vehicle impact with overhead bridges:

1. A primary focus, particularly in the context of the issues faced by INDOT, was to conduct a thorough review of technological solutions that are readily available to detect and forewarn overheight vehicles to prevent a collision - technologies collectively known as Overheight Vehicle Detection \& Warning Systems (OVD\&W Systems). 
2. A secondary focus was to examine and summarize the availability of off-the-shelf technologies that could detect a vehicle-bridge collision and automatically alert appropriate authorities of the incident.

\subsection{RESEARCH APPROACH}

This synthesis effort consisted of a multi-pronged data gathering initiative focused on understanding the breadth of available means to detect overheight vehicles and avoid structurevehicle collisions, the commercial availability of such systems, and the experience of relevant DOTs with installed and functioning systems.

Insight into applicable technologies was gained through an evaluation of (1) literature and databases, (2) commercial vendor offerings, and (3) a survey of technologies/solutions utilized by other DOTs.

(1) Literature and databases that were examined include the following:

- FHWA Database of Priorities, Market-Ready Technologies, and Innovations

- AASHTO's Technology Implementation Group

- Technology Transfer News of the NYDOT

- The Caltrans Division of Research and Innovation

- The TRB Research In Progress (RiP) Database

- The TRB TRIS database

- The US DOT's Research and Innovative Technology Administration (RITA)

- The US DOT's Intelligent Transportation Systems unit

- The National Transportation Library

- The National Highway Traffic Safety Administration (Crash Avoidance and Intelligent Transportation Systems)

- The US DOT Research Development and Technology unit

- The US DOT Transportation Safety Institute

- The US DOT University Transportation Centers site

- The Volpe National Transportation Systems Center resource

- ITS International

- Compendex/Academic Search Premier/Omni File Mega/MetaLib technical journal review

- LexisNexis news search 
(2) The evaluation of vendor offerings was facilitated by internet searches, examination of commercial directories and company websites, and conversations/correspondence with vendor sales personnel and engineering staff.

(3) In addition to the sources cited above, DOTs from other states were surveyed to understand their experience with relevant technologies and/or their knowledge of potentially applicable systems. Specific characteristics of the systems under investigation (as outlined below) were obtained when available in addition to general evidence of deployment and satisfactory performance.

For each potential solution, information was gathered that could help inform INDOT's decision to pursue the specific technology for deployment within the State of Indiana. Specifically, efforts were made to define the following parameters:

- Operating principle (e.g., optical beam, image processing)

- Core sensor performance (e.g., accuracy, precision, error)

- Deployment requirements/capabilities (e.g., lane span, power)

- Associated alert system characteristics

- Overall advantages and disadvantages

- Ability to link to communication system

- Likely field performance (e.g., performance in rain, cold, snow)

- Reliability and maintenance requirements

- Cost (e.g., purchase, installation, maintenance)

- Compatibility with existing DOT systems (to the extent available)

Once identified, the performance characteristics of available systems were related to a set of site characteristics that have particular relevance to field deployment scenarios - for example, the traffic speed limits near bridges of interest, available location to place a system ahead of the bridge, proximity of bridges to alternate routes, distance from one side of the roadway to the other - to develop a OVD\&WS equipment selection guide/tool that will facilitate selection of equipment relevant to Indiana's needs. 


\subsection{OVERVIEW OF EXISTING/COMMERCIALLY AVAILABLE OVD\&W SYSTEMS}

A comprehensive literature review and database search was completed that encompasses perspectives on existing/commercially available OVD\&W system technologies from the sources outlined in Section 3.0. This review led to the development of a fundamental taxonomy of strategies to avoid/limit overheight vehicle incidents (Table 1).

\begin{tabular}{|l|l|c|c|}
\cline { 3 - 4 } \multicolumn{2}{c|}{} & Passive & Active \\
\hline \multirow{2}{*}{ Target } & Driver & $\begin{array}{c}\text { Education/ } \\
\text { Truck Marking }\end{array}$ & $\begin{array}{c}\text { In-cab Proximity } \\
\text { Alerts }\end{array}$ \\
\cline { 2 - 4 } & Structure & Protection & Alteration \\
\cline { 2 - 4 } & Roadway & Posting/ & $\begin{array}{c}\text { Detection/ } \\
\text { Re-routing }\end{array}$ \\
\hline
\end{tabular}

Table 1: Strategies to Address Overheight Vehicle-Infrastructure Collisions.

As illustrated in Table 1, measures to limit overheight vehicle collisions with infrastructure can be directed toward the driver, the structure itself, or the roadway. In addition, regardless of the focus, the steps taken can be passive or active in nature. Driver education and truck height marking (on driver's side and in the cab) have been shown to be an effective component of any programmatic effort aimed at reducing overheight vehicle collisions with structures. GPS based in-cab proximity alert systems that indicate the presence of a "low bridge" on the route of travel have also been shown to be helpful in alerting drivers to potentially unsafe conditions (e.g., Bridgewatch, BRIDGESAFE systems). It is also possible, albeit expensive, to limit the damage resulting from overheight vehicle - infrastructure collisions by erecting protective structures (e.g., in-line barriers, sacrificial beams or bars) that bear the brunt of a collision, or to avoid the potential for damage by increasing the vertical clearance between road surfaces and the underside of overhead structures (e.g., raising bridges or lowering roadway surfaces). However, from a DOT perspective, the most practical and economical measures to limit overheight vehicle incidents involve a combination of posting and marking roadways to warn 
drivers of upcoming obstacles along with active sensor systems that detect, warn, and re-route vehicles in jeopardy of a collision (shaded area of Table 1). This latter category of integrated sensing and warning systems on the roadway represents the focus of this work.

\subsection{ROADWAY DETECTION, WARNING AND RE-ROUTING SYSTEM DESIGNS AND OPERATING PRINCIPLES}

A typical active OVD\&W strategy involves three key elements, namely a sensor capable of detecting an overheight vehicle, an alarm or warning mechanism to alert the driver of the overheight vehicle, and, when possible, a communication mechanism that can convey an alternate route or information about other corrective action. Figure 1 provides a visual example of a typical installed configuration. The figure shows a truck passing through a single eye detection system (discussed in more detail below). In the figure both visual and auditory warning systems are utilized to alert the driver of an impending collision. Finally, the figure highlights a message board that directs the truck driver to an off ramp where the driver could exit the current roadway and avoid collision with the bridge. This is an ideal example of how a system would prevent an overheight vehicle from colliding with a structure. 


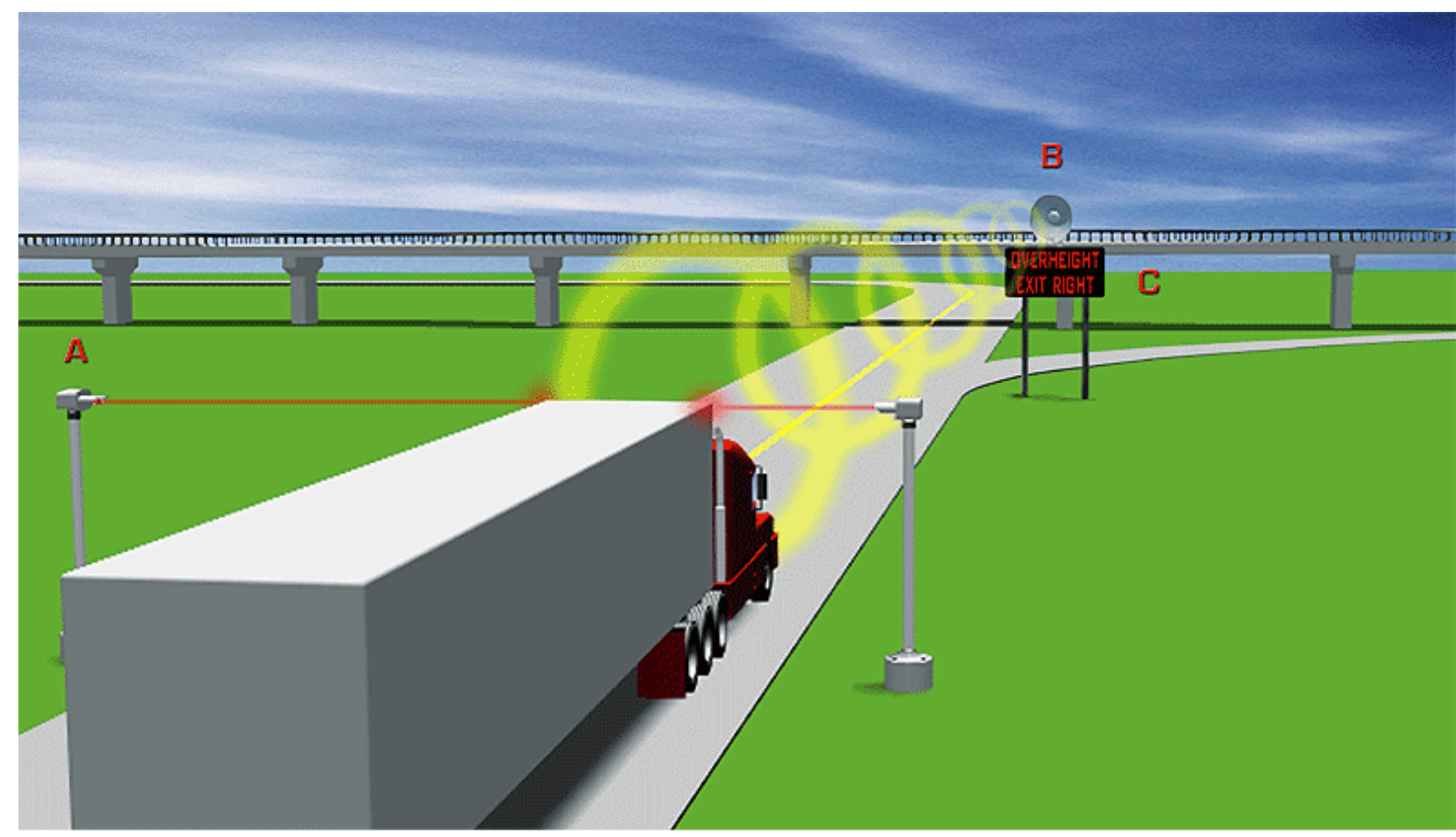
A
Overheight vehicle is detected by OVDS.
B O
C QVERHEIEHT
EXIT RIGHT
Alarm Bell activates with Warning Sign. Parabolic shield focuses sound toward vehicle, drawing attention of driver to Warning Sign.
Warning Sign activates with Alarm Bell. Sign message alerts driver of overheight hazard and provides
directions for appropriate respose.

Figure 1: Typical installed configuration (Source: Trigg Industries Inc.).

Examination of the sources of information outlined in Section 3.0 indicates that currently available overheight vehicle sensing and warning systems can be organized at a fundamental level by the sensing approach employed in any given device or method and its specific operational configuration. Specifically, overheight vehicle detection and warning systems make use of three primary sensing mechanisms (Figure 2): 1) optoelectronic sensors that rely upon the interruption of a beam or sheet of light to indicate that a vehicle exceeds a predefined height threshold, or to construct profiles of vehicles that can be interpreted to obtain accurate vehicle dimensions, 2) ultrasonic sensors that emit and receive ultrasonic frequencies from an overhead gantry-like structure down onto passing vehicles to assess their height, and 3) mechanical systems that provide direct indications of vehicle impact with a warning structure positioned at a limiting height. 


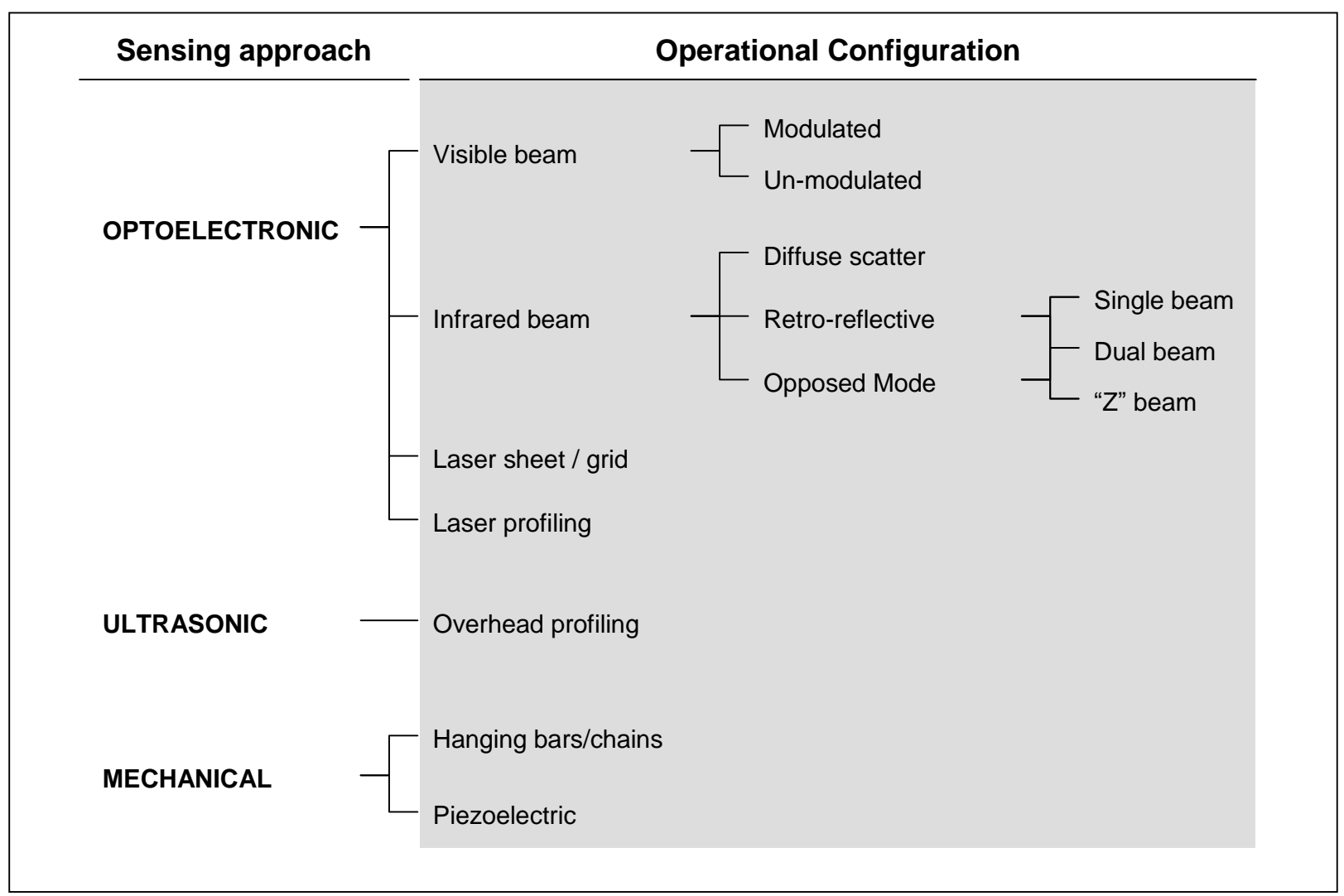

Figure 2: Taxonomy of currently available overheight vehicle sensing systems.

Each of the fundamental sensing approaches can be realized in multiple ways and offer specific advantages and disadvantages. These are discussed in detail below.

\subsubsection{OPTOELECTRONIC APPROACHES}

\subsubsection{OPTICAL BEAM BASED SYSTEMS}

Optical beam based systems are characterized by three key parameters: the wavelength region of the optical spectrum employed, the modulation of the optical beam itself, and the operational configuration of the transmission $(\mathrm{Tx})$ and receiving $(\mathrm{Rx})$ optoelectronics.

\subsubsection{VISIBLE BEAM SYSTEMS}

Visible beam systems are the simplest types of optoelectronic sensors employed in overheight vehicle identification applications. As their name implies, a visible beam operational configuration works by directing a beam of visible light from a source unit (Tx, for Transmission) to a detection unit ( $\mathrm{Rx}$, for Receiver) (either directly, or through reflection). These systems are generally low cost, but also low performance. Although the visible beam configuration works 
well in some situations, particularly indoors, it is easily influenced by ambient light and weather conditions. The visible beam systems can take two forms based primarily on the modulation scheme of the optical source:

\section{a.) MODULATED VISIBLE BEAM}

A modulated visible beam's output intensity varies with a defined period in time. The receiver in the system can be synchronized at the modulation frequency to reject potentially interfering sources of un-modulated light. However, even when modulated, the system's reliance on visible light makes it particularly prone to ambient light interference that approaches the modulation frequency. Although it is technically feasible to modulate the light frequency as well as its phase, these steps are rarely taken in the context of an overheight vehicle sensing unit as they require sophisticated electronics that is not warranted given other available means of countering interference.

\section{b.) UN-MODULATED VISIBLE BEAM}

An un-modulated visible beam system makes use of an unmodified optical source transmitter and is thus highly prone to interference from ambient and stray light. This is the simplest type of optoelectronic system and as such is not unlike the storefront optical beam systems used to detect pedestrian traffic in retail settings.

\subsubsection{INFARED BEAM}

An infrared beam operational configuration works by directing a focused beam of light in the infrared region of the optical spectrum from a transmission unit to a reflective target or detection unit. Unlike the visible beam, the infrared beam is less subject to ambient light interference and other outside factors due to the generally lower fraction of directed and intense infrared frequencies present in the general environment. Further, this kind of system offers performance benefits in adverse weather due to the use of infrared wavelengths that penetrate moisture (rain, snow, fog) better than visible light. Infrared beam systems typically take on one of three operational configurations as outlined below.

\section{a.) DIFFUSE SCATTER}

A diffuse scatter infrared system works by directing an infrared beam at an object and expecting at least some light to return to the detector. This method is dependent on the object being detected and the reflectivity of the surface of the object. This dependency 
leads to a reduced effectiveness at detection. Figure 3 is an illustration of how the diffuse scatter system operates.

\section{Diffuse scatter}

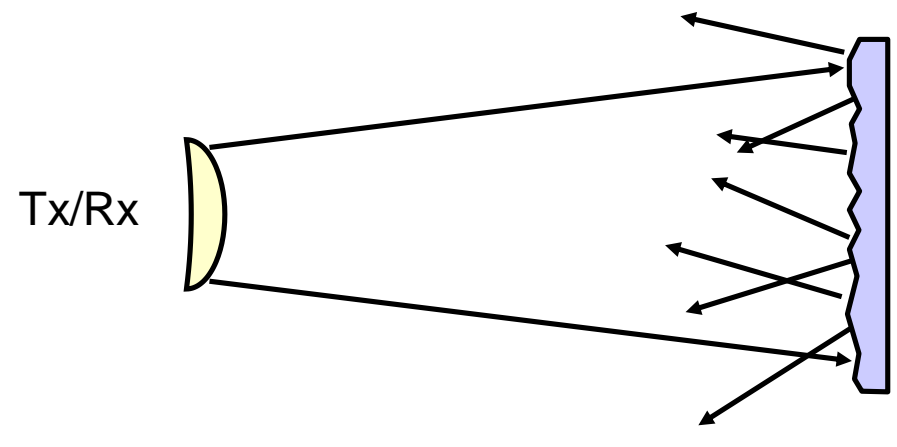

Figure 3: Diffuse scatter operational configuration of infrared optoelectronic sensor.

\section{b.) RETRO-REFLECTIVE}

An infrared retro-reflective system operates by directing an infrared beam at a mirror that redirects a fraction of the beam back to a receiver (see Figure 4). This system is quite effective and achieves a good balance of low cost, general reliability and tolerance to outside interference. Figure 3 is an illustration of how a retro-reflective system operates.

\section{Retro-reflective}

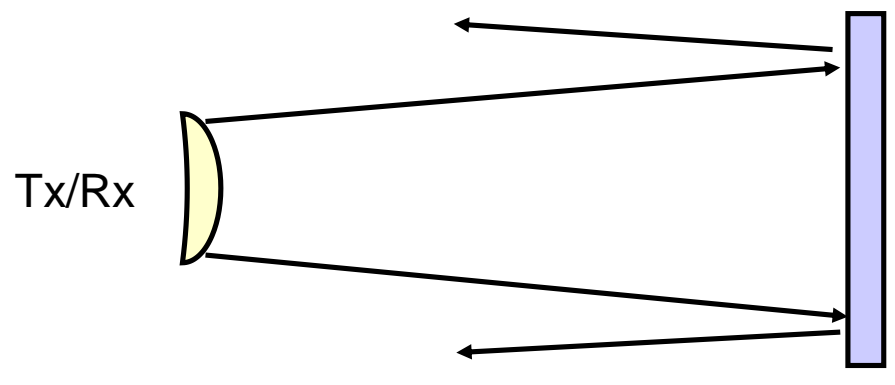

Figure 4: Retro-reflective operational configuration of infrared optoelectronic sensor.

\section{c.) OPPOSED MODE}

Opposed mode systems involve the use of pairs of aligned infrared emitters and receivers. The receiver and emitter are located on opposite sides of the roadway in a typical overheight vehicle detection scenario. This system greatly decreases the amount of outside interference as the optics of the transmission and receiver units are closely matched to 
optimize the collection angle of transmitted light. Figure 5 is an illustration of several opposed mode system designs.

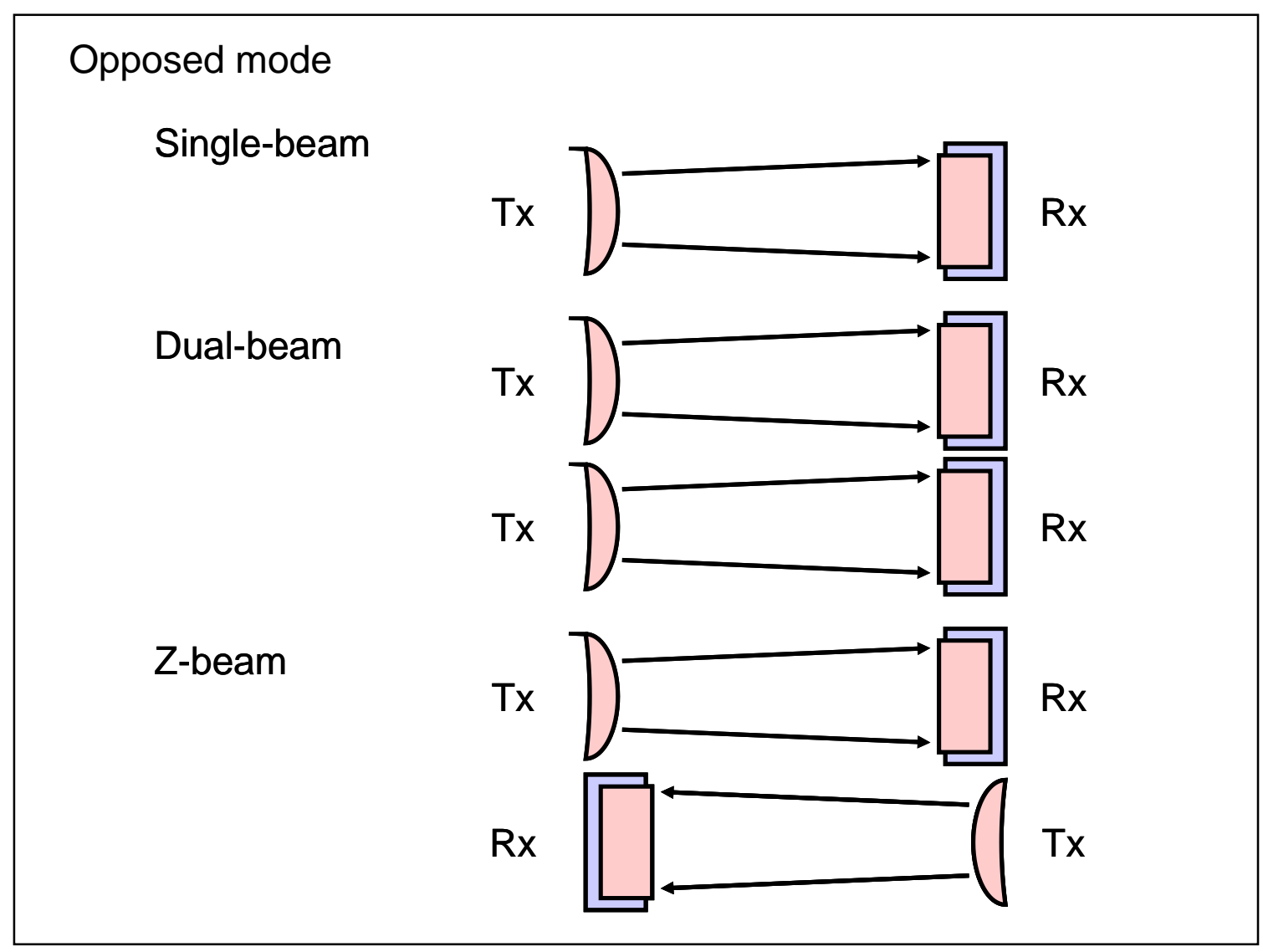

Figure 4: Optoelectronic designs for an opposed mode system.

The single beam system merely involves direction of an (infrared) light beam from a transmitter to a detector. The strength of this general approach is that the detector is positioned to receive a significant portion of the transmitted beam. The dual beam configuration builds on this benefit but provides the added ability to facilitate direction sensitive observation (based on beam break order), enabling system installation across bi-directional roadways using support posts on only the outermost edges of the road. In a simple dual beam configuration, both emitters are on one side of the roadway and both receivers are on the other. This type of system, although quite robust, could still be vulnerable to ambient light interference at some times of the day. In contrast, the "Z" beam configuration utilizes two pairs of infrared emitters and receivers oriented parallel to each other in a horizontal plane at a predefined height above the road surface, but with one emitter and one receiver located on each side of the roadway. In addition to the aforementioned benefits, a " $Z$ " beam configuration further limits ambient light interference by 
ensuring that one receiver is always out of direct alignment with the Sun.

\subsubsection{LASER SHEET / GRID}

A laser sheet system makes use of one or more, horizontally stacked laser units arranged in an opposed-mode or multiple reflection geometry to form a "plane" that is interrupted by the passing of an object (see Figure 5 for a representative illustration).

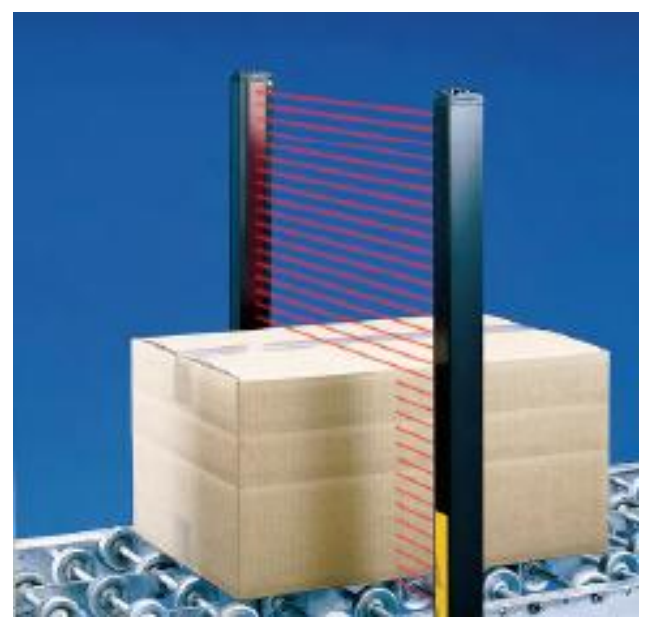

Figure 5: Representative operational design of a laser sheet system (Banner Engineering).

When applied for overheight vehicle detection, breaking a beam at a preset height in the sheet will indicate an overheight condition. The cost of these systems is quite high; and they are most effective when detecting objects passing at low speeds. These factors, coupled with the adverse effects of interference from outside light sources, make laser sheet systems an illogical choice for simply detecting overheight vehicles.

\subsubsection{LASER PROFILING}

Laser profiling systems are more advanced than general sheet designs and make use one or more lasers arranged in diffuse scatter geometry to assess the distance from the laser source to the passing vehicle based on either time of flight observations (beam source to vehicle) or scatter intensity measurement using a position sensitive detector (PSD) to develop a complete profile of a passing vehicle. While generally effective for overheight vehicle detection, these devices are typically applied for a broader set of uses including vehicle classification and calculation of vehicle spacing. Figure 6 illustrates the type of vehicle image that can be captured with a laser profiling unit. 


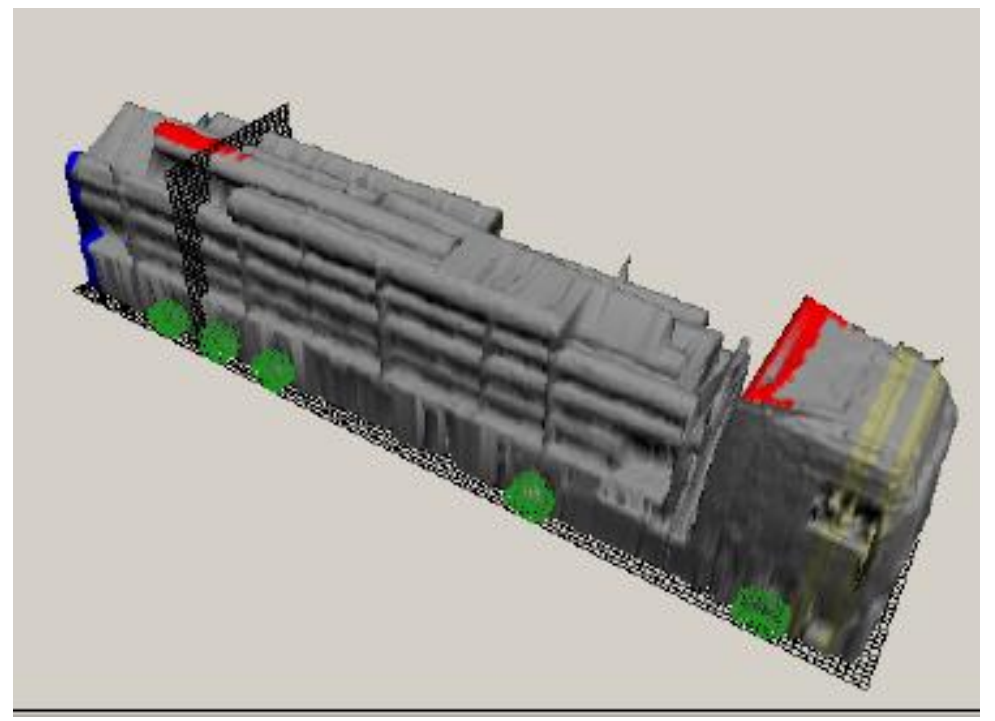

Figure 6: Representative vehicle image obtained with a laser profiling unit (ECTN AG).

Laser profiling units tend to be quite expensive, are less robust than simpler systems, and are generally limited to use on slow moving traffic. For these reasons, laser profiling systems are rarely employed solely for overheight vehicle detection.

\subsubsection{ULTRASONIC OVERHEAD PROFILING}

Ultrasonic overhead profiling systems make use of ultrasound emitters and detectors mounted on gantry like structures above traffic to assess vehicle height. The devices use time of flight measurements to define the distance between the emitter/receiver and the top of a passing vehicle. Unfortunately these units offer only limited coverage of the vehicle top surface profile and thus are less sensitive to non-continuous obstructions (e.g., small protruding vehicle parts) than a cross-beam optical system. While certainly a technologically feasible means to address the overheight vehicle challenge, these systems are rarely deployed in the field solely for overheight vehicle detection.

\subsubsection{MECHANICAL SYSTEMS}

\subsubsection{HANGING BARS/CHAINS}

Hanging bar or chain systems involve the use of a physical, "sacrificial" obstacle as an absolute indicator of an overheight condition. Effectively the obstacle, which may be mounted on a gantry a comfortable stopping distance ahead of a protected structure, provides awareness of an overheight condition when it is impacted by a passing vehicle. These types of systems of course only work if the driver realizes they have hit the bar or chains. This type of system is 
also only applicable when vehicles are expected to operate at low speeds to both ensure the driver is aware they are overheight, and to ensure the bar is not damaged or does not cause damage to any vehicles. For these reasons, mechanical systems of this type are rarely useful as a sole line of defense, particularly in highway scenarios.

\subsubsection{PIEZOELECTRIC SENSORS}

Piezoelectric materials are self-generating and reflexive in their behavior, meaning that an electric polarization is generated when they are subjected to stress and that they will deform when exposed to an appropriate electric field. In the context of overheight vehicle detection, piezoelectric sensors depend on the force of impact with a vehicle to generate an electrical response that can be used to trigger any of a variety of warning and signaling devices to an overheight condition (Song et al., 2007). In this regards, piezoelectric sensors are not completely preventive. For this to be effective as a means of preventing overheight vehiclestructure collisions, the sensors would have to be mounted a safe stopping distance from the structure of interest, possibly on a gantry. These types of sensors exist in research contexts but do not appear to be present in field settings.

\subsubsection{OPTIMAL SENSOR CONFIGURATION}

Overall, the results of this analysis indicate that infrared based optoelectronic sensors operated in an opposed mode dual or "Z" beam pattern appear to provide the greatest potential for reliability and environmental robustness at a reasonable level of cost. More advanced systems bolster the already robust capabilities of these dual beam units with an inductive loop or ferromagnetic sensor that ensures that a triggered overheight detection sensor signal is supported by indications of the presence of a vehicle on the roadway - a method that limits false positive detection caused by birds or animals that may break the optical beams employed in the OVD unit.

Integrated systems that couple active overheight vehicle detection devices with active warning units appear to have the most merit. In these systems, detection of an overheight vehicle triggers a signal that is sent (via wireline or wireless communication) down the road, ahead of the offending vehicle and before the height limited structure, to gain the attention of the offending vehicle driver. The warning systems may consist of flashing or steady lights or variable message signs and can encourage the vehicle to stop, or, when feasible, re-direct the overheight vehicle to an alternate, safe route. 


\subsection{COMMERCIAL AVAILABILITY}

A thorough international search for suppliers of optoelectronic OVD\&W systems indicated that there are approximately 10 major suppliers. These suppliers include:

- ASTI Transportation Systems (USA)

- Banner Engineering (USA)

- Coeval Group (UK)

- International Road Dynamics Inc. (Canada)

- Measurement Devices Ltd. (Scotland)

- Peter Berghaus GmbH (Germany)

- Schuh \& Co. GmbH (Germany)

- Sick-Maihak (USA)

- Trigg Industries Inc. (USA)

While there are a host of re-sellers and distributors for the products made by the above listed companies, those listed represent organizations that offer proprietary product designs. Background and offerings of these organizations have been examined in depth. Available specification sheets for systems offered by each company are presented in Appendix $A$ and contact information for each of the companies is provided in Appendix B. Several key specifications differentiate the systems (Klein, 2001; Cawley, 2002; Kowal, 2002), including:

- Transmitter / receiver configuration - directional sensitivity

- Allowable vehicle speed

- Optical transmission / detection range

- False positive check

- Warning system sophistication

- Cost

- Availability of back-up warning system

- Video capability

- Power requirements

- Environmental robustness

- Ease and versatility of installation

Specifications for each of the major vendor offerings are provided in Table 2. 


\begin{tabular}{|c|c|c|c|c|c|c|c|c|c|c|}
\hline Company & Model & $\begin{array}{l}\text { 2-way } \\
\text { detection }\end{array}$ & \begin{tabular}{c|} 
Speed \\
Parameters
\end{tabular} & Width Range & $\begin{array}{l}\text { Temperature } \\
\text { Parameters }\end{array}$ & $\begin{array}{l}\text { Backup } \\
\text { Warning } \\
\text { System }\end{array}$ & $\begin{array}{l}\text { Video } \\
\text { Capability }\end{array}$ & Power & $\begin{array}{c}\text { Enviromentall } \\
\text { y sealed }\end{array}$ & $\begin{array}{l}\text { Internal } \\
\text { thermostat }\end{array}$ \\
\hline $\begin{array}{c}\text { ASTI } \\
\text { Transportation } \\
\text { Systems } \\
\end{array}$ & & 0 & 0 & $200 \mathrm{ft}$. & $(-) 25 \mathrm{~F}$ to $150 \mathrm{~F}$ & 0 & 0 & $10-30 \vee D C$ & 0 & 0 \\
\hline Autotron & LRML & 0 & 0 & $35 \mathrm{ft}$. & $(-) 40 \mathrm{~F}$ to $55 \mathrm{~F}$ & 0 & 0 & $\begin{array}{l}12 \mathrm{~V} \mathrm{DC} \text { or } \\
120 \mathrm{~V} \mathrm{AC}\end{array}$ & yes & yes \\
\hline \multirow{3}{*}{$\begin{array}{c}\text { Banner } \\
\text { Engineering }\end{array}$} & $\begin{array}{l}\text { Magnet- } \\
\text { resistive }\end{array}$ & 0 & 0 & 0 & 0 & 0 & 0 & 0 & 0 & 0 \\
\hline & QS30 & 0 & 0 & 0 & 0 & 0 & 0 & 0 & 0 & 0 \\
\hline & \begin{tabular}{|c|} 
A-gage \\
Mini Array \\
\end{tabular} & 0 & 0 & $55 \mathrm{ft}$. & 0 & 0 & 0 & 0 & 0 & 0 \\
\hline Coeval Group & & 0 & 0 & $165 \mathrm{ft}$. & 0 & 0 & 0 & 0 & 0 & 0 \\
\hline $\begin{array}{c}\text { Internaltional } \\
\text { Road Dynamics } \\
\text { Inc. }\end{array}$ & & yes & 1 to 75 (mph) & $200 \mathrm{ft}$. & $(-) 40 \mathrm{~F}$ to $135 \mathrm{~F}$ & yes & yes & $\begin{array}{l}24 \text { V DC or } \\
115 \text { V AC }\end{array}$ & yes & yes \\
\hline $\begin{array}{l}\text { Measurement } \\
\text { Devices Ltd. }\end{array}$ & \begin{tabular}{|c|}
$\begin{array}{c}\text { Laser Ace } \\
\text { IM }\end{array}$ \\
\end{tabular} & 0 & 1 to 75 (mph) & $500 \mathrm{ft}$. & $14 \mathrm{~F}$ to $140 \mathrm{~F}$ & 0 & yes & $9-24$ V DC & yes & 0 \\
\hline IDT & & yes & 1 to $75(\mathrm{mph})$ & $65 \mathrm{ft}$. & $5 \mathrm{~F}$ to $150 \mathrm{~F}$ & yes & yes & UK mains & yes & no \\
\hline $\begin{array}{c}\text { Peter Berghaus } \\
\text { GmbH }\end{array}$ & & yes & 0 & $200 \mathrm{ft}$. & $(-) 4 \mathrm{~F}$ & 0 & 0 & $\begin{array}{l}12 \mathrm{~V} \mathrm{DC} \text { or } \\
230 \mathrm{VAC}\end{array}$ & yes & yes \\
\hline Schuh \& Co. & & yes & 1 to 75 (mph) & $100 \mathrm{ft}$. & $(-) 10 \mathrm{~F}$ to $140 \mathrm{~F}$ & yes & yes & 24 V DC & yes & yes \\
\hline $\begin{array}{l}\text { TEC Traffic } \\
\text { Systems }\end{array}$ & & 0 & 1 to 75 (mph) & $100 \mathrm{ft}$. & 0 & 0 & 0 & 0 & no & no \\
\hline Sick Maihak & & no & 1 to 75 (mph) & $300 \mathrm{ft}$. & $(-) 25 \mathrm{~F}$ to $150 \mathrm{~F}$ & yes & no & $\begin{array}{c}24 \mathrm{~V} \text { to } 240 \mathrm{~V} \\
\mathrm{UC}\end{array}$ & yes & no \\
\hline \multirow{4}{*}{$\begin{array}{l}\text { Trigg Industries } \\
\text { Inc. }\end{array}$} & Z-Pattern & yes & 1 to 75 (mph) & $200 \mathrm{ft}$. & $(-) 40 \mathrm{~F}$ to $135 \mathrm{~F}$ & yes & yes & $\begin{array}{l}24 \mathrm{~V} \mathrm{DC} \text { or } \\
115 \mathrm{VAC}\end{array}$ & yes & yes \\
\hline & $\begin{array}{l}\text { Double } \\
\text { Eye }\end{array}$ & yes & 1 to 75 (mph) & $200 \mathrm{ft}$. & $(-) 40 \mathrm{~F}$ to $135 \mathrm{~F}$ & yes & yes & $\begin{array}{l}24 \mathrm{~V} \mathrm{DC} \text { or } \\
115 \mathrm{~V} \mathrm{AC}\end{array}$ & yes & yes \\
\hline & $\begin{array}{l}\text { Single } \\
\text { Eye }\end{array}$ & no & 1 to 75 (mph) & $200 \mathrm{ft}$. & $(-) 40 \mathrm{~F}$ to $135 \mathrm{~F}$ & yes & 0 & $\begin{array}{l}24 \mathrm{~V} \mathrm{DC} \text { or } \\
115 \mathrm{~V} \mathrm{AC}\end{array}$ & yes & yes \\
\hline & \begin{tabular}{|c|} 
Metro \\
Economy \\
\end{tabular} & no & 1 to 75 (mph) & $200 \mathrm{ft}$. & 0 & no & 0 & $\begin{array}{l}24 \text { V DC or } \\
115 \text { V AC }\end{array}$ & yes & no \\
\hline
\end{tabular}

Table 2: Vendor offerings and related system specifications. 


\subsection{ASSESSMENT OF DOT DEPLOYED SYSTEMS}

\subsection{IDENTIFICATION OF STATES WITH OVD SYSTEMS}

Following the literature review for this study, there were indications that 19 states and the District of Columbia may have some form of OVD system installed and/or in use (USDOT, 2006; Bretz, 2000; Hanchey and Exley, 1990; Mimbela and Klein, 2007) (Table 3).

\begin{tabular}{|c|l|}
\hline \multicolumn{1}{|l|}{ States } & Metropolitan Area \\
\hline CA & Bakersfield, Fresno, San Diego, San Francisco, Oakland, San Jose \\
\hline CO & Denver, Boulder \\
\hline CT & Hartford, New Britain, Middletown \\
\hline DC & Washington \\
\hline KY & Louisville \\
\hline LA & Baton Rouge, New Orleans \\
\hline MD & Baltimore \\
\hline MI & Detroit, Ann Arbor \\
\hline NY & $\begin{array}{l}\text { Albany, Schenectady, Troy, Buffalo, Niagara Falls, New York, Northern New } \\
\text { Jersey, Southwestern Connecticut, Syracuse }\end{array}$ \\
\hline OH & Cleveland, Akron, Lorain \\
\hline OK & Oklahoma City \\
\hline OR & Portland \\
\hline PA & Philadelphia, Wilmington, Trenton \\
\hline TN & Knoxville \\
\hline TX & Dallas, Fort Worth, San Antonio \\
\hline VA & Hampton Roads \\
\hline WA & Seattle, Tacoma \\
\hline WI & Milwaukee, Racine \\
\hline
\end{tabular}

Table 3: States with reference to an OVD\&W system.

Each state DOT was contacted to confirm or refute the existence of an OVD\&W system in the state. The results from the state confirmation calls can be seen in Table 4 . Table 4 highlights the point of contact as well as their contact information and the status of any overheight vehicle detection system(s). 


\begin{tabular}{|c|c|c|c|}
\hline State & Contact Person & Phone Number & Findings \\
\hline \multirow{3}{*}{$\mathrm{CA}$} & Operator & $510-286-4444$ & \multirow{3}{*}{ No response } \\
\hline & Nadal Ebrahimi & $916-654-6914$ & \\
\hline & James Anderson & $916-654-5548$ & \\
\hline \multirow{4}{*}{$\mathrm{CO}$} & Operator & $303-757-9011$ & \multirow{4}{*}{ System in use } \\
\hline & Permits & $303-757-9011$ & \\
\hline & Thersea Lawser & $303-757-9843$ & \\
\hline & Rod Henderson & $303-512-5735$ & \\
\hline \multirow{2}{*}{$\mathrm{CT}$} & Operator & $860-594-2000$ & \multirow{2}{*}{ System no longer in use } \\
\hline & Linda Hope & $860-594-2878$ & \\
\hline \multirow{2}{*}{ DC } & Operator & $202-673-6813$ & \multirow{2}{*}{ No response } \\
\hline & Livett Williams & $202-673-6813$ & \\
\hline$\overline{K Y}$ & Nancy Albright & $502-564-3730$ & System no longer in use \\
\hline LA & Peter Holland & $225-242-4631$ & System no longer in use \\
\hline \multirow{2}{*}{$M D$} & Permits & $410-865-1000$ & \multirow{2}{*}{ System no longer in use } \\
\hline & State Highway & $410-545-0300$ & \\
\hline \multirow{3}{*}{$\mathrm{Ml}$} & Operator & $517-373-2090$ & \multirow{3}{*}{ No response } \\
\hline & Mark Dianese & $517-373-2121$ & \\
\hline & John Goke & $517-373-2123$ & \\
\hline \multirow{4}{*}{ NY } & Operator & $518-457-5826$ & \multirow{4}{*}{ No response } \\
\hline & Sreenivas Almapliai & $518-457-4544$ & \\
\hline & \begin{tabular}{|l|} 
James Patterson \\
\end{tabular} & $845-431-5771$ & \\
\hline & Jane Alexander & $845-575-6071$ & \\
\hline \multirow{5}{*}{$\mathrm{OH}$} & Operator & $330-786-4940$ & \multirow{5}{*}{ System in use } \\
\hline & Dave Holstein & $614-644-8137$ & \\
\hline & Turnpike & $440-234-2081$ & \\
\hline & Gary Calley & $440-234-1273$ & \\
\hline & Bill Keaton & $440-234-2081$ & \\
\hline $\mathrm{OK}$ & Bruce Jeffcoat & $580-332-1526$ & System no longer in use \\
\hline \multirow{3}{*}{ OR } & Operator & $888-275-6368$ & \multirow{3}{*}{ System no longer in use } \\
\hline & Mike dunning & 503-986-3059 & \\
\hline & Donn Wence & $503-986-3594$ & \\
\hline \multirow[b]{2}{*}{ TX } & Operator & $214-320-6100$ & \multirow[b]{2}{*}{ System not yet operational } \\
\hline & $\begin{array}{l}\text { Tony Oakafer } \\
\text { "Mainenance Director" }\end{array}$ & 214-320-6171 & \\
\hline \multirow[b]{3}{*}{ VA } & Operator & $757-925-2500$ & \multirow[b]{3}{*}{ System in use } \\
\hline & Jessy Niel & $757-727-4811$ & \\
\hline & $\begin{array}{l}\text { Joe Reed "Electronic } \\
\text { Technichian Supervisor" }\end{array}$ & 757-592-8088 & \\
\hline \multirow{2}{*}{ WA } & Operator & $360-705-7099$ & \multirow{2}{*}{ System in use } \\
\hline & Permits & $360-705-7000$ & \\
\hline $\mathrm{WI}$ & Permits & $262-548-5903$ & System no longer in use \\
\hline
\end{tabular}

Table 4: Summary of DOT confirmation phone calls. 
Out of the 19 states believed to have an OVD\&W system, 4 were found to still have a system in use, 8 were found to no longer use a system and one was not yet operational.

The eight states that no longer employ the system had different reasons for stopping use of the system. Maryland for example decided to switch back to a height pole, in which a truck travels ahead of the oversize load and checks for possible height interferences. Oklahoma had one system in use that became obsolete after the bridge was raised to accommodate overheight vehicles. Connecticut also raised the structure that was being monitored by the sensor system. Michigan utilized the sensor during a construction project and removed the system once construction was complete. Wisconsin now relies on signage and operator awareness instead of the sensor system. The Texas DOT was in the bidding phase of their sensor system setup when this survey was conducted.

The four states that were confirmed to have an active OVD\&W system include OH, WA, VA, and $\mathrm{CO}$.

\subsection{SURVEY OF ACTIVE SYSTEM USERS}

Specific DOT experiences with active OVD\&W systems were explored in the latter half of this project through a structured interview and survey process. A survey (shown in Figure 7) was administered via phone to knowledgeable DOT personnel in each state to learn what equipment was in use, how well the system worked in the field, and if any major problems arose with the system. 


\section{Survey Questions}

- From which company did you purchase your OVD\&W system?

- What were the costs of this system?

- What were the costs for supporting structures and installation?

- Was the system easily integrated into the DOT's information system?

- To-date has the system failed to maintain any of its specified performance?

- To-date how would you grade the overall system in-field performance (on a scale of 1 to 10$)$ ?

- To-date have there been any incidents in which the weather directly interfered with the system?

- What were the conditions of the incident (rain, snow, sunny)?

- How often is system maintenance needed (given)? What does maintenance entail?

- Since implementing the OVD\&W system, has there been an increase or decrease in over height vehicle incidents?

Figure 7: Survey administered to each state DOT with an OVD\&W system.

The results of enquiries with the four states possessing active systems are summarized below.

Washington's DOT uses a Trigg Industry single eye sensor purchased from International Road Dynamics Inc. for $\$ 5782$. The system is installed before an overpass. The system took two people, three days to install. No lane closure was needed which kept installation costs down to $\$ 2500$. A four inch diameter pole was set in concrete and the sensor was placed at the top. IRD was able to easily integrate the sensor into the DOT's information system. A representative from the Washington DOT rates the system as 8 out of 10 for field performance. There are some weather conditions that affect the system, such as heavy fog and a few minutes of direct sunlight. Both heavy fog and direct sunlight obscure the beam of light and therefore trigger the system. There are covers that extend over the lens and could help keep out direct sunlight. Maintenance is only needed once a year to ensure the sensor is aligned properly. Alignment is generally checked by taking a wooden paddle and 
passing it in front of the sensor. Since installing the system there has been no recorded incident with an overheight vehicle striking the protected structure. The installation of more systems is being heavily considered for other locations.

Colorado's DOT also uses a Trigg Industry single eye sensor purchased from Tripp Lite for $\$ 3000$. The lane closure, alarms, and video sensing cost a total of $\$ 25,000$. There were no problems integrating the system in the DOT's information system. Colorado DOT gave 8 out of 10 for field performance. There are some weather conditions that affect the system, such as heavy snow and ground heave. The heavy snow will sometimes build up and block the lens of the sensor. The snow blocks the lens and causes the system to trigger a false alarm. Generally a worker is sent out to check the problem and clean off the lens. There are covers that extend over the lens to keep out the snow. Ground heave sometimes alters the alignment of the system and therefore maintenance is done every three months to ensure the sensor is aligned properly. Like in Washington, maintenance is simply conducted with a wooden paddle. The Colorado DOT has a manned station by the monitored bridge to stop overheight vehicles from continuing. The need for the station was based on the volume of collisions the bridge was experiencing. The amount of incidents has greatly decreased since system installation, however illegal late night drivers still hit the bridge.

Virginia's DOT uses Cutler Hammer (patent assignee Trigg Industries) dual eye sensors purchased from Jo-Kell Inc. for $\$ 2000$. Installation for this unit cost approximately $\$ 2000$. The system was easily integrated into the DOT's new tunnel information system (NEWTIN). Minor technical problems were encountered with the system including a light source failure and a problem with AC powering of the sensing unit. Jo-Kell Inc. rapidly addressed the problems and the sensing units have been working fine ever since. A representative from the Virginia DOT rates the system as 8 out of 10 for field performance. There are some weather conditions that affect the system, such as ice forming over sensor and a few minutes of direct sunlight. The ice and direct sunlight results in the system being triggered. Generally a worker is sent out to check on the system and identify the problem. The ice is removed manually from the lens, and the sun is only a problem for a few minutes. Maintenance is done on a quarterly basis to ensure alignment. As with the other DOTs, the maintenance is done with a wooden paddle. The light sources in the sensor are replaced 
every 9 to 12 months and the lenses are cleaned every 3 months due to cloudiness. The sensor for the unit is tested every 8 hours to ensure it is working properly. At the Hampton Roads Bridge-Tunnel, forty to forty-five overheight vehicles are stopped every weekday, approximately seventy-five overheight vehicles are stopped on Saturday and Sunday. The Hampton Roads Bridge-Tunnel connects the cities of Norfolk and Hampton, Va. Though the number of overheight vehicles is high, there has been a decrease in the number of tunnel impacts since installation of the OVD system. Virginia DOT also has systems at Memorial Bridge in Arlington, Elizabeth Tunnel, and the Monitor-Merrimac Bridge-Tunnel, and is considering placing a system at Big Walker Mountain in Southwest Va.

Ohio's DOT uses single eye Autotron sensors purchased from Trans Corporation. This system allows for the entire car to be scanned. This can tell the height of the vehicle, what type of vehicle it is as well as the distance between it and the car in front of and behind it. The system was easily integrated into the DOT's information system. The Ohio DOT rates the system 10 out of 10 for field performance, stating the system is "very user friendly". There are some weather conditions that affect the system, such as snow collecting on top of trucks and causing false alarms. To counteract the snow accumulation on the trucks the motto "if its snow let them go" has been implemented in the state. Preventive maintenance is conducted once a month to ensure stability and alignment. Ohio's preventative maintenance involves a single worker checking calibration and tightness of bolts on the unit and its mountings. Since implementing the system there has been a decrease in the amount of hits on the protected structure.

\subsection{CONCLUSIONS}

Based on the data collected from DOT's, it is clear that most states have updated their infrastructure to account for overheight vehicles. Some states continue to check for height limitations using escort vehicles for oversized loads. While this method is effective most of the time, it does not account for the illegal trucks traveling through the state. The few states that still actively employ OVD\&W systems have stated that the systems have decreased the amount of damage occurring to their structures, but have not been able to provide solid quantitative data to support these assertions. The initial equipment and installation costs of the active systems range from a few thousand to twenty-five thousand dollars based on DOT interviews, and ongoing maintenance appears minimal. Overall, considering that the only other completely 
effective option to avoid overheight vehicle impact with structures is to raise the height of the structure, or lower the roadway surface, an (optoelectronic) OVD\&W system is a relatively inexpensive and effective method for decreasing structural damage due to overheight vehicles.

\subsection{RECOMMENDATION FOR SYSTEM SELECTION PROCESS}

Findings from the review of available and in-use systems provide valuable information for the selection of OVD\&W systems. Site characteristics define the parameters by which a system is selected.

\subsection{OVD\&W SYSTEM SELECTION CONSIDERATIONS}

Relevant site characteristics that influence both sensor selection and overall OVD\&W system design are described below.

\section{Sensor selection considerations:}

- ONE-WAY/TWO-WAY HIGHWAY: A select few sensors found in this project are bidirectional, which allows a single sensing unit to be used for a two-way highway. The bidirectional sensors offer an opportunity to place support systems at the far edges of a two-direction highway, yet only trigger warnings for a single direction of traffic flow.

- NUMBER OF LANES: The number of lanes across which a sensing system must span is important because it defines the optical range parameters of the system. Certain systems can work properly over longer ranges and are therefore ideal for multi-lane highways.

- WEATHER: As with many electronic devices, an OVD\&W system can be influenced by the weather. The degree to which each system is affected can be seen in Table 2. The most common problems stem from direct sunlight, fog, and heavy snow. The Z-beam system by Trigg Industries almost completely eliminates these concerns. Beyond weather interference effects, a system exposed to the elements should likely be weather proof and may benefit from an on-board thermostat that can actively compensate for environmental temperature fluctuations and maintain sensor performance.

- USABLE SPACE 1000 FT. BEFORE STRUCTURE: The usable space before the structure influences placement of the sensors. In settings where there is limited distance available between the placement of an overheight detector and the structure to be protected, it can be valuable to install a backup warning system that is likely to gain the attention of those driving overhead vehicles and help avert a collision. Warning signs should be placed 100 to $150 \mathrm{ft}$. after the sensors, to ensure the driver has time to see 
them and stop, or exit the highway, if possible. More distance could be needed for the warning system, depending on the type of signage used.

- SECURITY: In some circumstances, particularly when monitoring structures on roadways prone to off-hour traffic, interference from wildlife, or where remote locations preclude easy access and physical monitoring, it may be valuable to install a video monitoring system in conjunction with an overheight sensing unit.

- SPEED LIMIT: All of the sensors identified through this effort can successfully monitor traffic traveling at up to $75 \mathrm{mph}$. Therefore it is important to keep in mind the speed around the structure and account for people who may travel slightly over the posted speed limit.

\section{Macro design considerations:}

- ACCESS TO OFF RAMP: Access to an off ramp is a convenience characteristic and can influence the need or desire to make use of message boards to inform drivers of alternate routes. If an off-ramp is not present it is possible to have warning signs that stop the vehicle instead of directing it off the highway. With this option however the truck must then be removed from the highway via u-turn or reverse, often with police supervision. The lack of an off ramp should not however be a determining factor in not investing in an OVD\&W system. The truck will still be stopped and the damage averted.

- NUMBER OF POSSIBLE ENTRY POINTS TO REACH STRUCTURE: Considering the number of possible entry points to reach the structure is important when considering how many warning systems are needed. It is sometimes more beneficial to go further out from the structure to more easily direct traffic in a different direction. The distance between warnings and a structure should be kept within a mile due to some reports indicating OVD\&W systems are ignored when no structures are visible.

\subsection{OVD\&W SENSOR SELECTION GUIDE}

Building on the site characteristics outlined above, a simple MS Excel based Equipment Selection Tool has been developed to guide selection of optoelectronic OVD equipment models. The tool provides the designer with a set of 7 questions and associated answer options. Changing any of the responses to this set of characterization questions alters an accompanying list of viable equipment alternatives based on manufacturer specified performance capabilities. The user interface for this OVD Equipment Selection Tool is illustrated in Figure 8. The tool can 
be easily updated with new equipment characteristics as they become available by entering specific performance parameters on data sheets in the Excel file.

Please select an answer for each question from the drop-down menu provided.

\begin{tabular}{|l|c|}
\hline Is 2 way detection a requirement? & No \\
\hline What is the maximum range, in feet, required for the system? & 35 \\
\hline $\begin{array}{l}\text { What is the minimum temperature, in degrees F, required for the } \\
\text { system? }\end{array}$ & 15 \\
\hline Is a backup warning system a requirement? & No \\
\hline Is video capability a requirement? & No \\
\hline Is it required that the system be enviromentally sealed? & No \\
\hline Is an internal thermostat required? & No \\
\hline
\end{tabular}

\begin{tabular}{|c|}
\hline Recommended System(s) \\
\hline Trigg Industries 'Z Pattern' \\
\hline Trigg Industries 'Double Eye' \\
\hline Trigg Industries 'Single Eye' \\
\hline Trigg Industries 'Metro Economy' \\
\hline Sick Maihak \\
\hline Schuh \& Co. \\
\hline Peter Berghaus \\
\hline Integrated Design Techniques Limited \\
\hline Measurement Devices Ltd. 'Laser Ace IM' \\
\hline International Road Dynamics \\
\hline Autotron 'LRML' \\
\hline ASTI Transportation Systems \\
\hline
\end{tabular}

Figure 8: User interface for this OVD Equipment Selection Tool.

\subsection{CASE EXAMPLE}

A case example has been developed to illustrate implementation of an OVD\&W system and highlight the logic behind the sensor selection process outlined above. The case centers on the I-65 - I-70 merger location in Indianapolis, IN (known as the south-split). A detailed schematic of the proposed solution to limit overheight bridge impact in this region is provided in Appendix $C$ and a simplified schematic of this same solution is illustrated in Figure 9 herein for convenience. This solution makes recommendations on where to place sensors, warning signs, and prevention signs. The sensors were selected using the "system selection process" discussed earlier in this report. The type of signage used to warn drivers of overheight limitations is not specified in this report. It is recommended that the signage be large enough to ensure driver awareness, and if possible both visual and auditory signaling should be used close to the protected structures. The following sub-sections describe in detail the specific site, as shown in Figure 9.

\subsection{LEGEND}

The legend and compass for the map provided in Figure 9 can be found in the upper left corner of the page. There are six components of the legend. Two parallel lines represent one complete sensor unit. A sensor unit consists of a transmission and receiver unit. The transmission unit will be placed on one side of the roadway and the receiver unit on the opposite side of the roadway, in an opposed-mode configuration. The arched line represents a bridge marker. Located beside each bridge marker is the respective bridge number. 


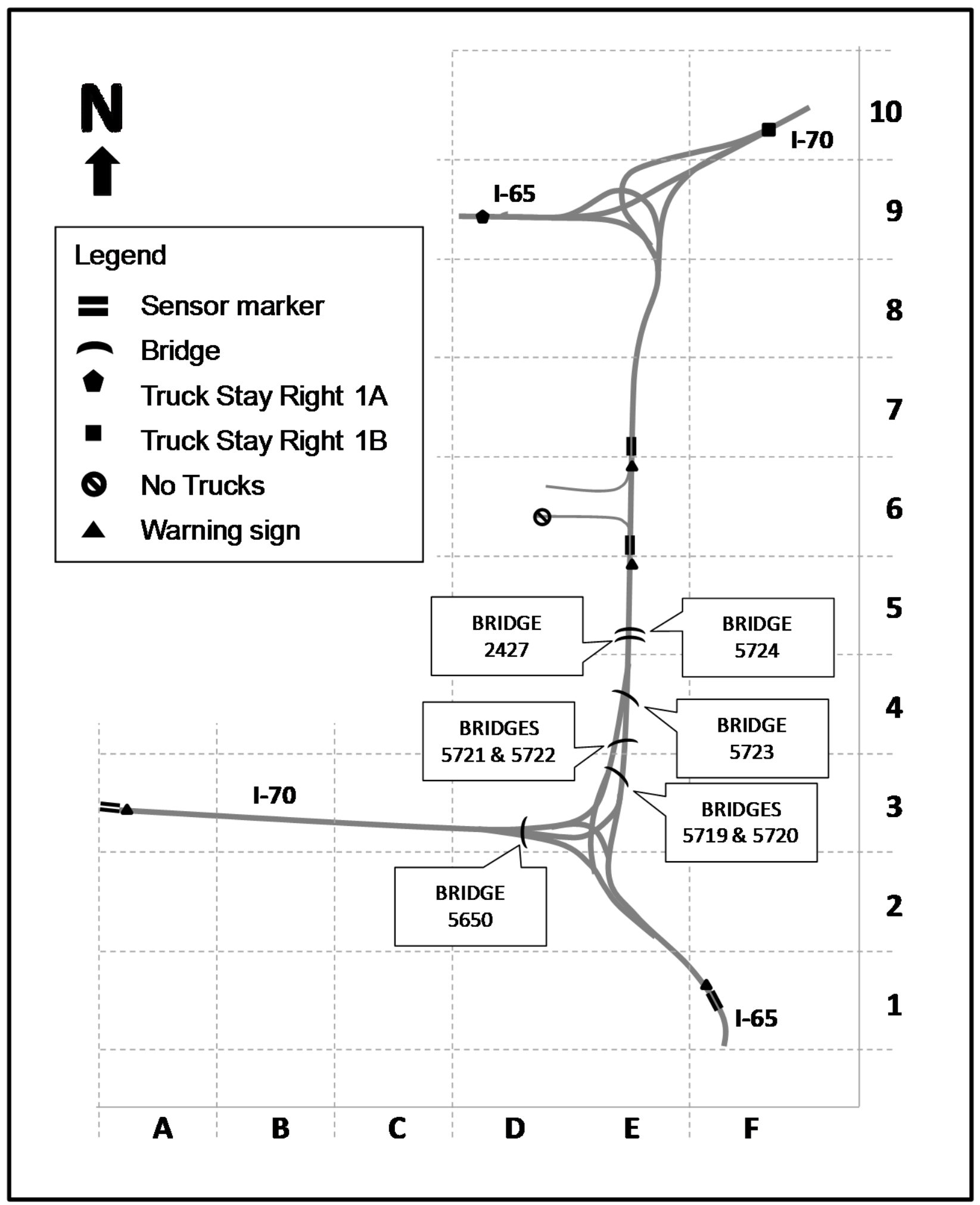

Figure 9: Schematic of I-65 - I-70 merger location in Indianapolis, IN and proposed OVD\&W system deployment plan (Illustrative - see Google Earth rendering in Appendix for details). 
The "Trucks Stay to the Right" $1 \mathrm{~A}$ and 1B signs are marked with a pentagon and a square, respectively. The "No Trucks Allowed (over 14' 6")" symbol is a circle with a diagonal line through it. The "Warning Sign" symbol is a solid triangle. These signs are associated with the sensors. They are located $100 \mathrm{ft}$ behind the sensor locations. Each sensor should be equipped with two warning signs, except for the sensor in southern region of quadrant E6 on the map, which should have three warning signs. The number of warning signs is related to how many lanes a sensor must cover and the driver's ability to see the warning signs.

\subsection{Prevention Signs}

There are three prevention signs for the area indicated on the map. The first prevention sign is located in quadrant D6. This prevention sign is a No Trucks Allowed prevention sign. This sign is intended to stop trucks over a specified height defined by the related bridge clearance from gaining access onto the interstate. This sign could be replaced with a height warning sign or with another sensor. However, if a sensor were placed at this location the truck would not be able to exit the on ramp and would be forced to turn around.

The second prevention sign is located in quadrant D9. This sign is the Trucks Stay to the Right $1 \mathrm{~A}$ in the legend. The purpose of this sign is to ensure the trucks stay in the right two lanes on 165. $165 \mathrm{~S}$ is composed of four lanes separated in the middle by a wall. If the trucks stay to the right, the sensor in quadrant E7 will read the height of the truck and they will be able to exit via an off ramp if they are indeed over height. If the trucks ignore this, the sensor in quadrant E6 will catch any overheight vehicle. However, there will be no place to turn the truck around.

The third prevention sign is located in quadrant F10. This sign is the Trucks Stay to the Right $1 \mathrm{~B}$ in the legend. The purpose of this sign is the same as the for prevention sign, $1 \mathrm{~A}$. Sign 1B is simply meant to keep trucks from the east to stay in the right two lanes of the road. Again, if the trucks ignore the signage, the sensor in quadrant E6 will catch any overheight vehicle. However, there will be no place to turn the truck around. 


\subsection{Sensors and Warning Signals}

There are four recommended sensors for the area indicated on the map. Based on conditions at the site appropriate OVD sensors for sensor locations in quadrants F1, A3, and E7 are available from any of the manufacturers listed in Figure 10.

$\begin{aligned} & \text { Please select an answer for each question from the } \\
& \text { drop-down menu provided. }\end{aligned}$
\begin{tabular}{|l|c|}
\hline Is 2 way detection a requirement? & No \\
\hline What is the maximum range, in feet, required for the system? & 65 \\
\hline $\begin{array}{l}\text { What is the minimum temperature, in degrees F, required for the } \\
\text { system? }\end{array}$ & -40 \\
\hline Is a backup warning system a requirement? & Yes \\
\hline Is video capability a requirement? & No \\
\hline Is it required that the system be enviromentally sealed? & Yes \\
\hline Is an internal thermostat required? & Yes \\
\hline
\end{tabular}

\begin{tabular}{|c|}
\hline Recommended System(s) \\
\hline Trigg Industries 'Z Pattern' \\
\hline Trigg Industries 'Double Eye' \\
\hline Trigg Industries 'Single Eye' \\
\hline \\
\hline \\
\hline \\
\hline \\
\hline International Road Dynamics \\
\hline \\
\hline
\end{tabular}

Figure 10: Viable sensor vendors for sensor locations 1, 2 and 4 in I-65 - I-70 merger location.

The first sensor is located in quadrant F1. This sensor is located $1000 \mathrm{ft}$ before the start of the upcoming off ramp. The warning signs or signals are located $900 \mathrm{ft}$ before the start of the off ramp. The significance of the $100 \mathrm{ft}$ differential is to ensure the driver has time to see the warning signs and recognize that he or she is the truck in violation of the height restrictions. The significance of the $900 \mathrm{ft}$ spacing from the off ramp is the approximate distance needed for an 18-wheeler to come to a complete stop under wet road conditions when traveling at highway speed. The detour routes for this sensor have been drawn in red on the map in Appendix $\mathrm{C}$. Truck drivers traveling north and west will need to exit immediately off the same off ramp. The driver would then need to follow the appropriate detour route, depending on which direction of travel is desired.

The second sensor is located in quadrant A3. The sensor is located $1000 \mathrm{ft}$ before the start of the upcoming off ramp. The warning signs or signals are located $900 \mathrm{ft}$ before the start of the off ramp. The detour routes for this signal have two separate off ramps. The first off ramp is intended for truck drivers traveling south. The second off ramp is the detour drivers traveling north would need to take. Two sets of warning signs may be needed for this area to take into consideration separate off ramps.

The third sensor is located in quadrant E6. The sensor is located $1000 \mathrm{ft}$ before bridge 5724. This is the first bridge with a height restriction. The warning signs or signals are located $900 \mathrm{ft}$ 
before bridge 5724. The span of traffic for this sensor is four lanes and therefore would need a sensor capable of handling that distance. This limitation alters the inputs to the Sensor Selection Tool as illustrated in Figure 11, but in this case, does not change the set of viable vendors.

Please select an answer for each question from the
drop-down menu provided.
\begin{tabular}{|l|c|}
\hline Is 2 way detection a requirement? & No \\
\hline What is the maximum range, in feet, required for the system? & 100 \\
\hline $\begin{array}{l}\text { What is the minimum temperature, in degrees F, required for the } \\
\text { system? }\end{array}$ & -40 \\
\hline Is a backup warning system a requirement? & Yes \\
\hline Is video capability a requirement? & No \\
\hline Is it required that the system be enviromentally sealed? & Yes \\
\hline Is an internal thermostat required? & Yes \\
\hline
\end{tabular}

\begin{tabular}{|c|}
\hline Recommended System(s) \\
\hline Trigg Industries 'Z Pattern' \\
\hline Trigg Industries 'Double Eye' \\
\hline Trigg Industries 'Single Eye' \\
\hline \\
\hline \\
\hline \\
\hline \\
\hline International Road Dynamics \\
\hline \\
\hline
\end{tabular}

Figure 11: Viable sensor vendors for sensor location 3 in I-65 - I-70 merger location.

Three locations for signs or signals would be needed to ensure driver awareness of the upcoming bridge. Unlike the other sensors, this sensor is put in place as a last chance prevention. There are no off ramps available if the truck driver has arrived at this location. The truck driver would need to stop and inform local authorities of the height restriction and inability to proceed without damaging the bridge. There is an off-ramp available after RR Bridge 2427. This would however involve the driver passing under two bridges before exiting the interstate. The slower speed accompanied with a police escort could however decrease the amount of damage done on the bridge, as well as decrease the potential threat to other drivers. Tire deflation could potentially enable safe passage.

The fourth sensor is located in quadrant E7. The sensor and signage are placed 1000 and 900 $\mathrm{ft}$ before the upcoming off ramp, respectively, the same as the other sensors. Although there are four lanes of traffic traveling southbound only two lanes are connected to an off ramp. This is due to the wall separating the two sets of roadway. Truck drivers driving in the west set of lanes (collector/distributor lanes) will trigger the sensor and be able to exit via the off ramp. After exiting, drivers will be able to take a detour to continue their route, either southbound or westbound. For truck drivers traveling in the east set of lanes (mainline lanes), the sensor in quadrant E6 will detect them if they are over height. The drivers in the east set of lanes will not however have the option to exit via an off ramp before encountering a low bridge. 


\subsection{BENEFITS OF STUDY AND RECOMMENDATIONS FOR USE OF FINDINGS}

The work performed in this study provides a guide to available and in-use overheight vehicle detection systems and suppliers of such equipment. In addition, the review outlines the underlying technologies that enable these sensors as well as the performance attributes that define their relevance for field deployment under various installation scenarios. The combined insights gained through this review were used to develop a straightforward decision tool that can be employed to identify equipment options to address site specific needs for overheight vehicle protection. This tool and its underlying principles were applied to a test case focused on the I65 - I-70 merger (south-split) location in Indianapolis, IN leading to a preliminary overheight vehicle detection and warning system strategy for that specific location." It is recommended that the sensor characteristics and design decision logic outlined herein be used for any future OVD\&W system deployment envisioned in the State. Ultimately, implementation of such systems could reduce vehicle-bridge collisions and prevent associated injuries and repair costs, prevent emergency bridge closures, and potentially prevent catastrophic bridge failures.

\subsection{REFERENCES}

Bretz, E. A.. "Boston builds a high-IQ highway," IEEE Spectrum, v 37, n 8, August, 2000, p 4752

Cawley, P.M. "Evaluation of overheight vehicle detection/warning systems," Proceedings of the Institute of Transportation Engineers Conference: Today's Transportation Challenge: Meeting Our Customer's Expectations, Palm Harbor, Florida, March 2002, Report CD-016, $11 \mathrm{p}$.

Fu, C.C., Burhouse, J.R., Chang, G-L., "Overheight Vehicle Collisions with Highway Bridges", Transportation Research Record, Volume 1865, 2004, pp. 80-88.

Hanchey, C.M. and Exley, S.F., "Overheight vehicle warning systems in Mississippi," ITE Journal (Institute of Transportation Engineers), v 60, n 6, Jun, 1990, pp. 24-29.

Klein, L. A., Data Requirements and Sensor Technologies for ITS, Norwood, MA, Artech House, 2001

\footnotetext{
* Note that the system should be designed to communicate with the Indianapolis Traffic Management Center (T.M.C.), the Indianapolis Sub-District, and the State Police.
} 
Kowal, E. "Innovative Video Technique for Overheight Collision Monitoring," Technical Standards Branch Newsletter, Alberta Transportation, v. 1, Issue 1, May 2002.

Mimbela, L. and Klein, L. "A Summary of Vehicle Detection and Surveillance Technologies used in Intelligent Transportation Systems," Vehicle Detector Clearing House - A multi-state, pooled-fund project managed by the Southwest Technology Development Institute (SWTDI) at New Mexico State University (NMSU), and sponsored in cooperation with the U.S.

Department of Transportation, Federal Highway Administration, July 31, 2007, 231 p.

Song, G., Olmi, C., and Gu, H., "An overheight vehicle-bridge collision monitoring system using piezoelectric transducers," Smart Materials and Structures, v.16, n.2, April 2007 , pp. 462-468.

USDOT, "Deploying automated over-height/over-width warning systems", National Summary, 2006 (www.itsdeployment.its.dot.gov) 
APPENDIX A 


\title{
OVER-HEIGHT VEHICLE DETECTION SYSTEMS
}

\author{
PURDUE UNIVERSITY \\ SCHOOL OF CIVIL ENGINEERING
}

Joint Transportation Research Project

SPR-3237 


\section{Table of Contents}

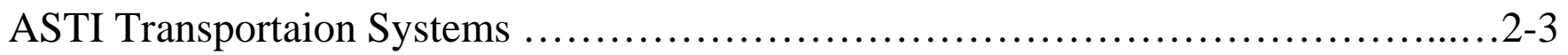

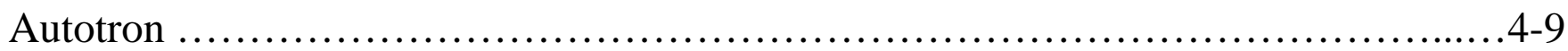

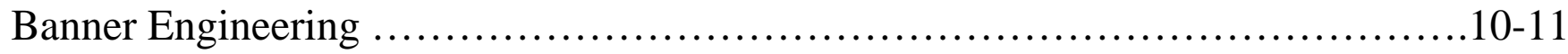

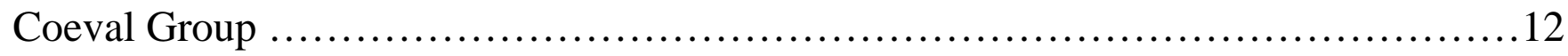

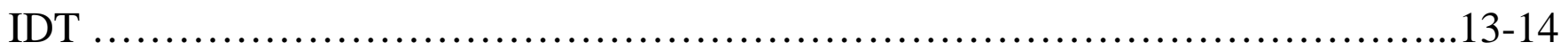

Measurement Devices Ltd. ................................................15-18

Peter Berghaus GmbH ............................................................. 19

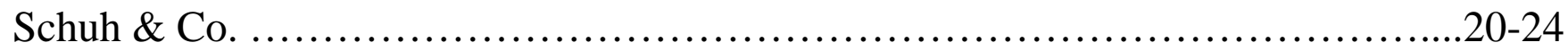

Sick-Maihak ............................................................25-26

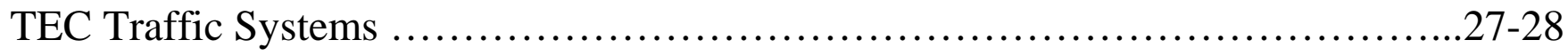

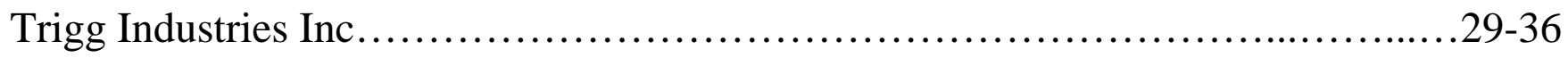



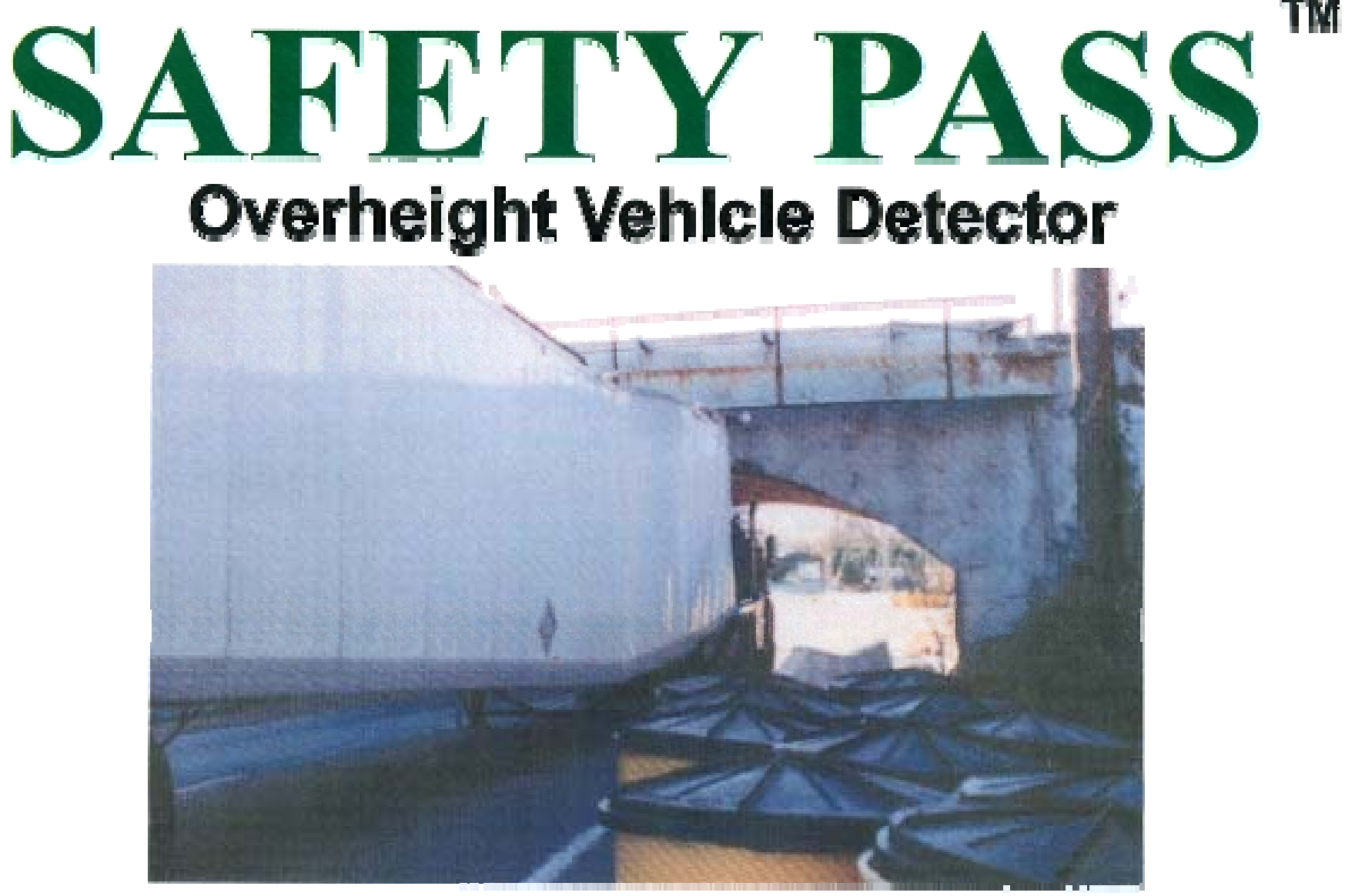

\section{Helps Prevent \\ Bridge \& Underpass Damage}

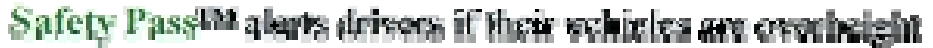

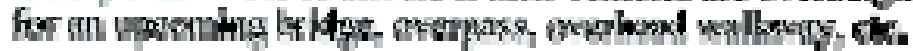

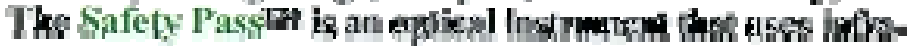

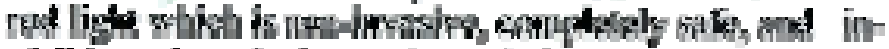

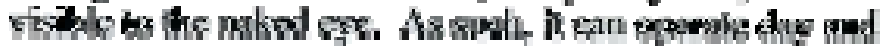

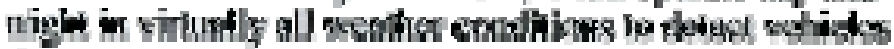

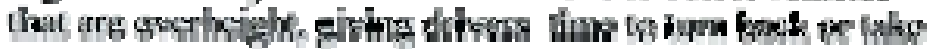

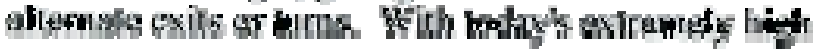

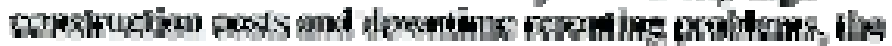

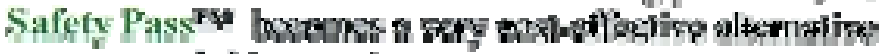

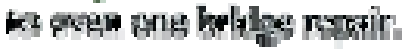

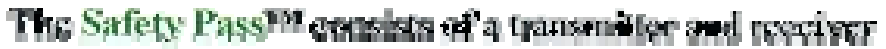

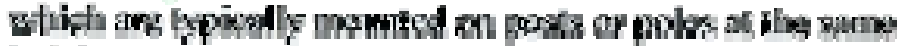

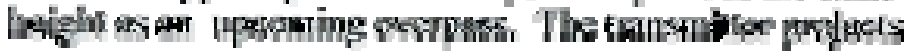

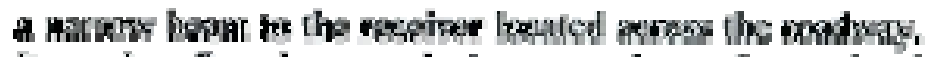

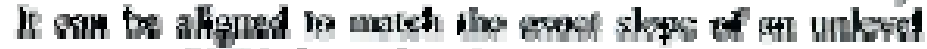

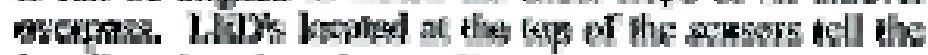

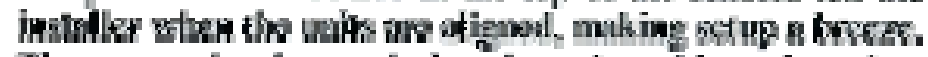

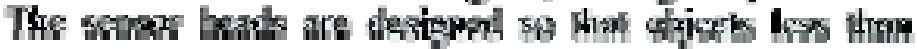

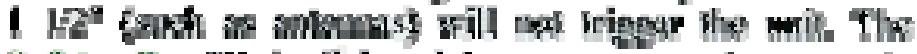

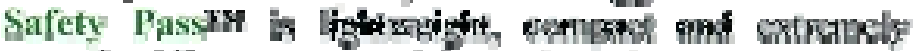

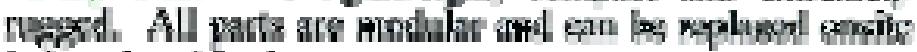
in lifes then 15 mingers.

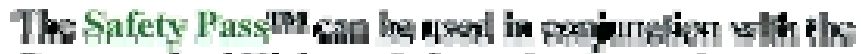

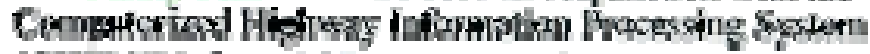

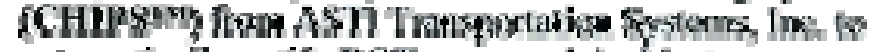

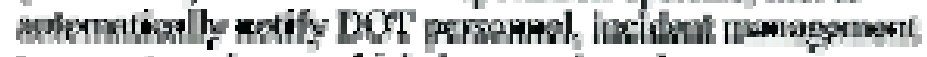

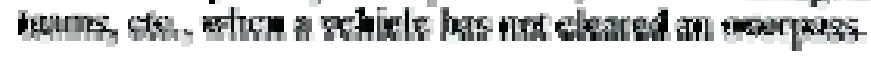

\section{SAFETY PRSE IS A TBADEMARK DYFI}

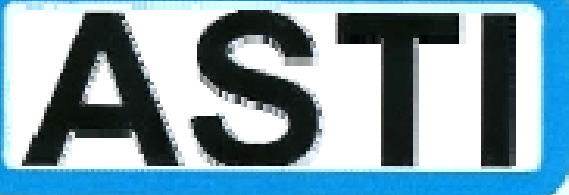

\author{
18 W Wvins Dviry \\ Nisw Castle, DL 1972⿰亻丨
}

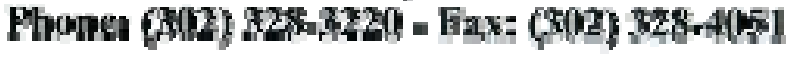




\section{THE}

\section{SAFETY PASS SPECIFICATIONS}

Flethod of Operatlon.

Range

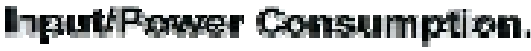

Timer Range

Amblent Temperature

Dimensions

Weilght

Nounting
Alares, pulsed dual bean Infrared wh" backgnound noles refection

200 2X margin $/ 260^{\prime}$ क $1 \mathrm{X}$ mangin

10 to 30 yde or 110 to 240 was. $4 \mathrm{VA}$ maximum

1 greornd to 100 seconds - edjustable lotiany dial

-25 to +153 degnees $F$

-30 to +70 degrees $C$
Transmitber

Receiver

Electronkes Enctesure....
4"H $\times 22^{2}$ \% $\times 3.25 \mathrm{D}$ same as fraาsmitter deperident upon system package - MEAAA rated
$1 \mathrm{lb}$. each fraceiner and transmilter fresols)

Ball \& swivel joint with 12 of vertical axjustment

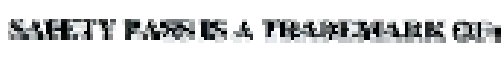

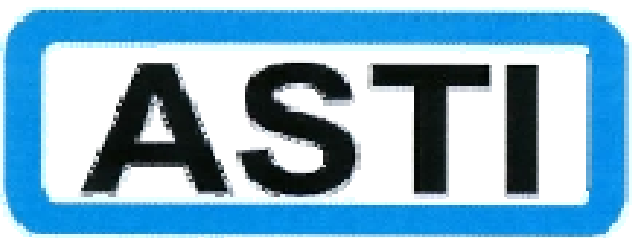

Trancepartalber Exsterts, Inc.

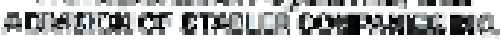
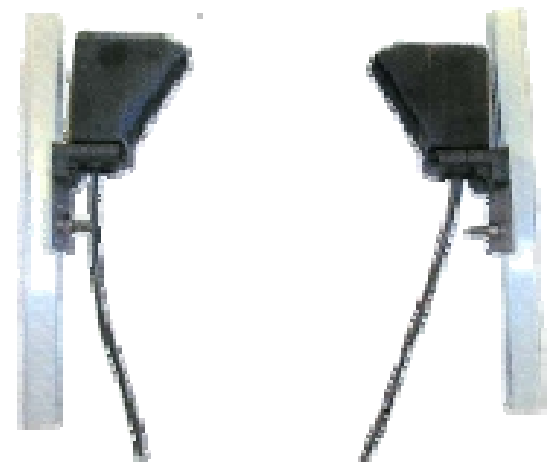

16 Blewhro Drive New Castle, DE 19720 Phone: (302) 328-3220

Fax: (302) 328-40E4

wwew.asti-trans.com
Ahubos of:

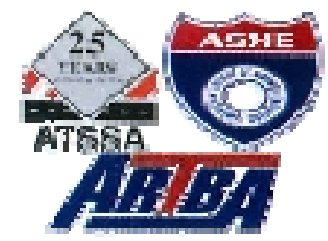




\section{Antaliean R Series General Purpose LED Controls}

The R Series controls from Autotron represent the finest in general purpose photoelectrics. The rugged die cast metal case takes up only 5 ?

cubic inches, making positioning and instaling to best serve your production requirements a snap, as well as insuring long life. The R Series eircuitry is field-1ested with highly engineered solid state technology which prowides years of trouble-ftee operation.

Modulated LED light allows uninterrupted operation under the brighest ambient light conditions. The indefinitely long life of the LED is unaffected by shack of wbration.

The flexibility and operation of the $\mathbb{A}$ Series is guaranteed through engineering thoroughness which has gained UL listing. LED alignment is made simple by a visible propertional intensify indicator. Lens wear is reduced, and lens efficienoy is enthanced through the use of recessed scratch resistant glass. Conirol functions are changeable through a series af plugin cands. These cards along with a choice of plug-in output options make the $\mathrm{R}$ series the uitimate in modular flexibility,

All of these elements go into making P Series controis from Autotron a dependable and cast efficient work horse, whatever your counting. measuring of sorting needs might be.
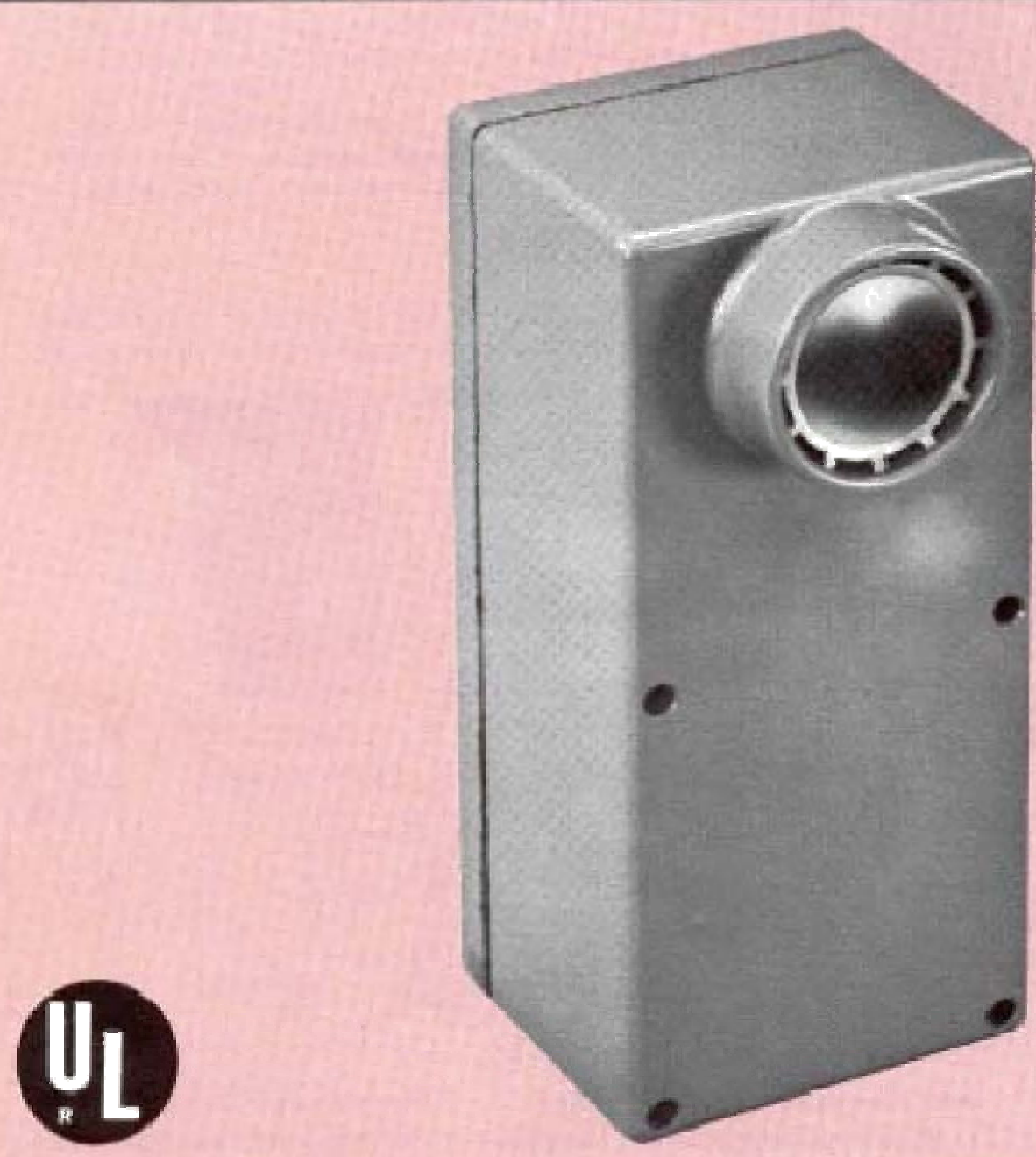


\section{R Series Engineering Puts You in Control}

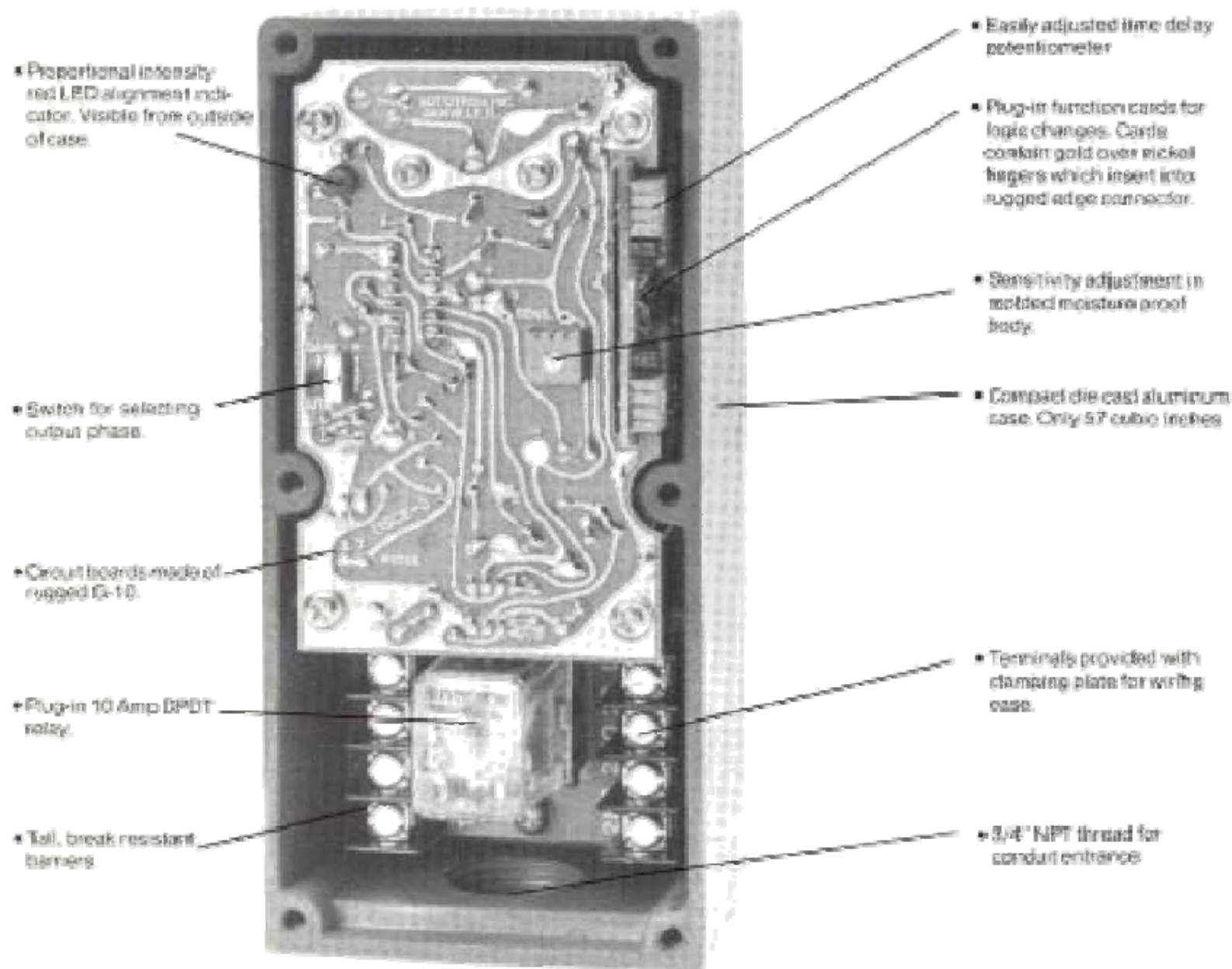

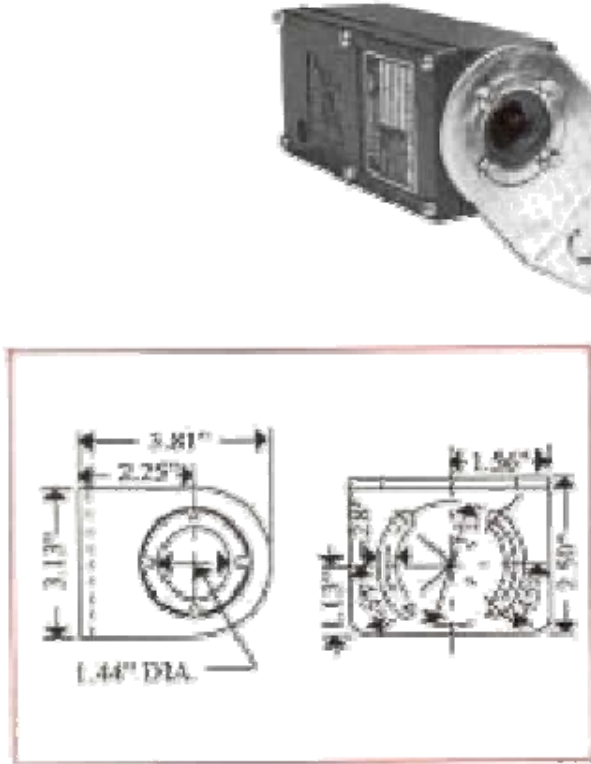

P876 Unkersal Swivel Erackel Option

* Allows rotation of control in all plentes.

- 380? horizontal rotakian.

- Made of heavy 76 C cad-plated seed

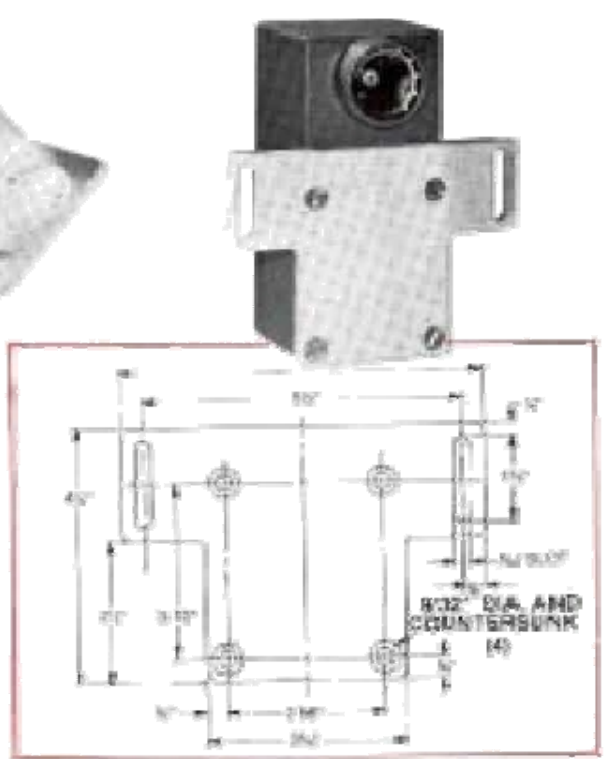

P961 Flange Mount Brackel Option

* Allows a addional monting capability.

- Aefs as adapker bracket to Aggo Series mounting

* Made of 3/16" ead-plated steel

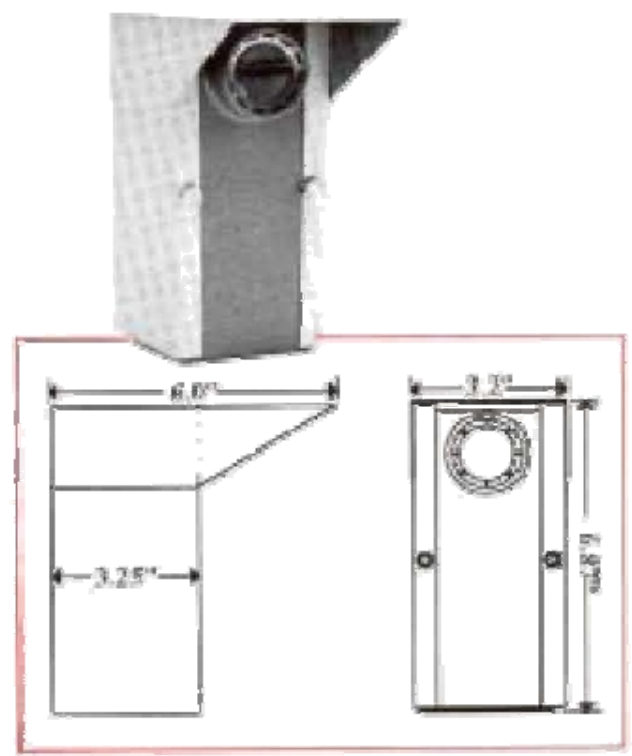

\section{P119s Weather shied}

- Inhbise dacumulation of fain, ise and snew on lens.

- Made of bighweight quld anodized aluminum.

* Stainiess sfeel mounting bolts provided. 


\section{RETRO-REFLECTION}

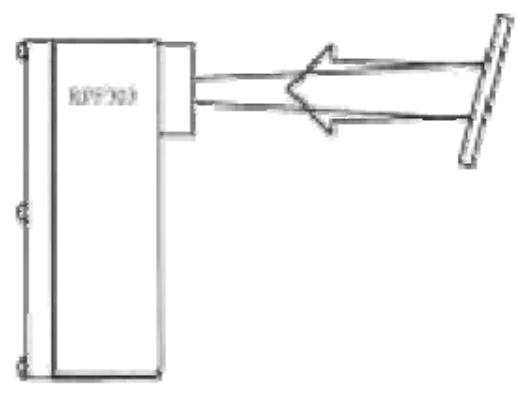

A retro-reflective control generally prowides a surer, simpler and more posthe deregson in apolications where a rellector can be used

Belvo-reflective controls project light thisough the control leng to a retroireflective surtace, which relects the light directy back to the cort fol lens. The milective sufere mary be up io $15 \%$ from perpendicular, and may twen be vibtaling. Allective diess are more etficient reflectarsa than retrofeflective tupe.

The gain of the control is set so that the contral will mot respond is thith retlected aft of the object breaking the light beam if the object is shiny or glossy, it may be necessary fo ang the light bearn so that if dnes not strike the object an right argiles.

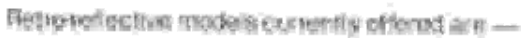 Pange oft 3." Diameten \\ Modal Na Operation Fetlectert

HeFpos oncil doster

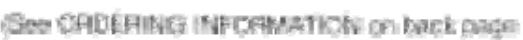

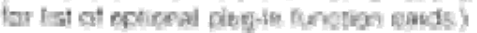

\section{PROXIMITY (Diffuse Reflection)}

\begin{tabular}{|c|c|c|}
\hline \multicolumn{3}{|c|}{ RANGE DFF GIHER HATHO BUFFACE 1} \\
\hline Surtace & Pant Ka. & Max, Fanees \\
\hline 3" da netorigh & point & 35 lest \\
\hline 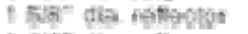 & popas & 19 fent \\
\hline I th" dia retifeltes & Putwo & 14 toest \\
\hline Wo do refledes & Psos & 12 texis \\
\hline sita dia netlecto & Psect & 10 राश \\
\hline $104 \times 34^{2}$ refiector & Rjoce & 29 feet \\
\hline $174^{\circ}$ \& $5^{-1}$ tetleator & Folege & 29 thet \\
\hline 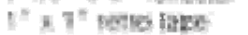 & 겨임 & 4 feat \\
\hline 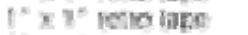 & 족고 & 3 fere \\
\hline 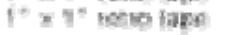 & 7529 & 5 Nere \\
\hline
\end{tabular}

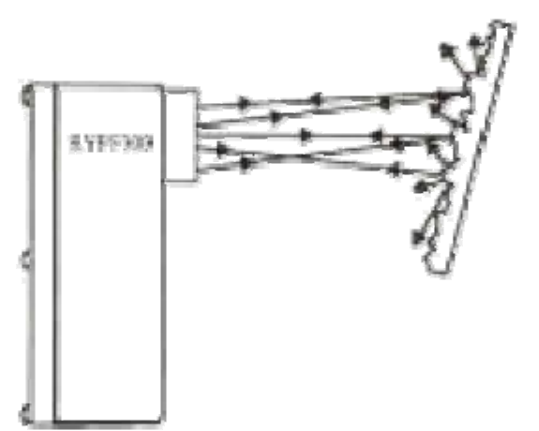

THROUGH BEAM

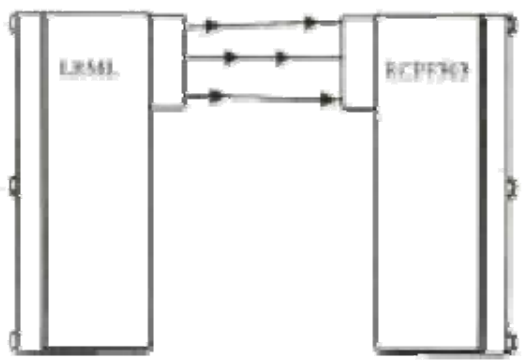

Progimity confols ate primaty used in apphications where retre-foflectors ear not be usad. They serese the presencen of ofifepts by bouncing light att of the object and

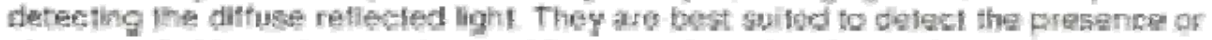
absence of objoté, but can be used for calor defection if there is engugh contrast

Procinity modele currenty affetest ale Aanpe Oer 90\%

\begin{tabular}{|c|c|c|}
\hline a & $\sigma_{p}$ & $\begin{array}{l}\text { Diffuse Whi } \\
\text { Surfacet }\end{array}$ \\
\hline 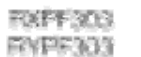 & $\begin{array}{l}\text { Croth } \\
\text { groth }\end{array}$ & 06을 fest \\
\hline
\end{tabular}

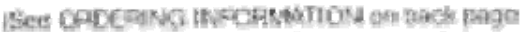

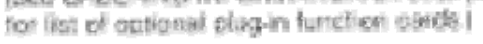

Through beam defection is generaly considered better than reve ar proximily detecttion beca use of greater sensing range and freedem trom tase dothrtion of shiny objects. However, becanse of difliculty in altgnment and the nocessily of locating a separate light source, this method of detection lo not used as dten.

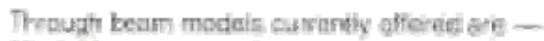

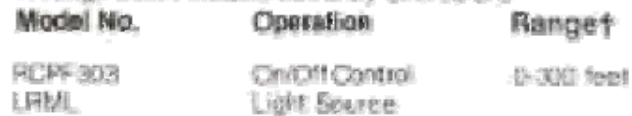

\begin{tabular}{|c|c|c|}
\hline \multicolumn{3}{|c|}{$\begin{array}{l}\text { HOW REFLECTIVITY AND DIRT } \\
\text { AFFECT GANGE }\end{array}$} \\
\hline \multicolumn{3}{|c|}{ 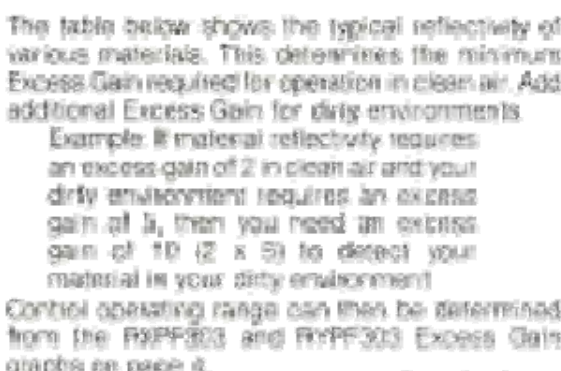 } \\
\hline & Typical & $\begin{array}{l}\text { Requited } \\
\text { Expesss Ealn }\end{array}$ \\
\hline $\begin{array}{l}\text { Naterial } \\
\text { Kodsa Whife Test }\end{array}$ & Reflectivity & Far Clarna Alis \\
\hline Cunst & $90 \%$ & 10 \\
\hline White Bond Paper & 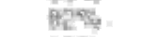 & 8.1 \\
\hline $\begin{array}{l}\text { Kuntl Paoce } \\
\text { Srag White Pore }\end{array}$ & 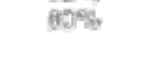 & 81 \\
\hline $\begin{array}{l}\text { Wood } \\
\text { Birck Polyejert }\end{array}$ & $75 \%$ & 1.2 \\
\hline 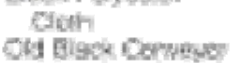 & ats & 3. \\
\hline $\begin{array}{l}\text { Balling } \\
\text { New Back Conwerat }\end{array}$ & $15 \%$ & 5ifi \\
\hline $\begin{array}{l}\text { Beiting } \\
\text { 34 Nextel Findalack }\end{array}$ & 9 & $\operatorname{tag}$ \\
\hline Pain & $47_{5}$ & 22.5 \\
\hline 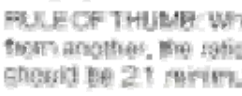 & 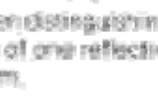 & $\begin{array}{l}\text { ngene matewal } \\
\text { isity to arvether }\end{array}$ \\
\hline
\end{tabular}

thasimum fangas apply foc ciean indro candisions anly. Cantase the tactory ter ditly of curdogr applications. 


\section{EXCESS GAIN}

How well a ghotoelectric controt can perform under less-than-ideal condifions is measured in terms of Excess Gain, Excess Gain is the rat lo of the light signal avallable to the light signat necessary for the control to banely work. The graphe below plot inis factor versus range from spechlic targets. If degrading lactors such as dirt, a pobrly reflective surface, or misalignment exist, an Excess Gain greater than one $\langle 1$ is required. How much Excess Gain is required lat the application is destermined by the customer. An Excess Gain of 3.5 should be altowed for light industrial envinonments, and $5-8$ for moderately dirty enwironments.

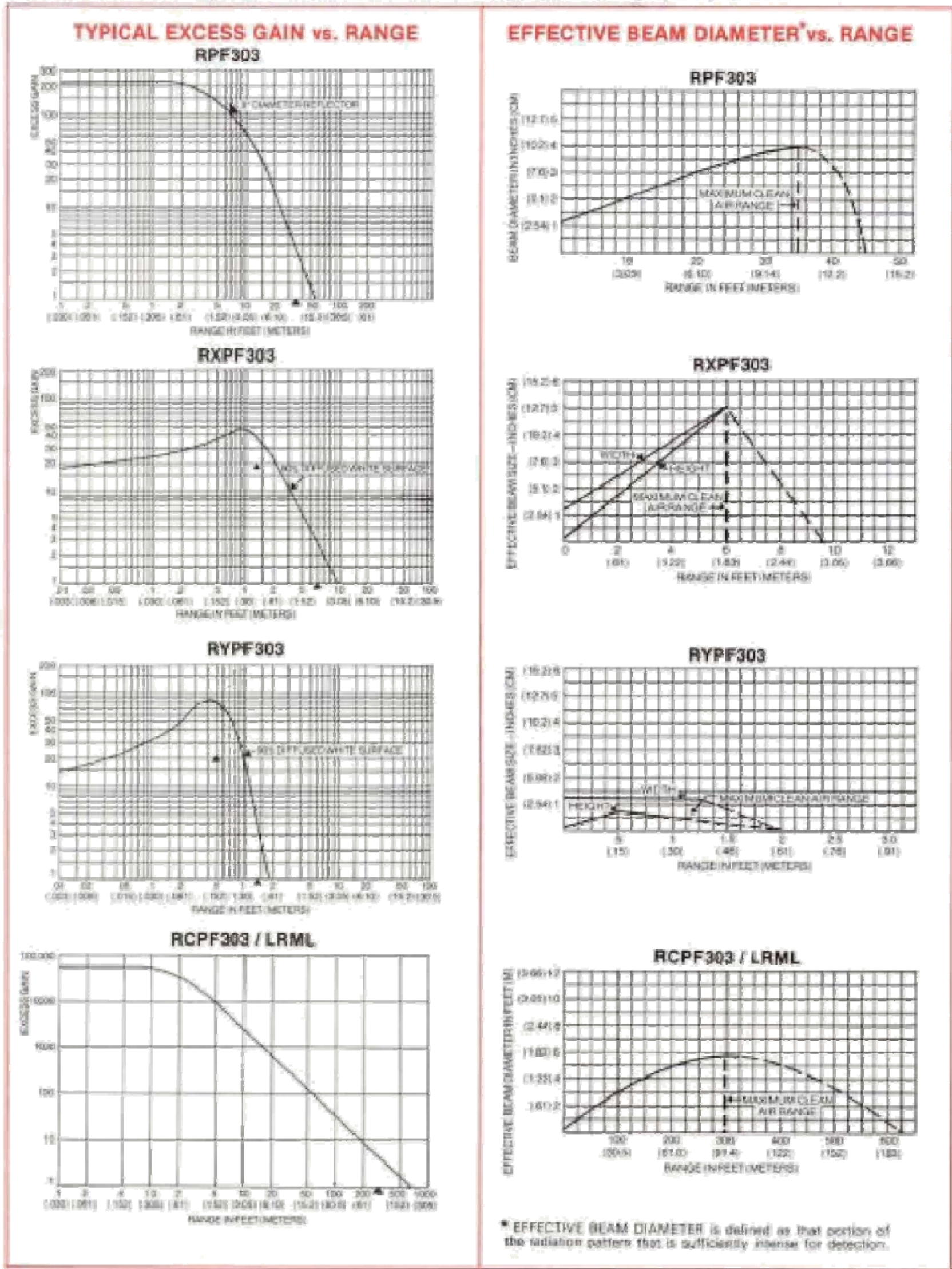




\section{A878R Counting Control Pak}

A high perlormanee pavinting package whth instant installation capability. Lang life combined with pluge in flexibility provides a unique counting system all rolled into one reat package, The all solid-state design (including the counter) eliminates moving parts that can wegr out.

\section{FEATURES}

- Packaged system comes ready to use-no whing to do.

* Pluga indo standard $120 \mathrm{~V}$ euter.

- Countar is Q-digit, push bution reser Counter lita is independent of the total number of counts.

Seli-contained Power Supply: B years typical Maximum Count Speed: 3000 CPM

- Cornplele package consists of:

RPT365 Contral itogic oufpufi

P875 Universal Swivel Brackel P390 Hellector

P1106 Solid.State Counter Assembly 6' Cond Set with Ground

- Retro-Reflector makes alignment easy. Beam can strike rellactor vo to a $15^{\circ}$ anqle and still activate.

- Adtustabte control sensitivity.

- Lighi beam distance a maximum of 35 ?-

- Adjustabie time dehy Ranger is trom 02 to 2.5 secorts. Provided to slcw response and prevent "double oounting."

* Shipping weight of 5 lbs.

- Orher teatures and options same as R Series.

- Not UL histed.
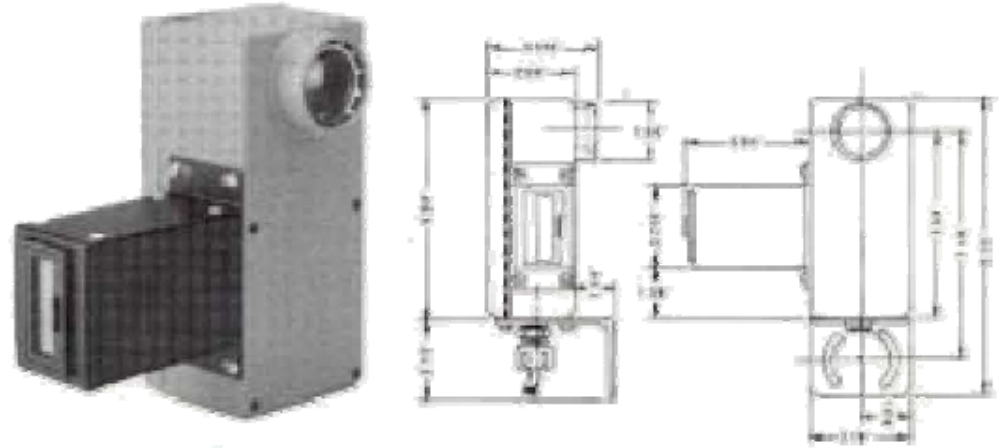

APPLICATION

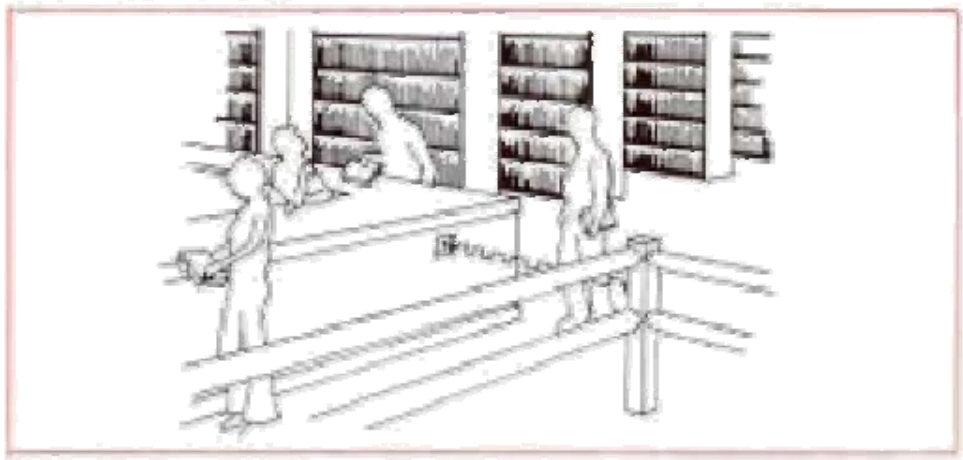

INPUT and OUTPUT OPTIONS

In addition to the standard input and output, the R Series can be supplied with any of the options shown to make the control

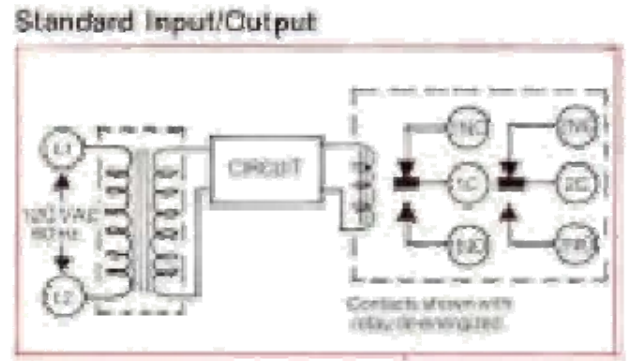

compatible with practically any pover supoly and load The optional inputs and outpuls are not UL listed.

Solid state AC Switeh Qutput (K)

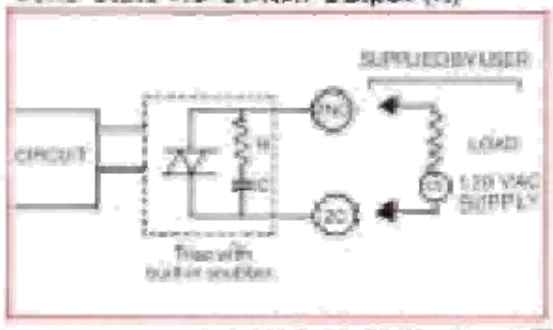

120 VAC 50-60 $\mathrm{Hz}$ input (T)

230 VAC 50-60 Hz input (E)

26 VIC 50-60 Hz howt (바

Logie Output (a)

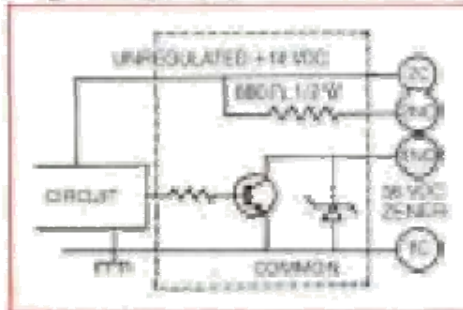

Logic Outpui $(\mathrm{G} A)$

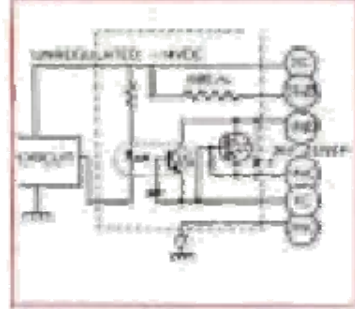

12 YAC 50-68 $\mathrm{Hz}$ inpul (A)

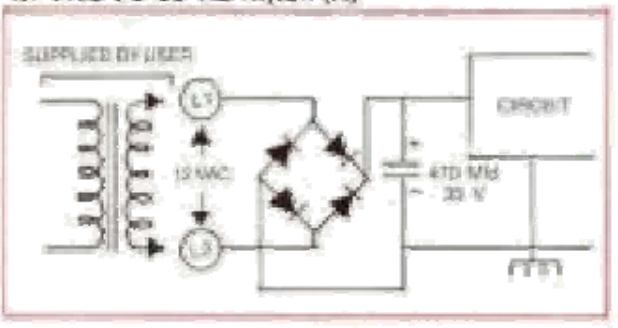

12 roc input (0)

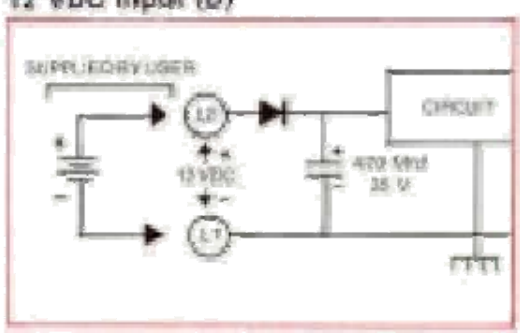

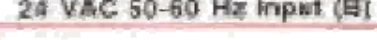

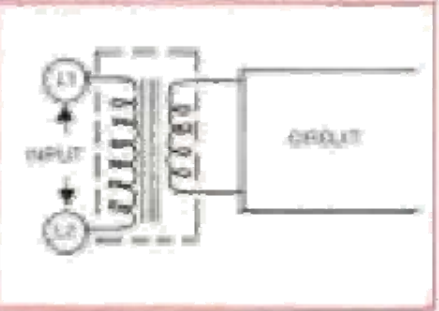

24 voc input $\mathrm{Wij}^{-}$

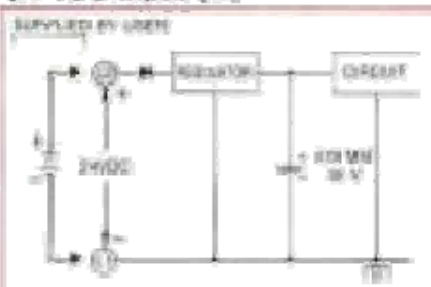




\section{FEATURES}

- Multitude of induatrial uses.

- Moclutafed LEO beam. Highy immune to ambient ligh Indelinitaly lang lite

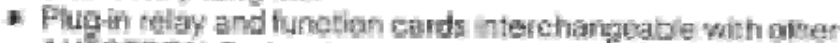
BUTOTRON Series. No sand novuired to ONOFF.

- Unique proportixnal intensily ned LED allgmment indicebor. The befier the alignment-1he brighter h glows. Visible from vuiside of cetrse

- Compact, fugrad die cast mbal case gisient seailad. Pro vidas maximum shielding frem sleotrical nopise. Heary epoxy Dain arbtec is againsi solvents and oor rosive agents

- Cover held fighly by six captive screws. lip on oover prewerts gasker "blow in" by oxternal high pressure wash domen

- Mela case hold shope. Does nol detorm when hot or ghatter when cold.

- Recessed glass lans resists seratohing

- Fales trip proteshon when powwor is furned of

- Adiustable sengivity is standard.

- Oubut phase selection is stardared.

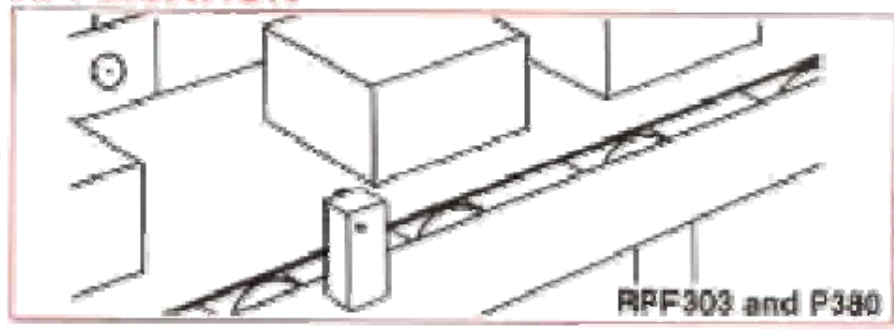

OPTIONS

* Pg75 Universal swivel bracket

- Pg61 flange mount bracket.

- Pugrin logic or fielite state AC swioh output.

- Poge meather shiely

- Antifog fens heater for extrame envisonmentis

- Optianal input voliages:

* 12 WAC 50-60 Hz

* 12 voc

- 200 VAC SO-EO Hz

- 123 VAC 50-EO Hz

\section{SPECIFICATIONS Ambient Oparaling

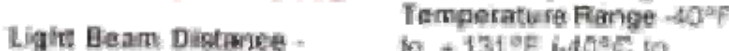 \\ Ste pacte 3.

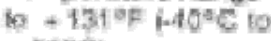 $4550 \mathrm{Cl}$

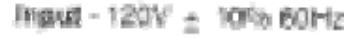 \\ Pwoter Consanmikan - BVA \\ Ambinat Light Toleranes \\ Fiesponse Time - ôt sec \\ to.078 toot candles \\ Enclosure = Die cast aluminum eqoxy gray paintad gastel-vealed, MEWA $1,3,4,5,12,13$ \\ Duigut-Reiny: Ixpt Con \\ Hasts Fated 1AR, 180 WAC \\ ressolve \\ tapres in bown for $34^{\prime \prime}$ exndiut? \\ Shipping weight -3 tbs. \\ Lania - Guats intarad L FD \\ For more defails ask for \\ A Sertes Owner's Manual

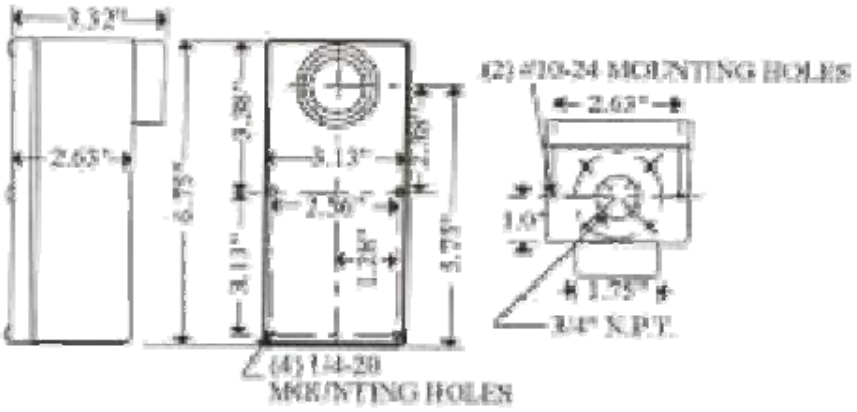 \\ Sienser silican \\ (Bulletin 179)}

\section{ORDERING INFORMATION}

\section{CONTROLS}

\begin{tabular}{|c|c|}
\hline $\begin{array}{l}\text { Moded Na. } \\
\text { RPFoog }\end{array}$ & $\begin{array}{l}\text { Deneription } \\
\text { ONGFF } \\
\text { Retno Conool }\end{array}$ \\
\hline AXPF30S & $\begin{array}{l}\text { OrdOFF } \\
\text { pros caitrat }\end{array}$ \\
\hline AYPFace & $\begin{array}{l}\text { Ondiar } \\
\text { Pras-Control }\end{array}$ \\
\hline 7CPFRE & $\begin{array}{l}\text { ONWwOFf Long } \\
\text { Arange Cantrol }\end{array}$ \\
\hline FML & $\begin{array}{l}\text { Lorry Riange } \\
\text { Lighi Sevise }\end{array}$ \\
\hline Asta: & $\begin{array}{l}\text { Counting } \\
\text { Conturs Patk }\end{array}$ \\
\hline
\end{tabular}

For osdering and ericing altowo Nowel Wos with plugin tunction cards instalest, sutest.

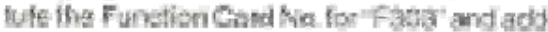
the rend poice.

Far fximple. the Ref aes Ongff Cantrol wit the T3Et Single Timer Card instalad is ardened as

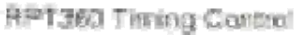

PLUG:W FUMCTION CARDS

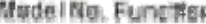

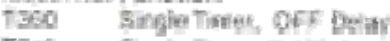

T318 Sngle Timur, cow Derles:

Twib Dual Trmes

We0 Diestime

Fexi Fin Finerion Times

1342 Tws Diph Batch Ceumter

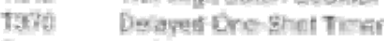

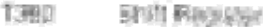

TMQ QHer of intw Spenth

Denctar

Tho Orengliaten

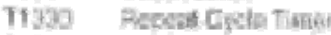

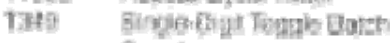

Cesuter

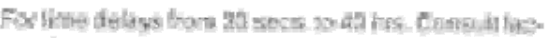
bory bor lime canos

T3es Long Bway One-Snct fimm

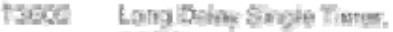
GFF Detar

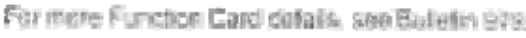

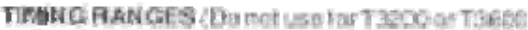

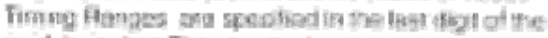

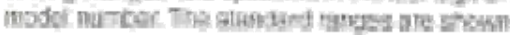

Firnge Mara therase

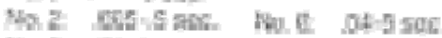

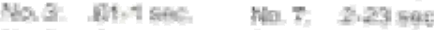

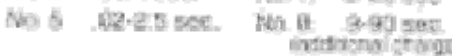

Oposs avaiatio upon regaits

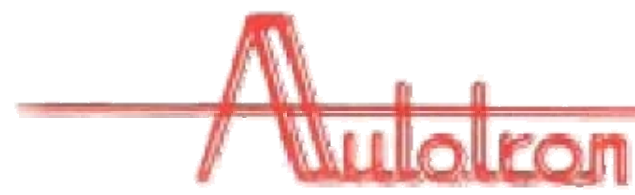

\section{ACCEBSOHIES NOAOEH SEPARATELW}

Pintlestore

Modell Ha Dianserms

Prent 1 it

Paoter if

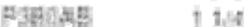

Fэम05 $7 \mathrm{~B}^{\circ}$

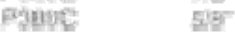

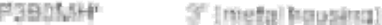

Puise $1114 \times 5$ reande

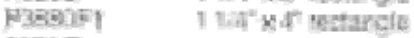

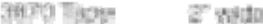

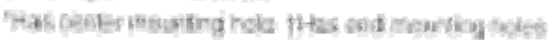

Brackels and Shiold

Wadil he. Oescription

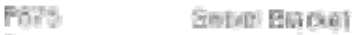

Paet Fange Howet Bradent

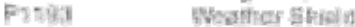

OPTIONAL FEATURES(Consuli fackoy toe modod degignation!

Desacriatioge

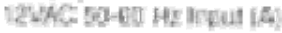

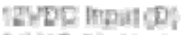

$24 \mathrm{k}$ C $50-68$ He Invut is

24utbe Insoregs

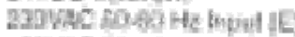

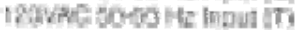

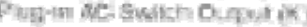

Pugin bage Dialpu f 6 or EA

Afereg Lense Heador ith 


\title{
Banner Engineering - Industrial Sensors for Vehicle Detection, Overheight Detection, Parking Control and Toll Booth Applications
}

\author{
(3) Email Article Print
}

Banner Engineering is a leading manufacturer of industrial sensors, using opto- electronics, ultrasonic, laser and magnetic-resistive technologies.

Sensor applications include vehicle detection and profiling for the traffic and rail industry. Typical applications include vehicle detection (cars, trucks, forklifts, etc.), overheight detection for tunnels and bridges, parking access control, measuring and profiling in toll booth applications and train and tram detection.

\section{M-GAGE MAGNETIC VEHICLE SENSORS (PATENTED TECHNOLOGY)}

This innovative sensor uses 3-axis magneto-resistive technology to sense large ferromagnetic objects (such as motorcycles, cars and trucks). Its compact size allows easy mounting and installation, either above or below ground.

A simple "click- \&-teach" routine stores the ambient background conditions into a non- volatile memory, after which the sensor will detect stationary or dynamic vehicles within its detection range. This makes the M-GAGE the ideal sensor to replace inductive loop technology at a much lower installed cost. In addition, this self- contained sensor requires only power, and it has a standard PNP and NPN switching output on-board.

Sensors that are mounted below ground are not required to be removed in case of rework of the road surface. A simple background re-teach is sufficient to get the sensor going again!

\section{QS30 HIGH POWER PHOTOELECTRIC SENSORS}

Banner's QS30 optical sensor is built for extreme temperature fluctuations and for high humidity conditions. With its IP69K sealing degree it can be submerged indefinitely, or exposed to high pressure cleaning at 120bar. Its optical power has been specially tuned to look through mist or fog but not miss any cars or trucks blocking its beam. It is also unaffected by direct sunlight or from optical crosstalk with other sensors.

\section{A-GAGE MINI-ARRAY MEASURING LIGHT SCREEN SYSTEMS}

Reliable information is needed for tolling applications if a car is entering the toll booth station, or if it has cleared the station. The main difficulty is that a wide variety of vehicles can come through the station: motorcycles, cars, cars with caravans, cars with trailers, light pick-ups, trucks, etc.

The MINI-ARRAY measuring light curtains are the standard solution for these problems. Composed of an array with multiple synchronized emitter / receiver pairs,

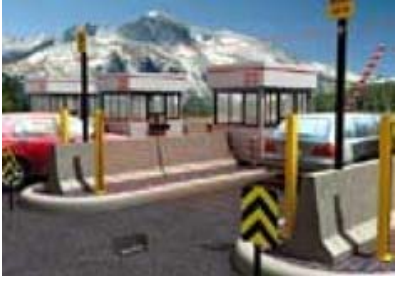

Expand Image

Multiple sensors such as optical, ultrasonic or magneto-resistive are being used for vehicle detection at a toll booth lane.

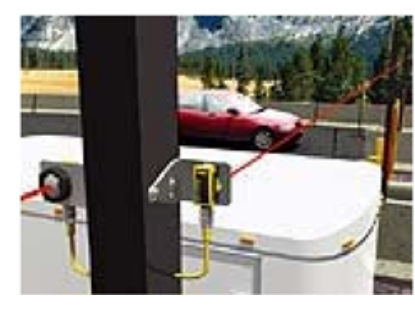

몰 Expand Image

A powerful QS30 optical sensor with a $200 \mathrm{~m}$ range, immune to direct sunlight, is being used for overheight alarm.

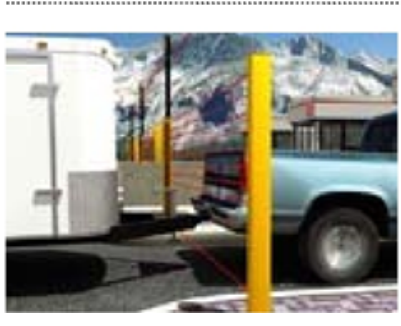

G Expand Image

The Mini-Array measuring light curtain is ideal for 
hey will detect the car or truck starting with its bumper, but sense even the smallest parts like the towing hook. This ensures reliable sensing, or even processing the car / truck profile for automated fee calculation.

\section{U-GAGE ULTRASONIC SENSORS}

Ultrasonic sensors are unaffected by rain, fog, snow, mud, extreme lighting conditions or colour of the object to be sensed. Many of these sensors have analogue outputs (voltage or current), discrete switching outputs, or both. All sensors have a compact housing and are completely sealed for harsh environmental conditions. Sensors can be easily set up using a simple "click- $\&$-teach" routine. Most ultrasonic sensors have built-in temperature compensation sensors to avoid any drift in sensing distance due to temperature differences.

\section{TYPICAL APPLICATION EXAMPLES: VEHICLE DETECTION, OVERHEIGHT DETECTION AND DOCKING GUIDANCE}

Car wash vehicle detection. This type of application requires sensors that correspond to the highest sealing degree possible, to avoid liquids entering the housing and affecting the electronics. Banner offers various optical, ultrasonic and magnetic vehicle detection sensors with an IP69K sealing degree. These resist continuous exposure to liquids, even at high pressure cleaning levels.

\section{Doc}

king station detection. A truck driver can be helped when backing his truck in a docking station. Ultrasonic sensors indicate the distance from the back of the truck to the docking station. Magnetic vehicle detection and optical sensors indicate that the truck is docked. After the truck drives away, the docking doors will be automatically closed.

Forklift entry / exit. Where forklift trucks are entering or leaving an area frequently, pull cords or transponders can be avoided by mounting multiple magnetic vehicle detection sensors below the concrete for invisible installation. These doors will only open when a forklift truck is in front of the door, and will not react to people. This avoids doors being opened by unauthorized personnel.

Toll booth detection. Banner offers measuring light curtains for vehicle detection and measurement (e.g. detecting trucks). Overheight detector optical sensors warn the tollbooth operator that the car or truck is too high. A magnetic vehicle detector can sense a vehicle to issue a ticket from an automatic ticket dispenser machine.

Please also see Railway Technology - Banner Engineering - Industrial, Radar-Based Sensors for Train Detection

(ब)

\section{Contact Details Banner}

Engineering BVBA

Park Lane

Culliganlaan $2 \mathrm{~F}$

B - 1831

Diegem Belgium

Tel: +32 24560780

Fax: +32 24560789

Email: mail@bannereurope.com

URL: www. bannereurope.com

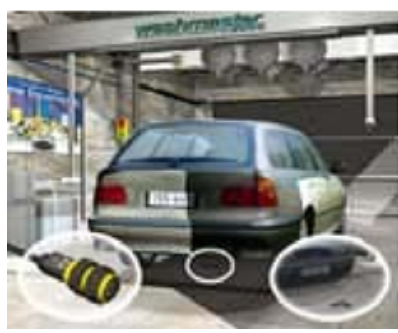

고 Expand Image

Car wash sensors need to have extreme sealing degrees (such as IP69K). Banner offers optical and magneto-resistive (M-Gage) sensors.

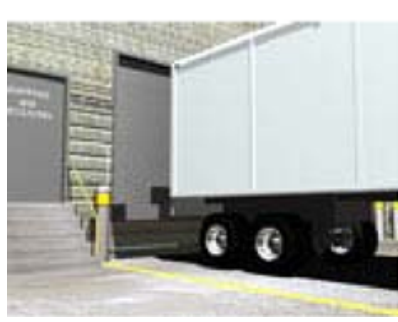

모 Expand Image

For docking large trucks, ultrasonic sensors offer measuring outputs. Magnetoresistive sensors are built into the ground for detection. 
The Coeval Group

Mercat House, 6 High Street,

Prestonpans, East Lothian,

Scotland, UK, EH32 9SN

Tel: +44 (0)1875-814555 , E-mail: info@coevalgroup.com

Web: http://www.coeval-group.com
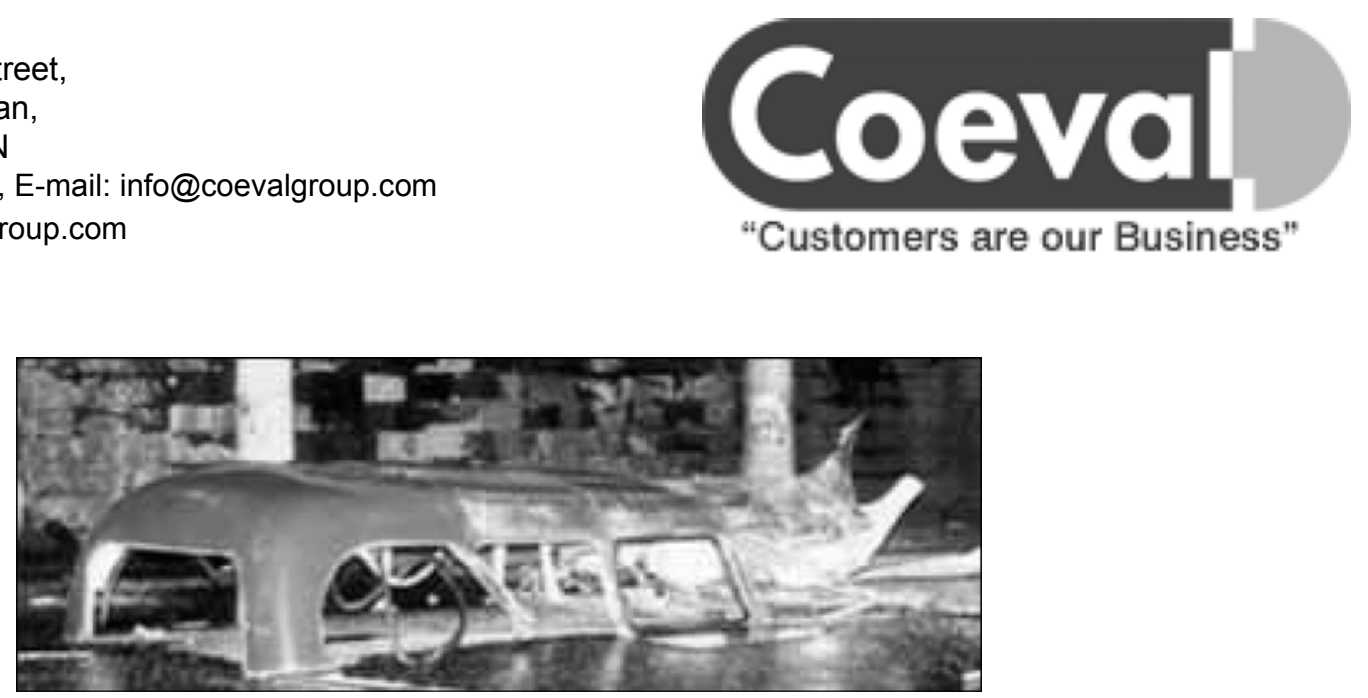

\section{Overheight Vehicle Detection}

Hundreds of low headroom locations throughout the world now benefit from the installation of Coeval overheight vehicle detectors. The infra-red based system, coupled with high intensity "secret" signing offer great reliability in detecting and warning drivers of high vehicles to "DIVERT or TURN BACK"

Type approved to UK Highways Agency specifications, the post mounted twin infra-red beams are normally set at the same height as the height restriction some distance farther down the road. The overheight vehicle harmlessly breaks the infra-red beams, causing the high intensity secret sign to illuminate for a short period of time. The driver then is fully aware that they are too high to pass under the obstacle ahead and takes the action to divert or turn back as the sign instructs.

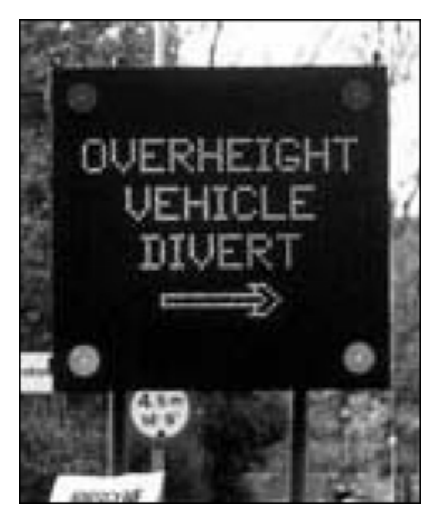

Inductive loops installed in the carriageway beneath the infra-red beams can also form part of the detection logic. The loop proves that a vehicle is actually present when the beams are broken.

Several lanes of traffic can be covered as the detectors can span up to 50 metres. 


\section{Low Bridge Warning Systems}

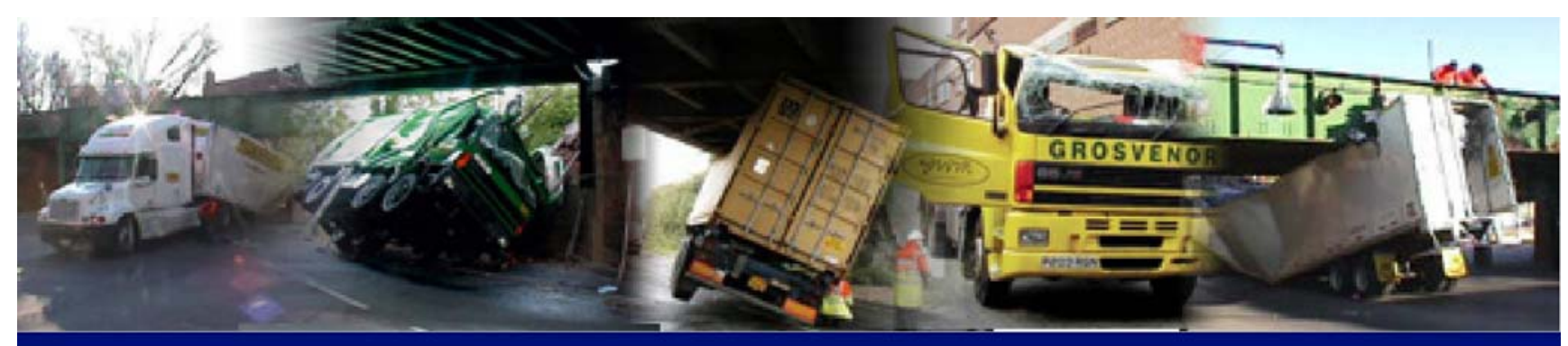

\section{Minimise the risk of high vehicles striking low bridges and}

\section{other structures}

Each year in the United Kingdom over 1500 bridges or other low str are struck by overheight vehicles. Although, fortunately, most of $t$ not cause injury, delays to road and rail traffic can be considerable.

IDT's overheight vehicle warning system is designed to help local authorities minimise delays caused by bridge strikes by providing dri of overheight vehicles with an immediate, highly visible warning that risk hitting a low structure.

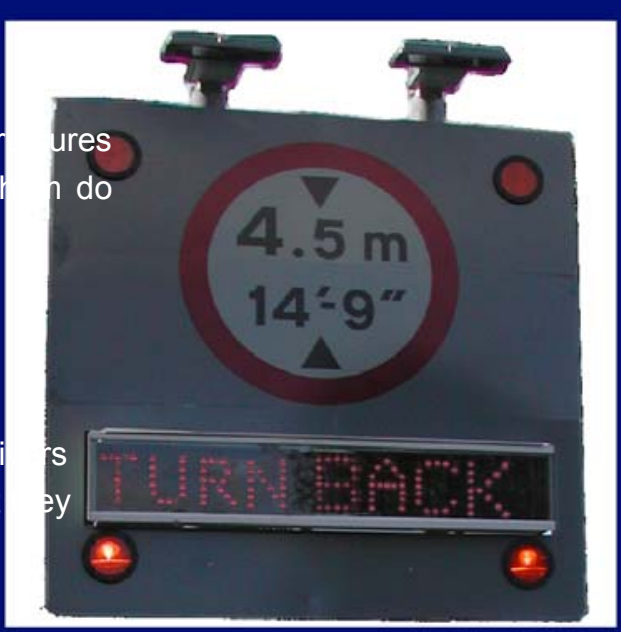

Through careful placing of the sign, drivers are given

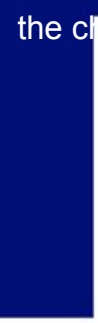

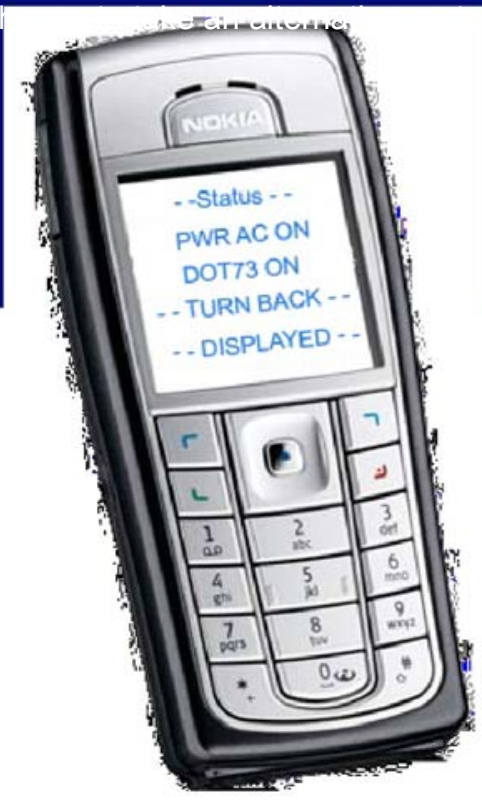

\section{Key Information}

Operational features

Radio link between detector and sign means no ducting required

Remote monitoring by mobile phone

Distinguish between arched or girder structures

DOT73 amberwarn lanterns

Options

$100 \mathrm{~mm}$ or $160 \mathrm{~mm}$ character

heights Bridge Incident Detection 


\section{How the system works}

The system consists of a vehicle presence detector $(A)$ and an overheight vehicle sensor $(B)$ installed upstream of the low structure. When an overheight vehicle is detected, a signal is transmitted by secure radio link to a variable message sign which then displays a message advising the driver to take an alternative route. A slightly more complex arrangement is required for arched bridges (see below).
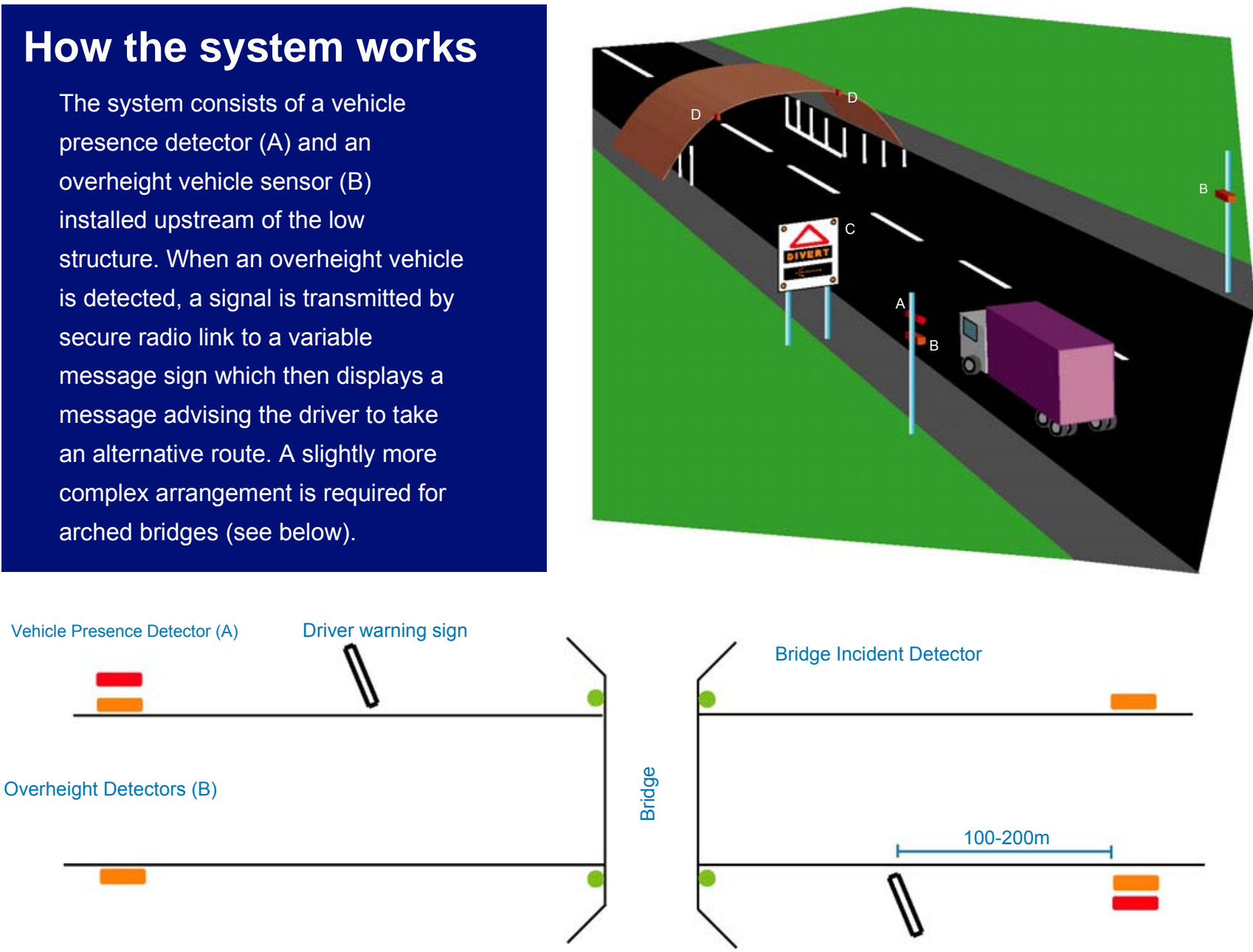

\section{Arched bridges}

Where the low bridge is an arched structure, some high vehicles can pass through the bridge provided they use the centre of the highway.

In this situation, the system uses a second set of detectors at B to distinguish between 'high' vehicles (ok to pass but must use the centre of the highway) and 'overheight' vehicles (must divert).

The 'high vehicle detector' detects high vehicles and directs them through the centre of the arch. The VMS on the opposite side of the bridge simltaneously displays a warning message such as "Vehicle in centre of road".

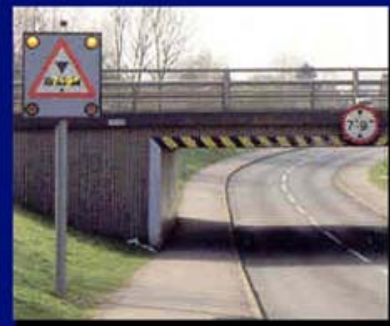

\section{Bridge Incident Detection}

In the unfortunate event that a bridge is still struck by an overheight vehicle, a Bridge Incident Detection unit (D) installed on the bridge (or as close as possible) will detect the event.

\section{For further information on IDT's Low Bridge Warning Systems contact us at:}

Integrated Design Techniques Ltd, Endurance House, Seventh Avenue, Team Valley, Tyne \& Wear, NE11 0EF
t: 01914910800
f: 01914910799
e: info@idtuk.com
www.idtuk.com 


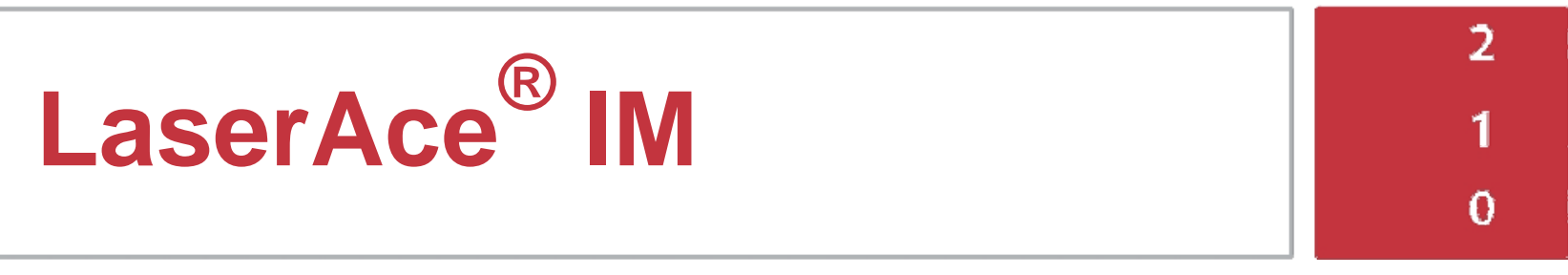

OEM LASER MODULE

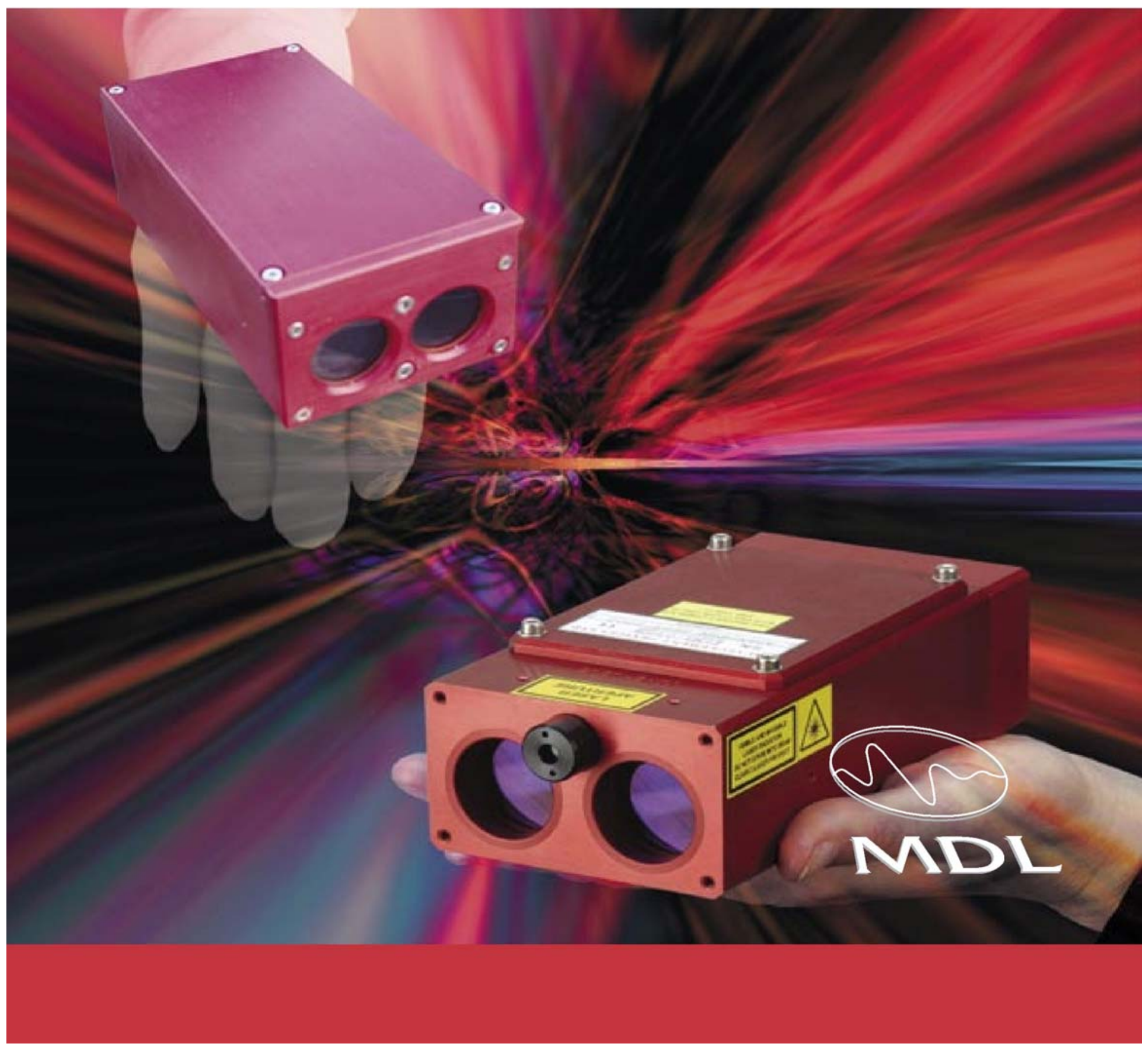




\section{LaserAce $\circledast_{\text {IM }}$}

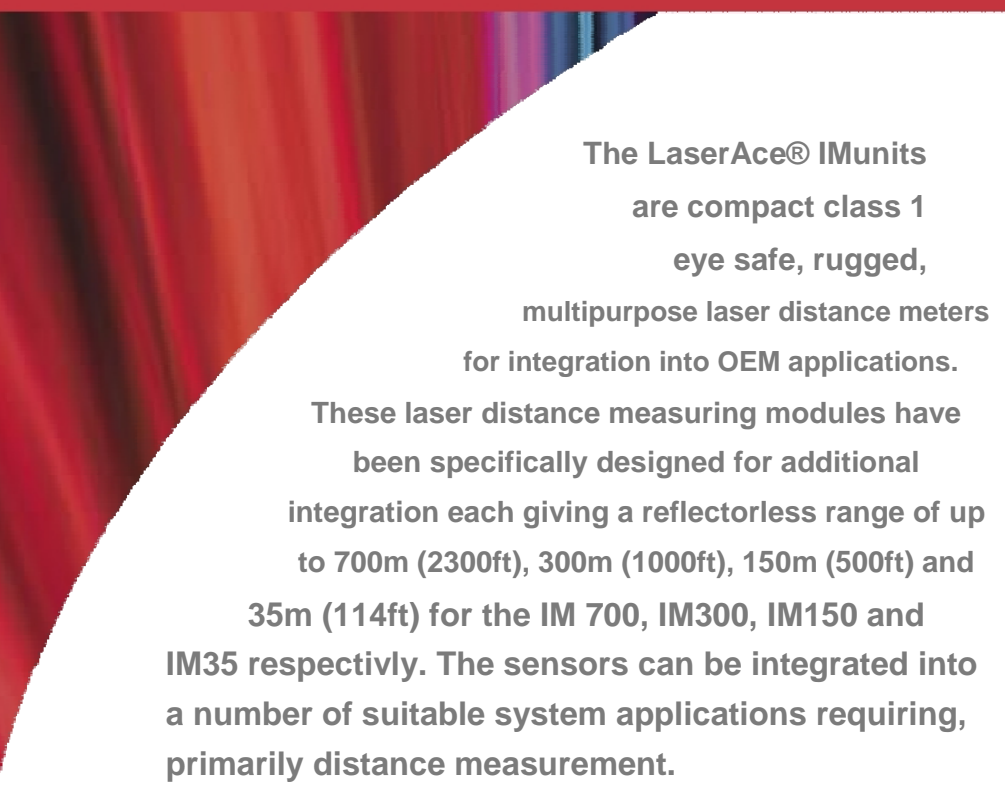

LaserAce ${ }^{\circledR} I M m o d u l e s$ can be configured to output range, speed and height of vehicles or objects and may also be set to trigger cameras in Tollbooth or Law Enforcement applications. The sensors can also be further integrated to produce vehicle profiles and scans, classify and identify them, count axles, over height detection and much more.

Alongside traffic applications the LaserAce ${ }^{\circledR} I M$ is used in Military, Security, Construction and Aviation markets. From a target designator, motion detector, surveying tool and altimeter, each market segment has its own special requirement. Here at MDL we are aware that no two applications are exactly the same so we work with our OEM partners to provide unique solutions to their individual applications and are always willing to help. LaserAce $₫ I M$ is cost effective, accurate, fast and environmentally sealed to IP67 making it the most robust sensor on the market today!

The laser modules use time-of-flight technology, put simply, it measures the time taken for a very short pulse of infrared laser light to travel from one window in the module, to a very low noise detector in a second window. The distance to the target is calculated from the time taken to make the round trip.

The reflected light signal levels are very low, so the greater the reflectivity of a target, the longer the range over which this target can be 'seen'. Therefore, reflective targets will increase the range of each of the LaserAce ${ }^{\circledR} I M$ modules.

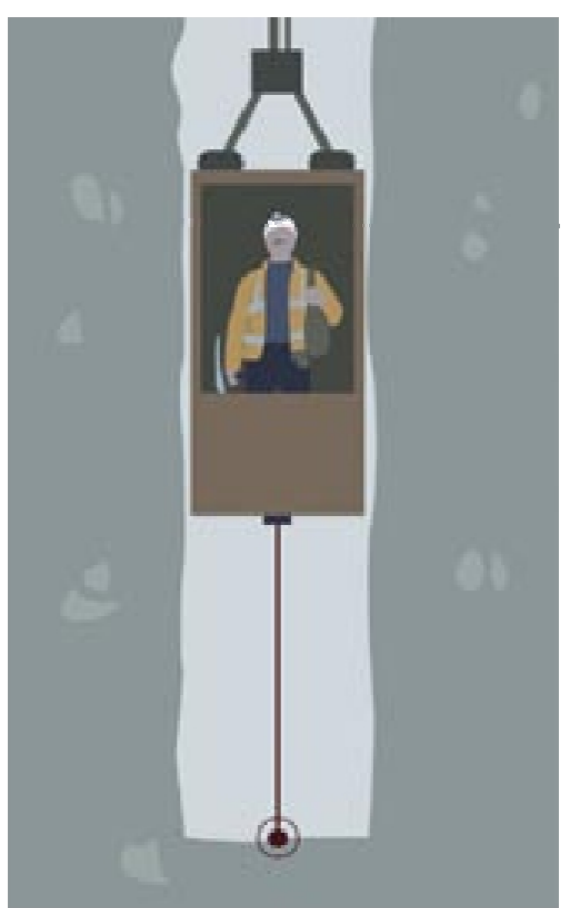

Elevator Position Measurement

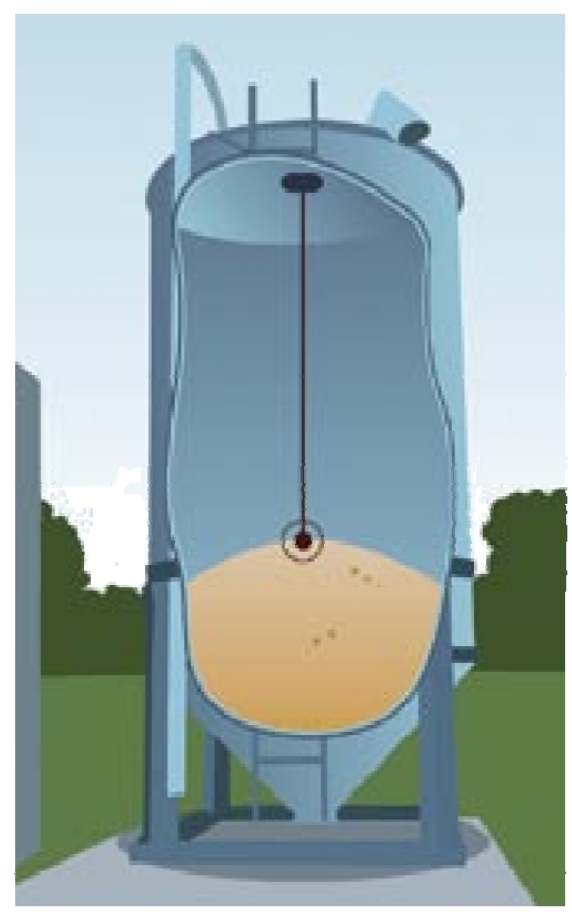

Silo Measurement 


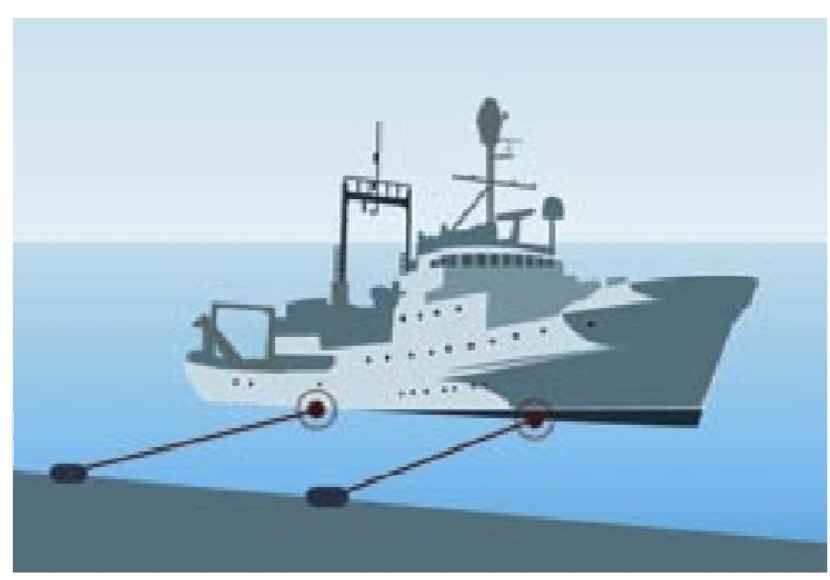

Ship Docking Measurement

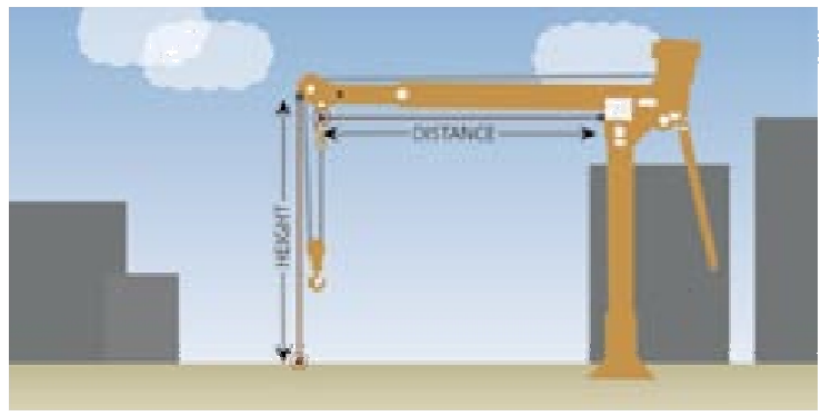

Load Height Measurement

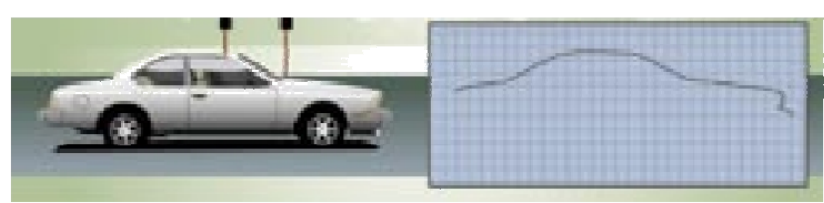

Vehicle Profiling / Height Detection

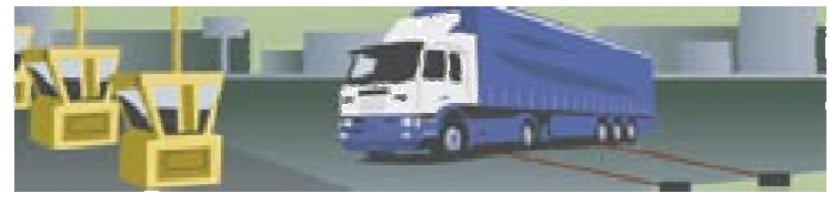

Axle Counting

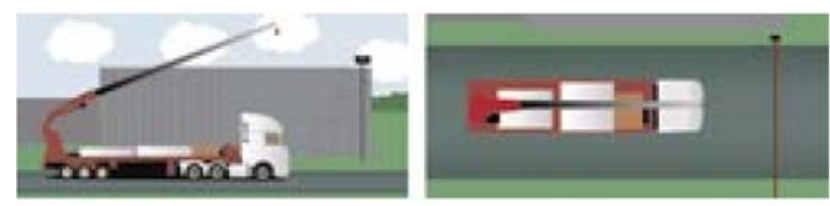

: Overheight / Height detection
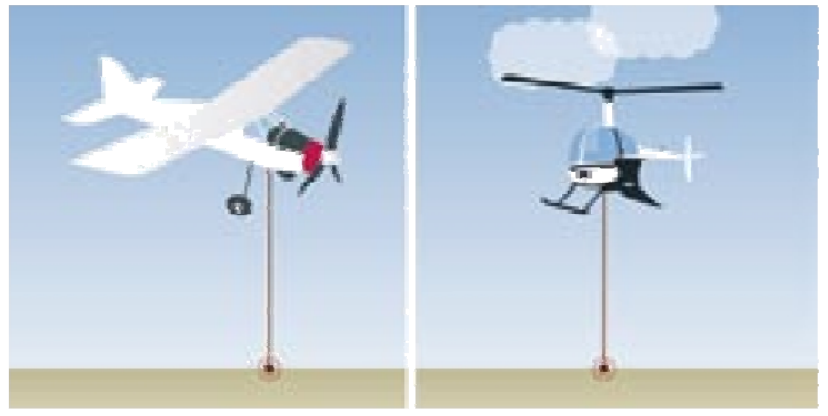

Altimetry

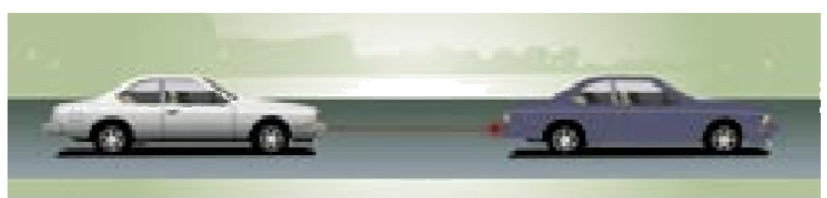

Car-to-Car Speed Measurement

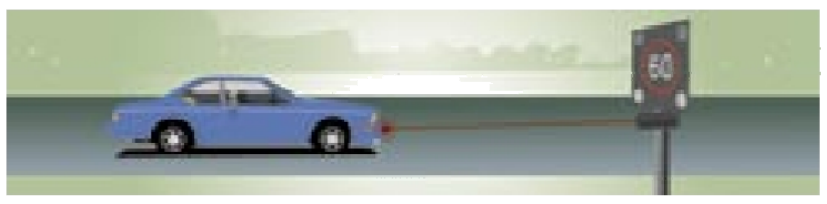

Active Sign

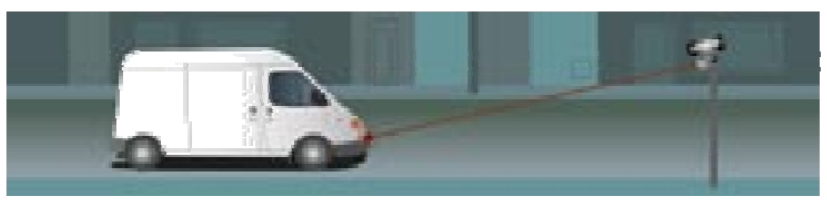

Camera Trigger

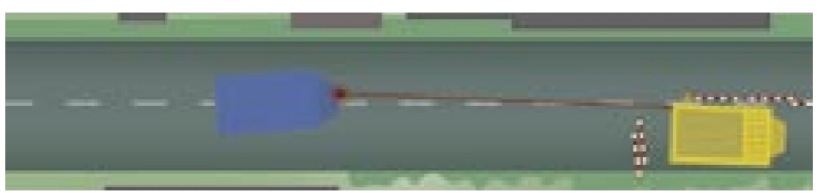

Safety for Roadside Workers

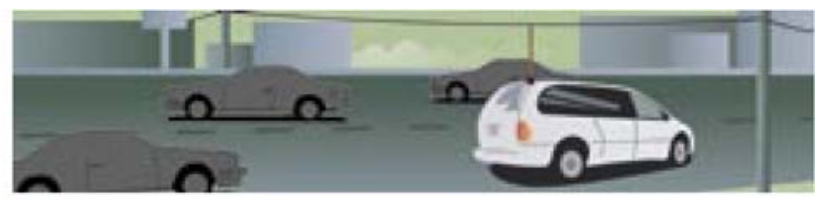

: Overhead Cable Measurement 
We provide a set of standard systems which are designed for easy integration in all applications based on commonly required specifications. Other variations are available and customisations can be provided for OEM integrators. Please talk to us about your application and needs so that we can show you how our LaserAce®IM modules can help you.

\section{Accessories}

- Sighting Scope: Aligned to the laser beam to visually see where the target currently being ranged is located.

- Red Dot Pointer: An additional red laser pointer, aligned to the mesuring beam to locate the current target.
LaserAce ${ }^{\circledR}$ IM-R

MDL's standard laser module with a repetition rate of $9 \mathrm{~Hz}$. This unit is used in airborne laser altimetry, distance measurement and collision avoidance.

\section{The LaserAce ${ }^{\circledR}$ IM-HR}

The high repetition rate distance meter, with a rep rate of up to $1000 \mathrm{~Hz}$. This unit is faster than the standard ' $R$ ' version and is also used in airborne laser altimetry, distance measurement, excess height measurement and traffic applications.

\section{The LaserAce ${ }^{\circledR}$ IM-T}

A Fixed distance high-speed camera trigger. This unit is ideal for integration into a camera system for vehicle recognition, vehicle classification, profiling and speed detection.

\section{The LaserAce ${ }^{\circledR}$ IM-S}

An OEM speed and distance meter used to detect speeding vehicles.

High repetition rates of measurement allow continuous distance measuring and speed calculation.

Please note that for our OEM customers we can customise the modules output information and repetition rate.

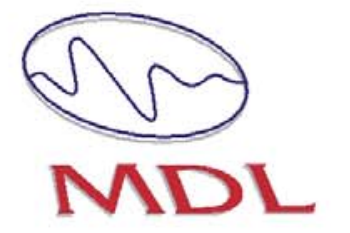

Agent:
LaserAce $\AA$ is a registered trademark of Measurement Devices Limited. All other products and company names mentioned may be trademarks of their respective owners.

Information contained is believed to be accurate However, no responsibility is assumed by MDL for its use. Technical information is subject to change without notice.
For more information on LaserAce ${ }^{\circledR}$

IM please visit www.laserace.com

Head Office

tel: + 44 (0) 1224246700 fax: + 44 (0) 1224824987 e-mail: info@mdl.co.uk

\section{England}

tel: + 44 (0) 1904791139 fax: + 44 (0) 1904791532 e-mail: york@mdl.co.uk

USA

tel: +12816460050 fax: +1 2816469565

e-mail: info@mdl-laser.com

www.mdl.co.uk 


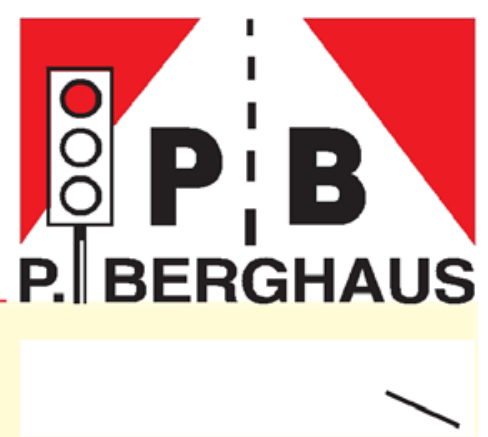

\section{HM Height measuring system PB 12/230}

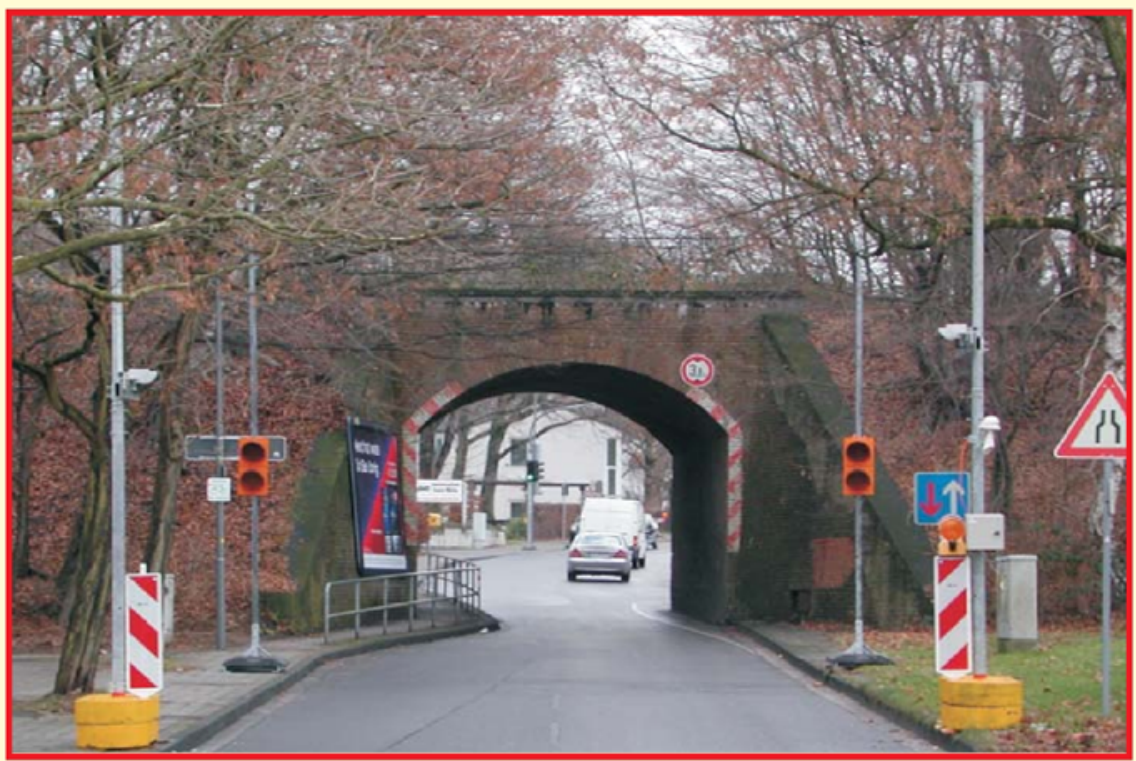

Technical data:

Care tension:

$12 \mathrm{~V} \mathrm{DC}$ and $230 \mathrm{~V} \mathrm{AC}$

Reach of the light

barrier: 0 to $60 \mathrm{~m}$

Protection kind: IP 67

Equipment of the light barrier: front heating and weather protection bonnet

Our new height measuring system was conceived for such areas with which it can come by disregard of heights and way through limitations to serious accidents. The measuring system $\mathrm{HM}$ PB 12/230 with direction recognition grasps with the two special light barriers oversized vehicles.

If such is grasped, the system for five seconds releases an acoustic signal. Two about 30 meters ahead put up $300 \mathrm{~mm}$ of high-luminous two-aspect signal heads (LED) are switched about yellow to long-term-red. The oversized vehicle is stopped.

The transfer to reserve of the system occurs according to option by means of key, about time module, radio or SMS. The height measuring system can be built up with our mobile stand system simply and fast at every place. The care tension occurs about $12 \mathrm{~V}$ accumulator or $230 \mathrm{~V}$ net. The control is accommodated in a watertight (IP 66) lockable case and owns serially net battery changeover, under voltage and polarity reversal protection.

All parts, like light barriers, horn, signal head and key tracer are connected about watertight plug connectors IP 67.

Areas of application are, for example: underpasses, bridge building works, tunnel entrances, halls entrances or multi-storey car- park entrances.

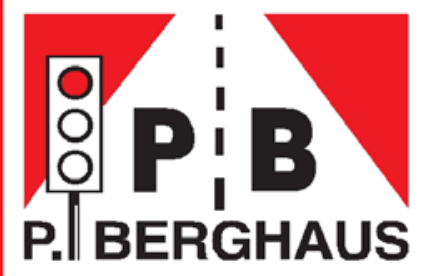




\section{SAM}

Sensing and Activating Module Laser

Sensor for Vehicle Detection

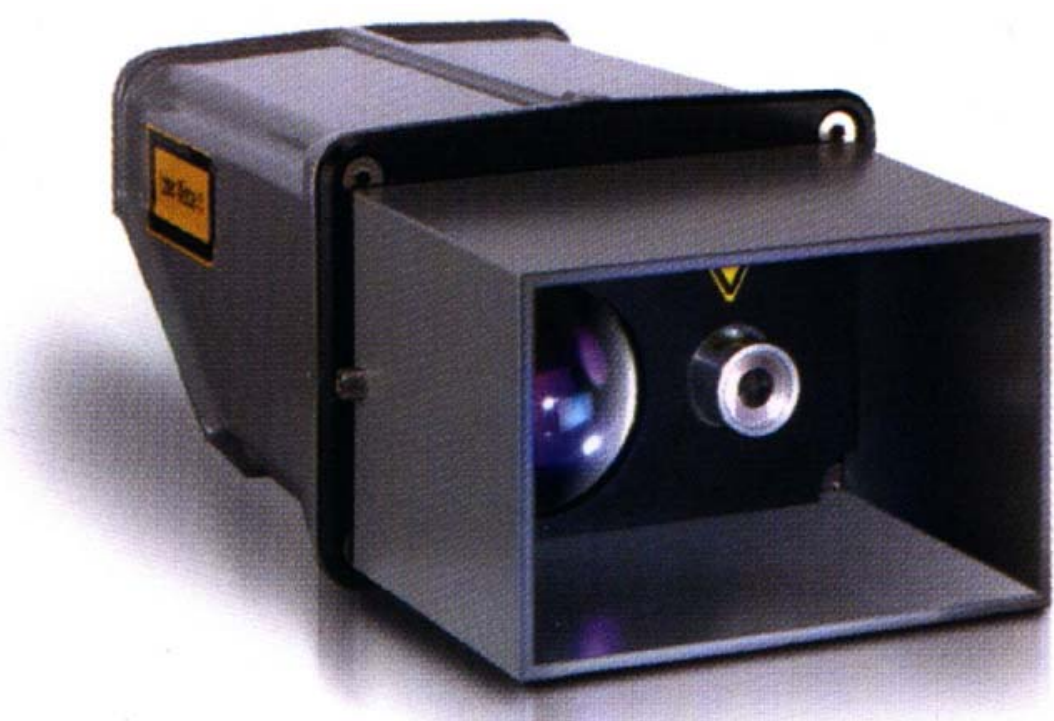

- Over height detection

- Determination of vehicle height

- Determination of traffic lanes

- Drawbar Identification 


\section{SAM}

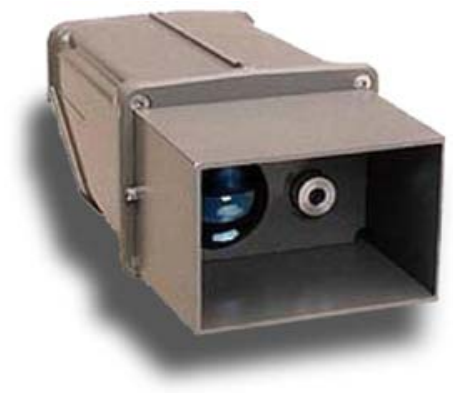

\section{Application Area}

Modern systems for traffic surveillance, traffic guidance and control require reliable sensoring. In contrast to conventional methods, laser sensors offer distinctive advantages. Owing to the optical mode of functioning of the laser detectors, the road construction remains untouched, in addition they can be installed and serviced without interferring with the flow of traffic.

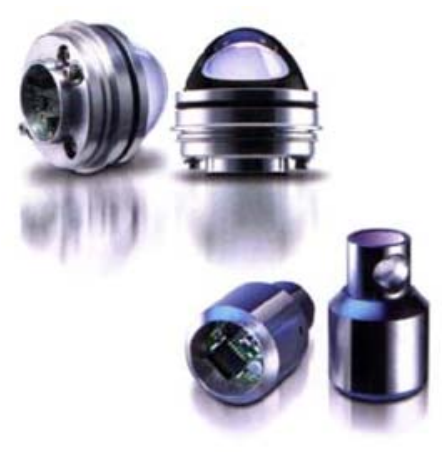

\section{SAM}

SAM (Sensing and Activating Module) is an infrared laser detector offering various possibilities for traffic surveillance. Due to the exceptional technology used for analysis SAM recognises objects in 12 selective range slots. Presence and distance information together result in a markedly fail-save and more precise analysis. The tightly focussed and modulated infrared laser beam, in connection with the employed narrow band filters, is insensitive to sunlight, fog and snow fall. These are considerable advantages over other optical detectors. SAM is able to detect stationary as well as moving vehicles, cyclists, pedestrians and objects up to a minimal size of $5 \mathrm{~cm}$.

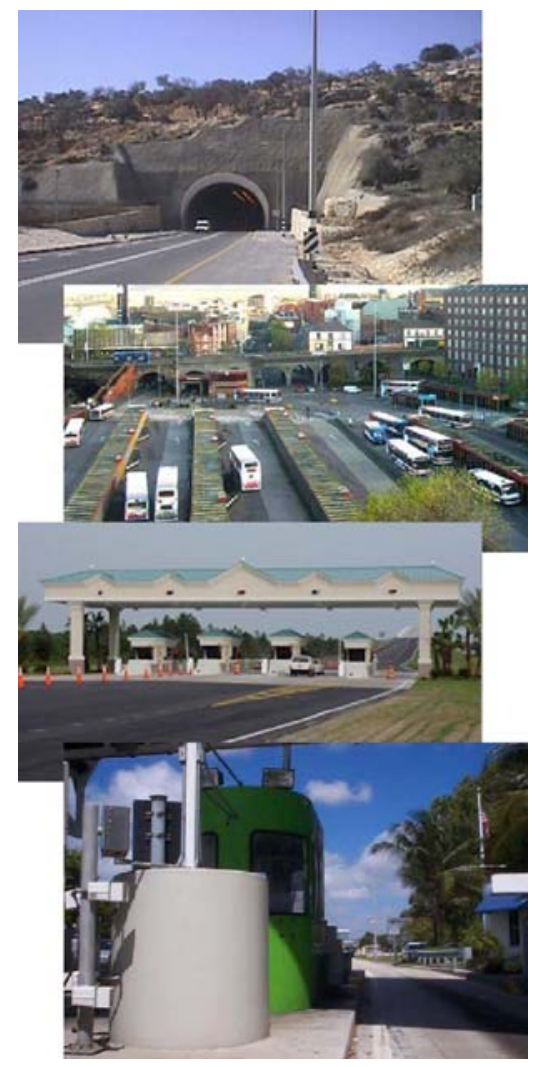

\section{Application}

SAM is excellently suited for the following application purposes:

\section{Over height detection}

to control vehicle heights before bridges and tunnels

\section{Identification of vehicle classes \\ to distinguish passenger cars from trucks / buses / street cars}

\section{2-range-detection}

lane distinction of vehicles based on distance measurements

\section{drawbar detection}

drawbar detection between truck and trailer, to distinguish from close individual car traffic.

\section{The Company}

The technical expertise of Schuh \& Co. GmbH is complemented with sound organisational and economical know-how. More than 30 years of experience in the realisation of complex projects in traffic engineering are the sound basis for the successful management of new customer oriented tasks.

Please feel free to contact us. We would like to advise you without obligation to win you as a satisfied customer. 

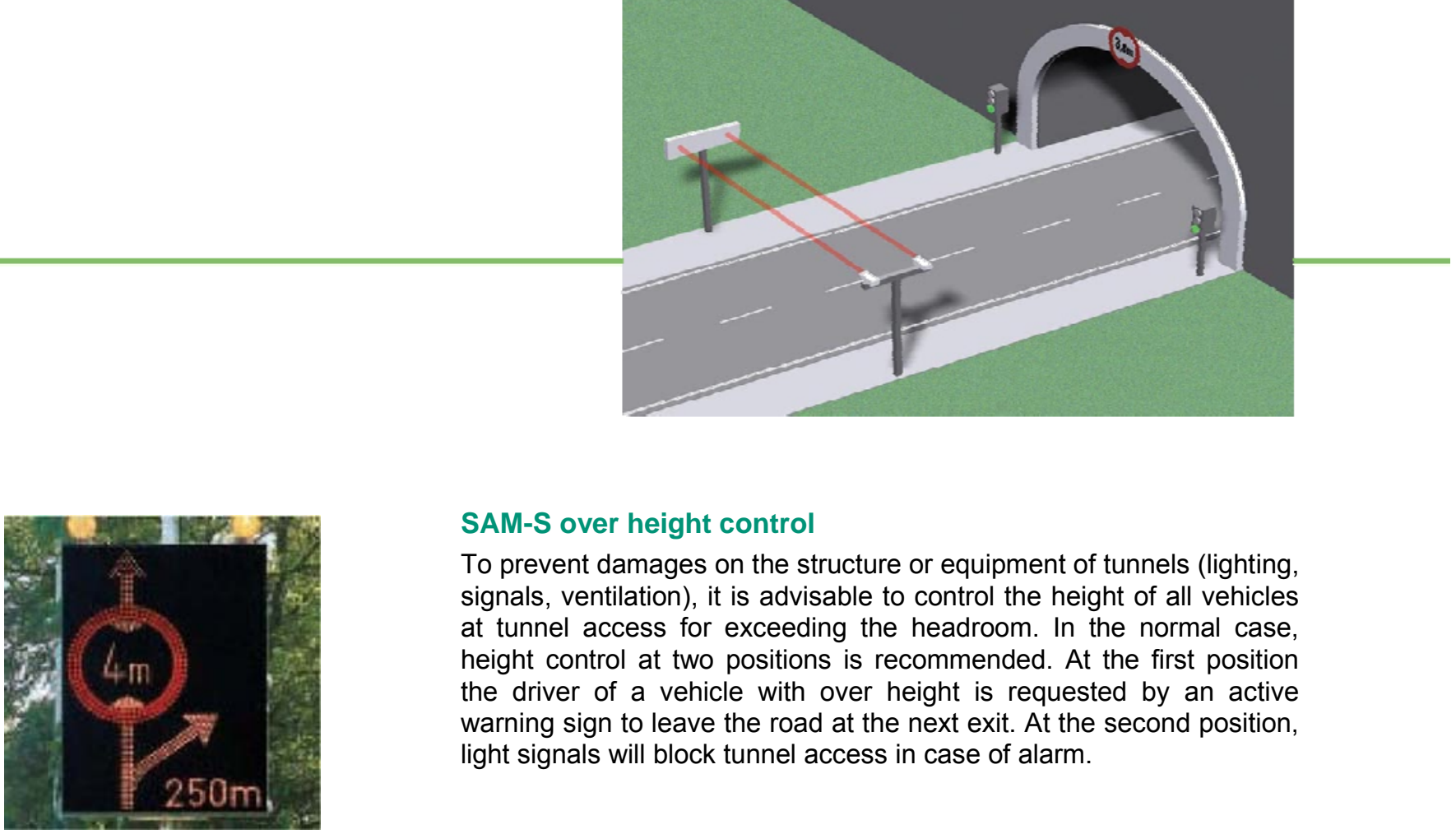

\section{SAM-S over height control}

To prevent damages on the structure or equipment of tunnels (lighting, signals, ventilation), it is advisable to control the height of all vehicles at tunnel access for exceeding the headroom. In the normal case, height control at two positions is recommended. At the first position the driver of a vehicle with over height is requested by an active warning sign to leave the road at the next exit. At the second position, light signals will block tunnel access in case of alarm.

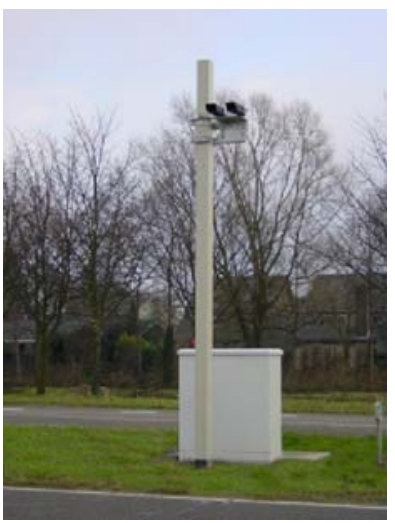

\section{Advantages}

The SAM over height control system recognises even small objects (minimum of $5 \mathrm{~cm}$ ) at a speed of up to $100 \mathrm{~km} / \mathrm{h}$. Roads with a width of up to 32 meters can be controlled for height with an accuracy of 2 $\mathrm{cm}$. Two SAM-S sensors work as reflection light barriers in this appliance. This way, only one electrical installation is required on one side. On the opposite side a passive reflector is to be mounted. Due to special beam widening, adjustment is very simple and there are no problems to be expected from percussions or the swaying of the supporting pole.

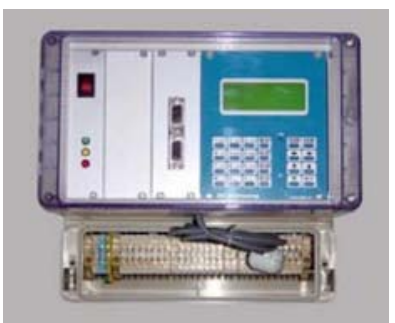

\section{The Controller}

The signals of both sensors - and inductive loops, if they exist - are logically combined in the controller to avoid false alarms that could be caused by birds or falling leaves. Additionally, the signal quality of the sensors is constantly monitored and an event of fault will be reported by a separate output. The over height alarm output allows to activate warning signs, flashing lights or traffic signals. All events will be logged in the controller to allow the complete documentation of SAM operation.
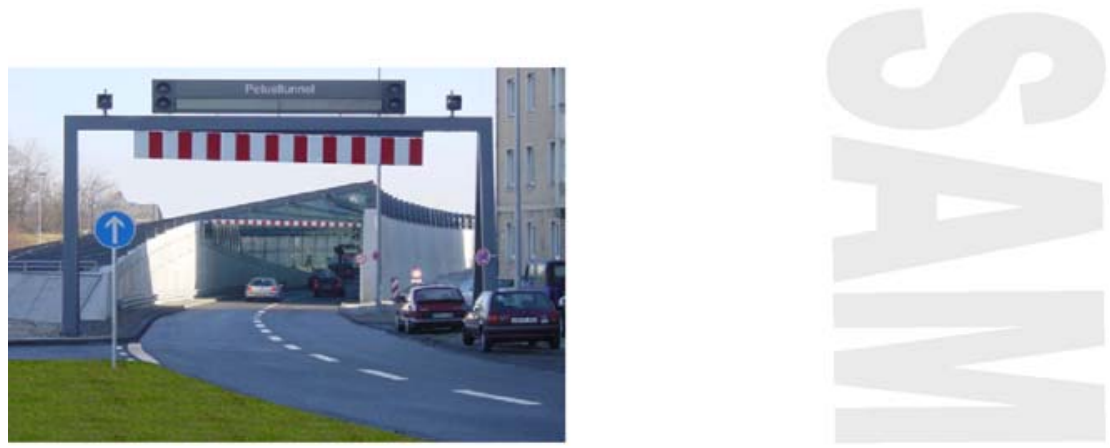


\section{SAM}

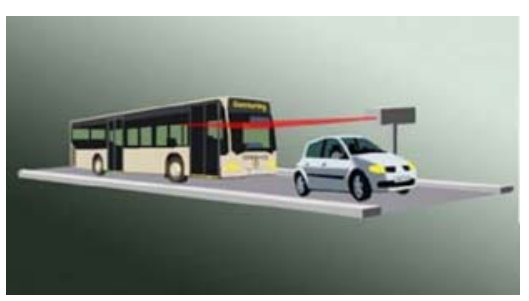

\section{Vehicle Detection}

Owing to the sharply focussed laster beam, SAM detects objects reliably even at great distance and in adverse weather conditions. Pointing across the direction of traffic, SAM detects - dependent on the height it is mounted at - all vehiclies or only vehicles starting at a minimum height. This way, light-signal systems, barriers or gates can be selectivly operated and controlled.

\section{2-Range-Detection (Lane Detection)}

SAM is able to recognize that part of its own laser beam that has been reflected by an object. The distance of the reflecting object can then be determined from the travelling time of the light. Being mounted pointing across the direction of traffic and across two lanes, SAM is able to determine the lane a vehicle is on. In this configuration, SAM is able to control light signal system, for instance at bus terminals and factory exits. Dependent on the lane they are on, vehicles can request a left or right turn.

\section{Drawbar Detection}

SAM-E is equipped with lenses, that widen the laser beam by $12^{\circ}$ to a line. This way, a large area can be scanned optically. Objects inside the laser beam triangle reflect part of the light and will be detected. This configuration is mainly employed in fully-automatic tollgates where SAM is used to distinguish truck trailers from individual vehicles by detecting the drawbar between truck and trailer. 
SAM Technical Data

Dimensions ex. tube

$180 \times 135 \times 105 \mathrm{~mm}$

Dimensions tube incl. heating $456 \times 135 \times 105 \mathrm{~mm}$

Weight

$1,8 \mathrm{Kg}$

Enclosure rating

Operation temperature

Laser

Power supply

Power consumption

Heating power supply

Heating current

Output signals

Communication Interface

Operating mode display
IP67

$-25^{\circ} \mathrm{C}$ bis $+60^{\circ} \mathrm{C}$

$850 \mathrm{~nm}$ pulsed,

$10 \mathrm{~mW}$, safe to the eye

$24 \mathrm{~V}+/-10 \%$

$100 \mathrm{~mA}$

$24 \mathrm{~V}+/-30 \%$

$\max .1 \mathrm{~A}$

$2 \times \mathrm{RS} 485$

RS485

ultra bright LED
SAM-S (Overheight Detection)

Operation method reflex sensor

Beam (spot) $\quad 0,5^{\circ}$

Detection range $\quad 3 m-32 m$

Reaction time $2 \mathrm{~ms}$

SAM (Vehicle Detection)

Operation method proximity sensor

Beam (spot) $\quad 0,5^{\circ}$

Detection range $3 m-20 m$

Reaction time $\quad 10 \mathrm{~ms}$

SAM-E (Drawbar Detection)

Operation method proximity sensor

Beam (line) $12^{\circ}$

Detection range $1 \mathrm{~m}-10 \mathrm{~m}$

Reaction time $\quad 10 \mathrm{~ms}$

Schuh \& Co. GmbH ${ }^{\circ}$ Goethestr. $17^{\circ}$ D-82110 Germering Telefon +49 (0) 89 / 8941 31-0 ${ }^{\circ}$ Fax +49 (0) 89 / 8402226 e-mail: info@schuhco.de Internet: www.schuhco.de

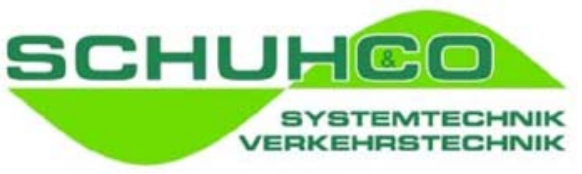




\section{HiSic450}

\section{overheight Vehicle detection in front of Bridges and tunnels}

\section{detection of vehicles with overheight}

The HISIC450 detects vehicles which are too high - at tunnel entrances, low underpasses or bridges, for exam- ple. Stop and alarm signals are immediately activated when a vehicle infringes the light beam.

The HISIC system is typically of a redundant design consisting of two subsystems, installed parallel to each other. Each are fitted with a sender and a receiver. The light beams across the road at required monitoring height. Any interruption of the light beam by an overheight vehicle sets off an alarm signal, and trafficlights switch to red for instance. Response- and OFF-delay times are selectable across a wide range allow- ing moving obstructions with a mini- mum diameter of $100 \mathrm{~mm}$, travelling at a speed of up to $100 \mathrm{~km} / \mathrm{h}$ to be reliably detected.

The usual operating distance of the HISIC450 is $100 \mathrm{~m}$ (330 ft) with a scanning range of $300 \mathrm{~m}$ (980 ft). As a rule, the width of carriageways is less than $25 \mathrm{~m}(80 \mathrm{ft})$, so the received signal strength is enhanced and there is sufficientlightin reserve to cope with difficult weather conditions, i.e. rain, snow or dust clouds. However, these atmospheric influences can not cause a false alarm.

\section{complete systems from one source}

Our measurement systems for use in traffic, road or tunnel control are ba- sed on the perfect combination of pre- cise optics and high speed intelligent electronics.

The systems are characterized by:

- high reliablity

- robust and weather proof construc- tion,

- easy to operate and low mainte- nance requirements

- modular and extendable design
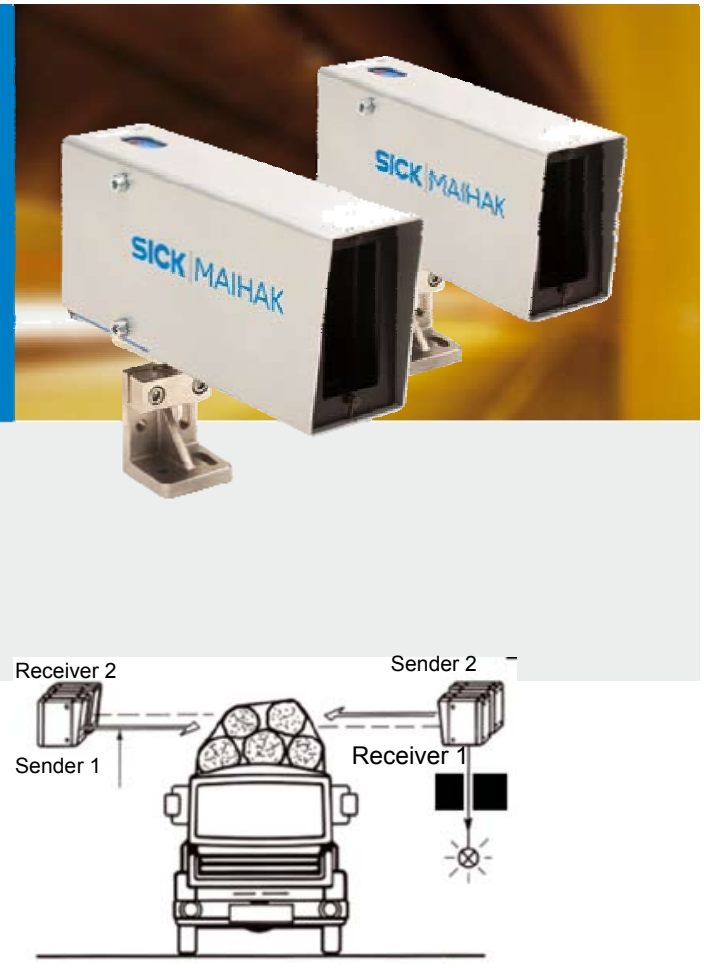

\section{Key features}

- Robust cast aluminium housing, sealed to IP 67

- Built-in lens heaters to prevent condensation or icing (option)

- Weather protection against snow, rain and dust clouds

- Optical alignment equipment

- Sensitivity adjustment

- Ambient light insensitivity

- Wide power supply range from 24 up to 240 V UC (universal) 
HiSic450 components

dimensions HiSic450 in mm (in)
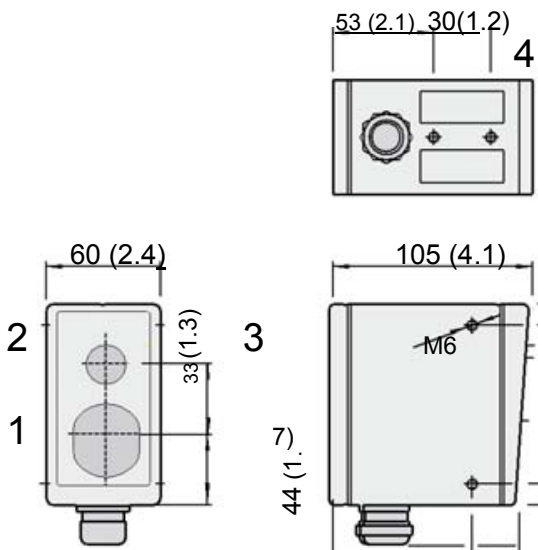

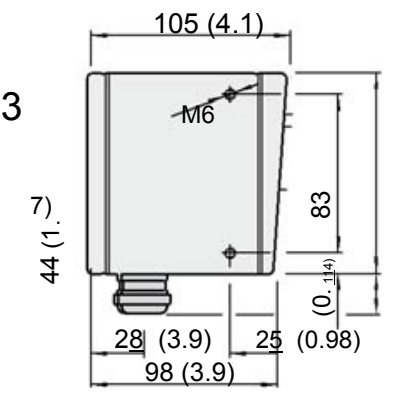

Possible adjustments

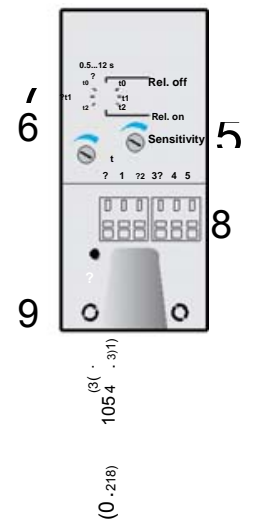

connection diagramm

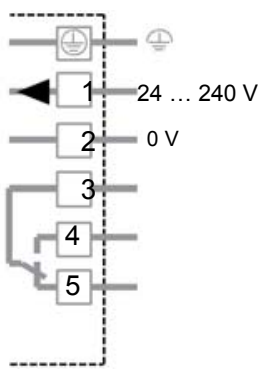

1 Center of optical axis, sender, center of

6 Time adjustment

7 Time delay selector switch;

left light-switching, right: dark-switching

8 Terminal strip

3 LED signal strength indicator

4 Threaded mounting hole M6 $\times 8$

9 Status indicator

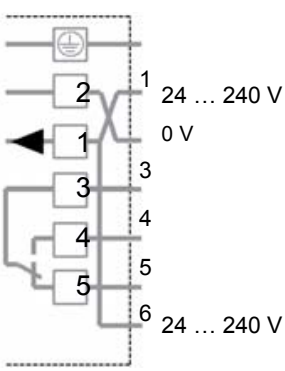

5 Sensitivity adjustment

dimensions dust protection

$\stackrel{m}{\stackrel{m}{\varphi}}$

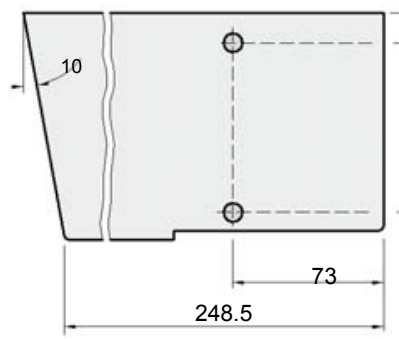

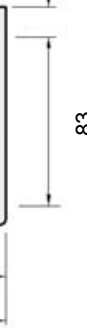

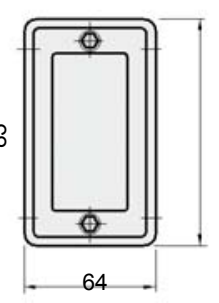

dimensions Ball joint bracket

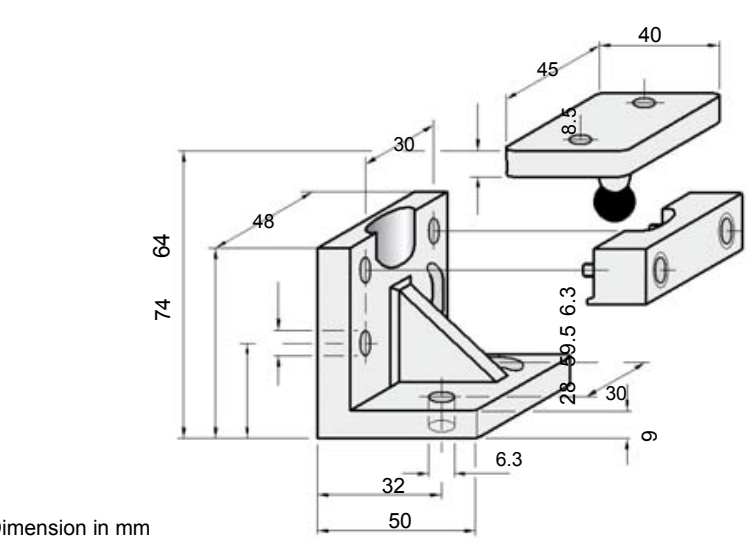

Dimension in $\mathrm{mm}$

\begin{tabular}{|l|l|l|}
\hline technical data & HiSic450 (WS/WE45) & HiSic450 (WS/WE transistor) \\
\hline Scanning range & $300 \mathrm{~m}(980 \mathrm{ft})$ & $300 \mathrm{~m}(984 \mathrm{ft})$ \\
\hline Supply voltage & $24 \ldots 240 \mathrm{~V} \mathrm{UC}$ (universal) & $10 \ldots 60 \mathrm{~V} \mathrm{DC}$ \\
\hline Current/power consumption & $250 \mathrm{~mA} / 6 \mathrm{VA}$ & $\leq 500 \mathrm{~mA}$ \\
\hline Light transmitter & LED, infrared, pulsed & LED, infrared, pulsed \\
\hline Average life time & $100,000 \mathrm{~h}$ & $100,000 \mathrm{~h}$ \\
\hline Switching outputs & SPDT, electrically isolated & PNP, Q and Q \\
\hline Max. switching voltage & $120 / 250 \mathrm{~V} \mathrm{AC/DC}$ & \\
\hline Max. switching current & $2 / 4 \mathrm{~A}$ AC/DC & $200 \mathrm{~mA}$ \\
\hline Max. braking capacity & $120 \mathrm{~W} / 750 \mathrm{VA}$ AC/UC & \\
\hline Max. response time & $\leq 10 \mathrm{~ms} ; \mathrm{max}$. switching frequency $10 / \mathrm{s}$ & $\leq 500 \mu \mathrm{s}$, max. switching frequency $1000 / \mathrm{s}$ \\
\hline Protection class & $\mathrm{IP} 67$ & $\mathrm{IP} 67$ \\
\hline Weight & approx. $800 \mathrm{~g}(1.7 \mathrm{lb})$ & approx. $800 \mathrm{~g}(1.7 \mathrm{lb})$ \\
\hline Contamination signal & & $100 \mathrm{~mA}$, open collector \\
\hline
\end{tabular}




\section{EC SYSTEMS}

To prevent vehicles that are too high for tunnels or low overpasses to cause severe damage, a reliable of these vehicles is necessary.TEC Traffi c Systems supplies and installs, for this application specifi cally developed laser detectors. The alarm contact is used to give early warning to operators or to set a number of automatic measures in action.

The basic principle is that a pulsating laser beam, which is projected at a certain height above the road surface, gets interrupted when (part of) a vehicle passes through it. An important plus of the detector is that it needs only to be installed on one side of the road, with a refl ection plate on the opposite side of the road. It has a reach of approximately 30 meters.

The laser is capable of detecting objects no spaller than 5 centimeters, traveling at 100 $\mathrm{km} / \mathrm{h}$, regardless of shape or colour. The laser is usually applied in a double confi guration, in combination with an inductive loop on each lane underneath the laser beam, as to maximize accuracy.

Consequently birds e.g. fl ying through the beams will not generate an alarm.

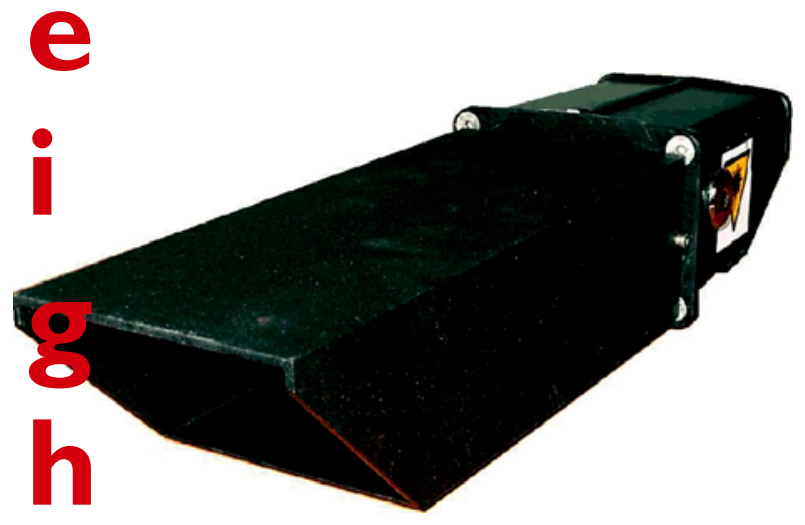

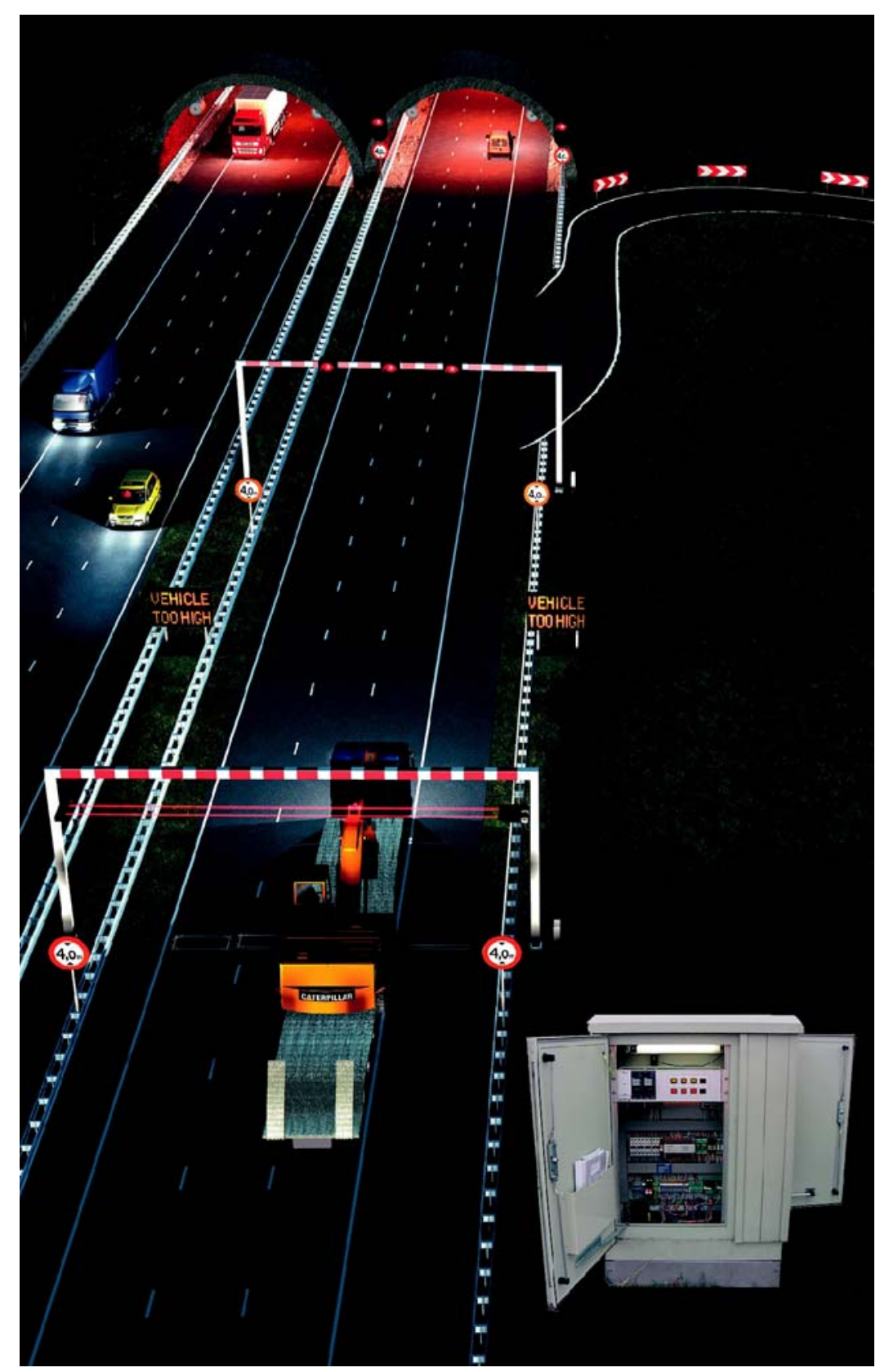

Neither mist nor snow will influence the operation signifi cantly. The lenses are equipped with heating elements to prevent condensation.Lengthened sun visors prevent the lenses from being obstructed by snow.

One installation consists of a roadside cabinet,a double laser detector and mounting constructions on existing gantries which provide for a variable height adjustment. 


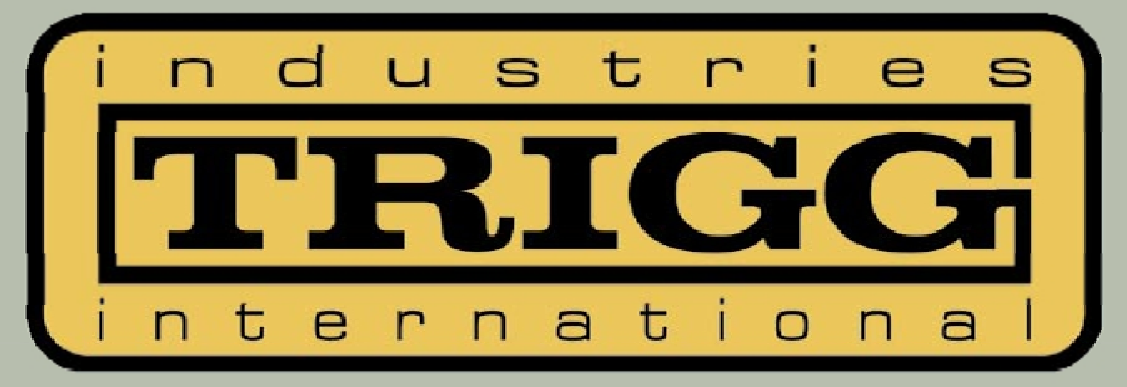

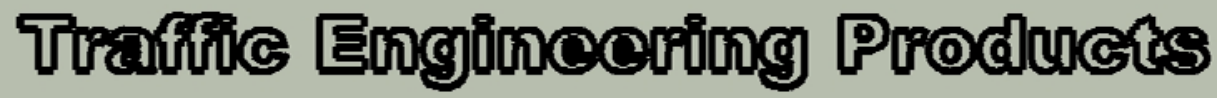

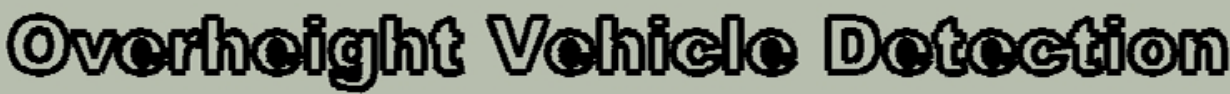 and W Warmơng Systcms}




\section{Overheight Vehicle Detection and Warning Systems (OVDS)}

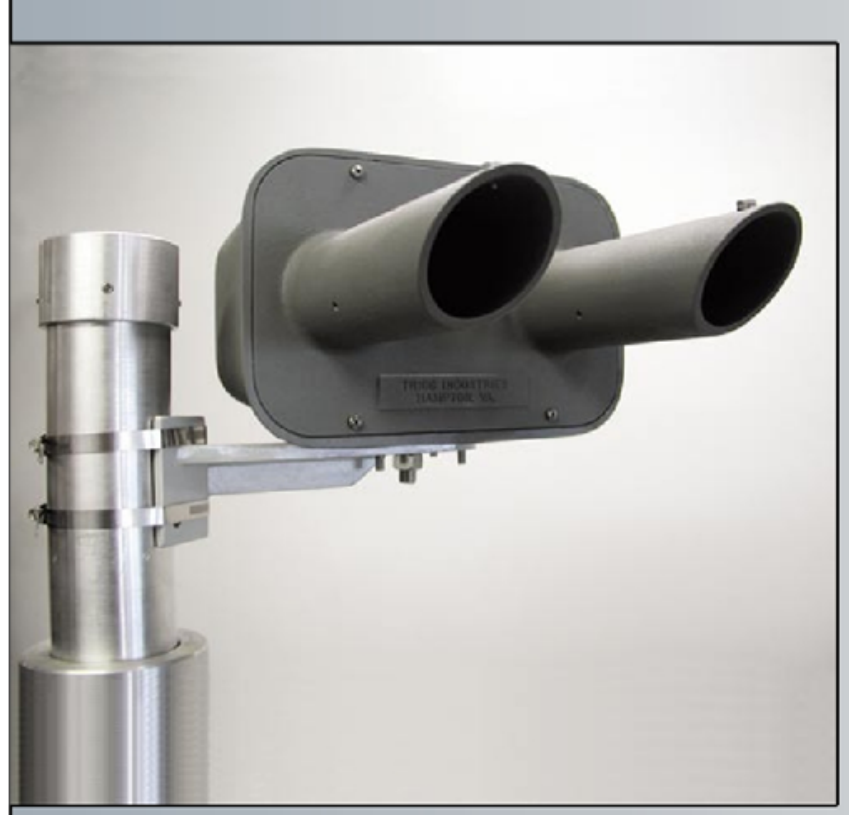

\section{What Does Trigg Industries OVDS Do?}

- Detects overheight vehicles and warns drivers of an impending problem.

- Directs the driver via warning signs and warning bells to take corrective action.

- Provides secondary warning beyond existing signage in the interest of public safety.

- Reduces exposure to costs associated with incidents or accidents.

- Proven to minimize or eliminate the occurrence of accidents and incidents caused by overheight vehicles.

\section{Industry Standard}

- The standard for quality and performance in all environments for thirtyfive years.

- Integral to hundreds of state, county and municipal infrastructures coast to coast.

- SystemofchoiceforBostonCentralArteryTunneIProject,Cumberland Gap Tunnels, Queens Tunnel and 25 DOTs.

- We provide technical support and documentation from the planning stage through installation.

\section{Applications}

- Bridges

- Tunnels

- Overpasses
- Airport Overhangs/Walkways

- Temporary Falsework

- Parking Structures
- Equipment Yards

- Railroads

- Car Carriers

\section{Cost Benefit}

One accident usually exceeds the cost of a complete detection and warning system. Trigg Industries OVDS adds an additional layer of protection and helps to minimize or eliminate costs associated with:

- Injury or loss of life

- Emergency Response

- Traffic Delays
- Administrative costs

- Structural Repair

- Insurance Premiums
- Dispute or Litigation

- Media Publicity

\section{Highest Reliability and Quality Control Standards}

Installed in some of the most adverse conditions worldwide. Proprietary cabinet design and internal environmental control allows continuous operation in fog, ice, snow, dust and heat. Systems meet ISO/IEC Guide 22 Compliance, CE Mark, NEMA 3R Cabinet Enclosure Rating, CALTRANS lightning and hi/lo voltage parameters. We provide extensive documentation and Factory Acceptance Testing protocols.

\section{Innovation}

The Trigg Industries Patented Z-Pattern ${ }^{\mathrm{TM}}$ Red/Infrared dual beam array provides the most advanced ability to reject ambient light and virtually eliminates false overheight alarms. Fault Detection and Alert Function notifies Central Control Facility when system is operating in Single Eye Mode (temporary condition) or has experienced a line power failure. Double and Single Eye systems also offer Fault Detection and Alert Function.

\section{Ease of Use}

Trigg Industries provides specialized mounting brackets for all systems and all elements of the system that allow it to be attached to any sturdy structure. Installation instructions are direct and easy to follow. 


\section{Descriptions}

\begin{tabular}{|c|l|}
\hline Device & Description \\
\hline \multicolumn{1}{|c|}{ ovDs } & $\begin{array}{l}\text { Point of detection and direction discernment. Four categories of systems, } \\
\text { encompassing ten different models for a wide range of applications. Sweep }\end{array}$ \\
\hline Audible Alarm & $\begin{array}{l}\text { of sight is attracted by alarm. First alarm after detection and second above } \\
\text { message sign. }\end{array}$ \\
\hline Warning Signs & $\begin{array}{l}\text { Standard Warning Sign with alternating flashers includes custom message } \\
\text { providing directions to drivers of overheight vehicles. }\end{array}$ \\
\hline \multirow{3}{*}{ Extras } & $\begin{array}{l}\text { Variable LED Message Signs (VMS) available in two, three and four line } \\
\text { formats. PC programmable. }\end{array}$ \\
\cline { 2 - 3 } & $\begin{array}{l}\text { Poles, sirens, bells, strobes, solar power, loop detector, radio frequency link } \\
\text { and alternate mounts available. }\end{array}$ \\
\hline
\end{tabular}

\section{Concept}

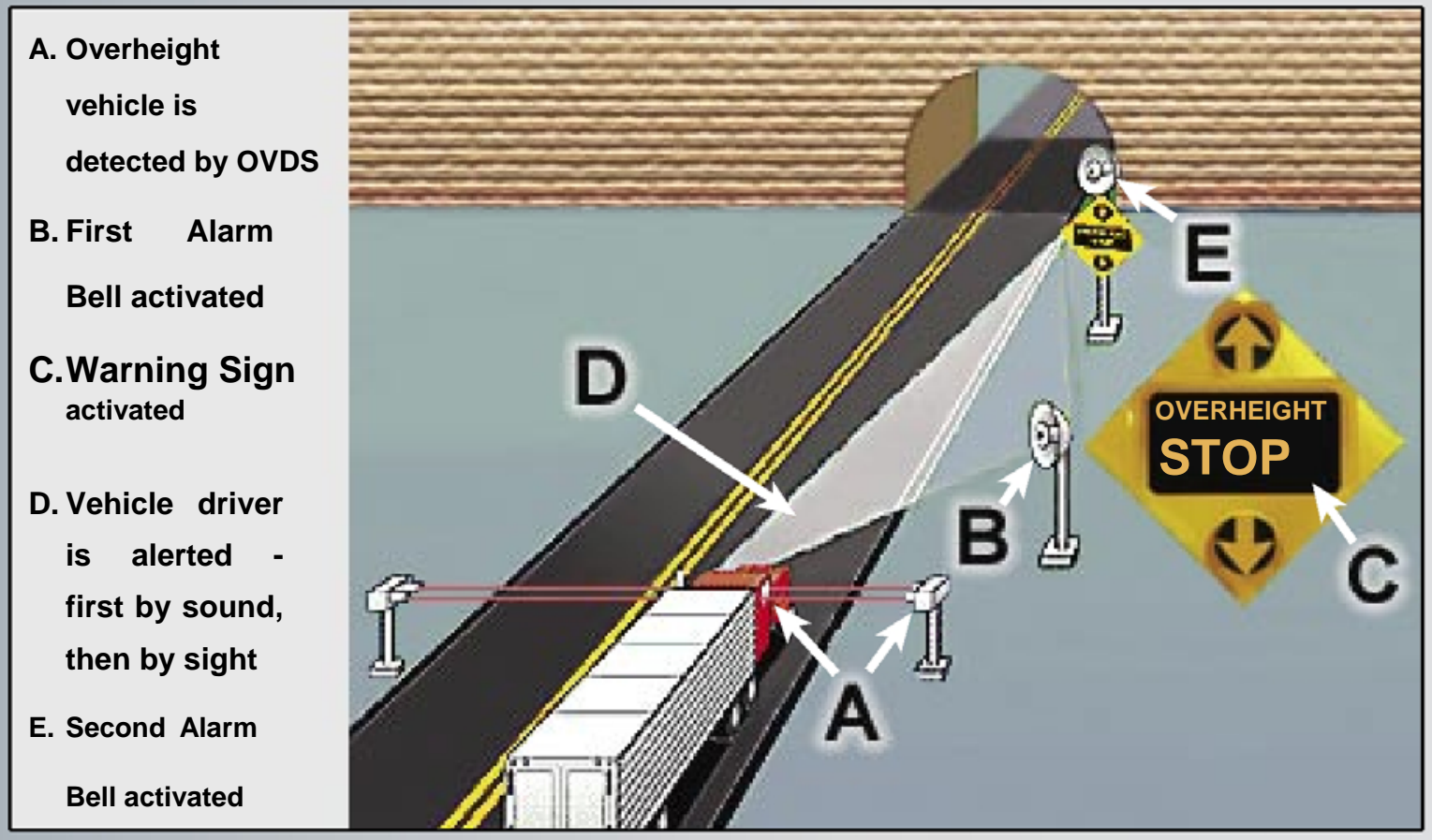




\section{Applications}

Trigg Industries manufactures complete systems, including detectors, warning signs, alarms, mounting poles and all needed accessories. We build to meet US and International power requirements, as well as AC and solar (DC) configurations.

Trigg Industries offers technical options to meet varying requirements and can provide cost effective solutions for virtually any overheight warning requirement. Custom systems can be provided as required.

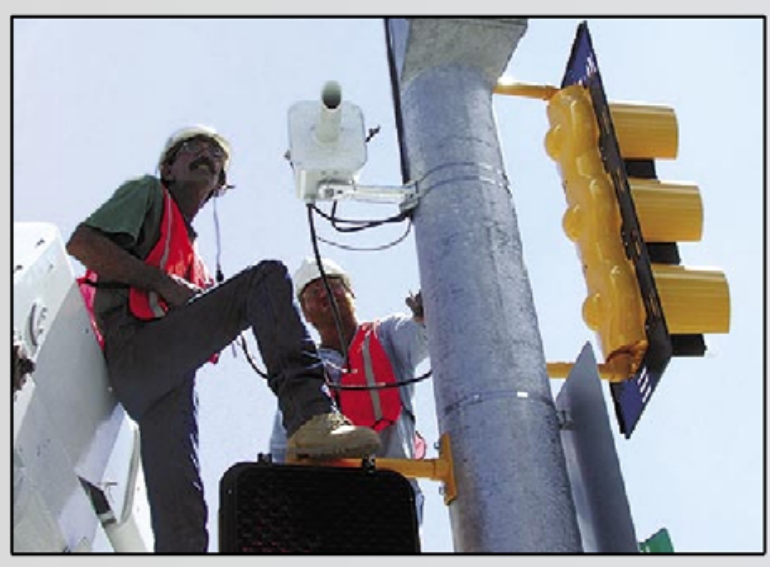

- Bridges

- Tunnels

- Overpasses

- Temporary Falsework

- Railroad Tunnels

- Airport passenger drop-off overhangs and pedestrian walkways

- Weigh Stations

- Load Height

Verification for:

- Equipment Yards

- Car Carriers
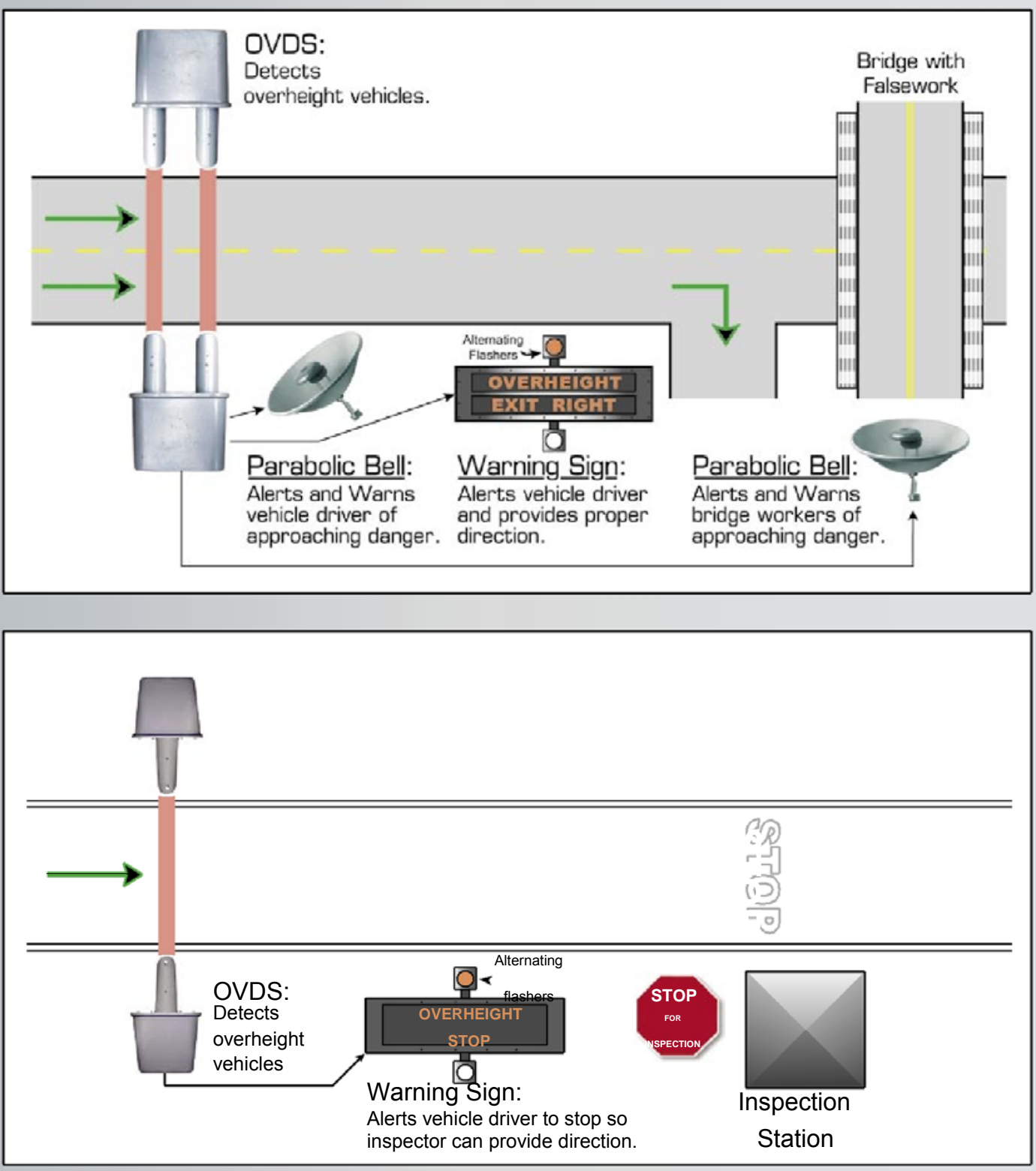
Metro Economy OVDS installed inside parking structure detecting a single height.

Dual Single Eye OVDS installed outside parking structure

detecting two different heights.

EXAMPLE:

- If vehicle is detected by OVDS $\# 1$, driver is instructed by VMS to park where clearance is adequate.

- If vehicle is detected by OVDS \#2, driver is instructed by VMS to stop and await further direction.

If a vehicle is overheight, the Variable Message Sign (VMS) displays a sequence of messages instructing driver where or where not to park. The gate can be delayed from opening while messages are displayed.

\section{EXAMPLE:}

- Iviessiaye I. oIUr

- Message 2: "VEHICLE TOO TALL"

- Message 3: "PARK LEVEL 1 ONLY" or "DO NOT ENTER"
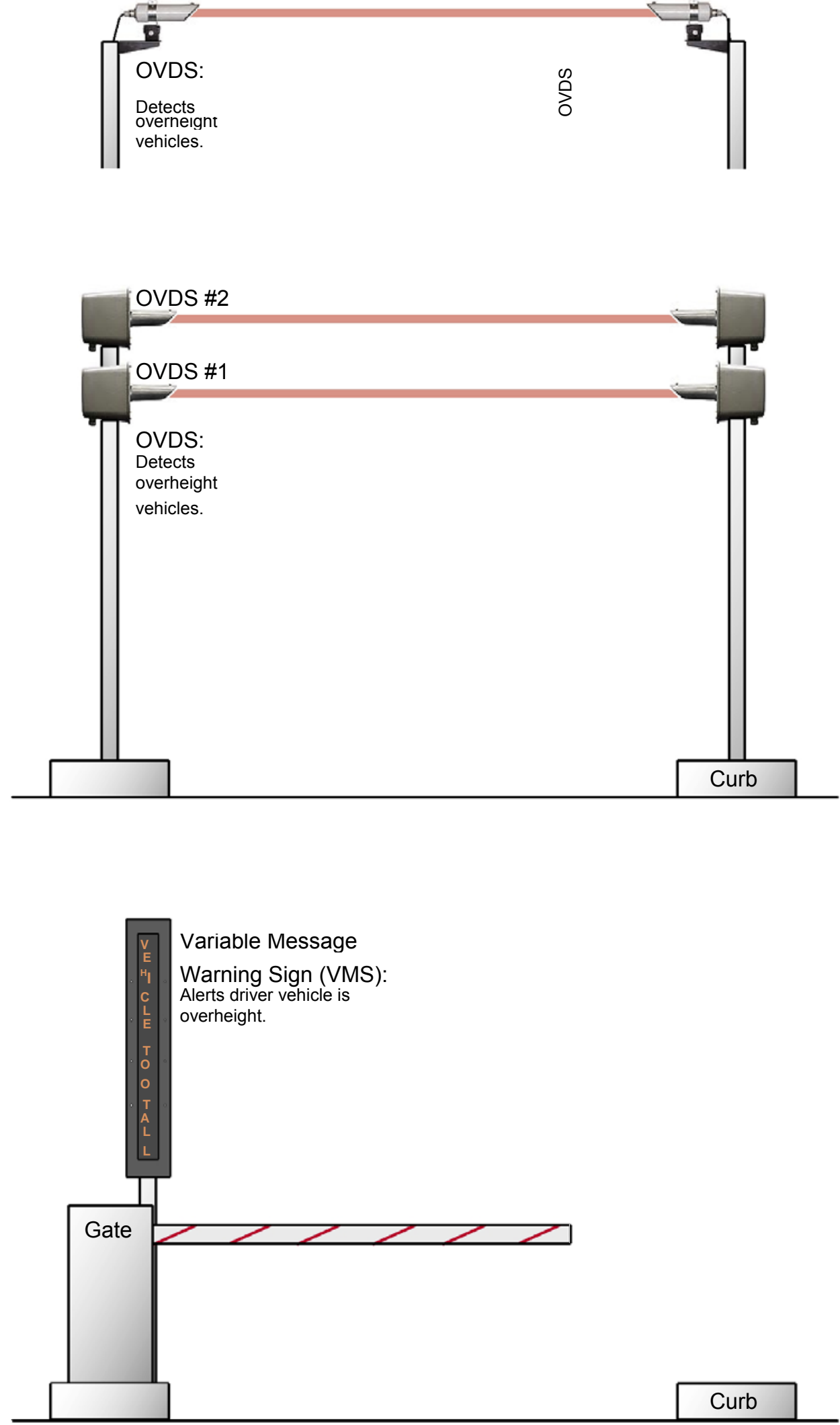


\section{Double Eye Z-Pattern •}

Visible Red and Infrared

Model \#: 3400-Z, 3401-Z, 3402-Z, 3403-Z

- *Patented Visible Red / Infrared Mixed

- Environmental control

- Enhanced rejection of ambient light

- Fault detection and reporting

- Nema 3R cabinet rating

- Direction discerning

- Proprietary ALMAG cabinet design

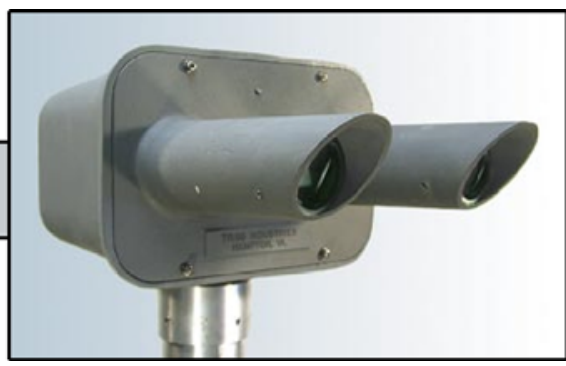

Remote

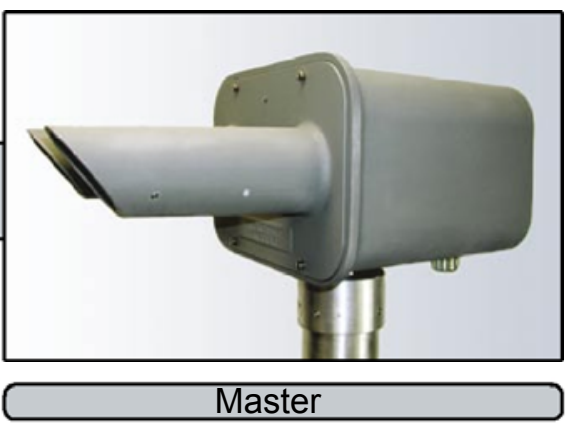

Z-Pattern
INPUT POWER

OUTPUT

FAULT REPORTING

\section{ALARM TIME}

ELECTRONICS

EFFECT OF AMBIENT LIGHT

MAXIMUM RANGE

DIRECTION SELECTION

ALIGNMENT

REACTION SPEED

TEMPERATURE RANGE

$-40^{\circ}$ to $+135^{\circ} \mathrm{F}\left(-40^{\circ}\right.$ to $\left.+57^{\circ} \mathrm{C}\right)$.

ENVIRONMENTAL CONTROL

HOUSINGS

DIMENSIONS $50 / 60 \mathrm{HZ}$ operation. breakers. and lens contamination. during cold weather.
$115 \mathrm{VAC},+/-10 \%, 50 / 60 \mathrm{HZ}$. Other options include $24 \mathrm{VDC}$ solar or $230 \mathrm{VAC},+/-10 \%$,

Two Form C, dry relay contact closures for Overheight Alarm Functions. One Form C, dry relay contact closure for Fault Reporting. Contacts rated 115VAC 10A, protected by $8 \mathrm{~A}$ circuit

DE-Z/3400 - Fault reporting output upon loss of source/detector power or total failure. DE-Z/3401, 3402, 3403 - Fault reporting output upon loss of source/detector power or total failure. Fault Relay toggles at one-second intervals during Single Eye Mode of operation.

DE-Z/3400 - Adjustable by customer from 2 to 30 seconds.

DE-Z/3401, 3402, 3403 - Adjustable by customer from 5 to 60 seconds.

Sensors are NEMA 6P enclosure rated.

Use of Dual Beam "Z" Pattern provides automatic switch to Single Beam Detection Mode of Overheight Protection if the sun or other interference saturates one detector.

700 feet $(213 \mathrm{~m})$. Suggested maximum range $200(61 \mathrm{~m})$ feet to allow for bad weather

Selection switch. No tools or adjustment required.

Four LEDs and meter (GO-NOGO functions) provided for ease of alignment and testing.

1 to $75 \mathrm{MPH}$ ( 1 to $121 \mathrm{~km} / \mathrm{h})$ for a 2 inch $(50 \mathrm{~cm})$ diameter object 1 inch $(3 \mathrm{~cm})$ above the detection height. Custom speed/size available.

Internal thermostat controls air flow which reduces moisture and maintains internal temperature

External housing is heavy ALMAG casting and sheet aluminum (not less than 1/8 inch or $.318 \mathrm{~cm}$ thickness) for rugged durability and extended life. Cabinet design minimizes effects of vandalism and provides rigid mounting. The pole cap serves as a mounting bracket and sighting base with our poles. NEMA 3R Certified.

Remote Cabinet: $123 / 4$ x 161/2 x 81/2 inches (32 x 42 × $22 \mathrm{~cm})$.

Master Cabinet: $12 \frac{3 / 4}{4} 183 / 4 \times 81 / 2$ inches $(32 \times 48 \times 22 \mathrm{~cm})$.

$60 \mathrm{lbs}(27 \mathrm{~kg})$ 


\section{Double Eye}

Visible Red or Infrared

\section{Model \#: DE-R/3110 or DE-IR/3111}

- Visible Red or Infrared systems

- Fault detection and reporting

- Environmental control

- Meets Nema 3R Intent

- Direction discerning

- Proprietary ALMAG cabinet design
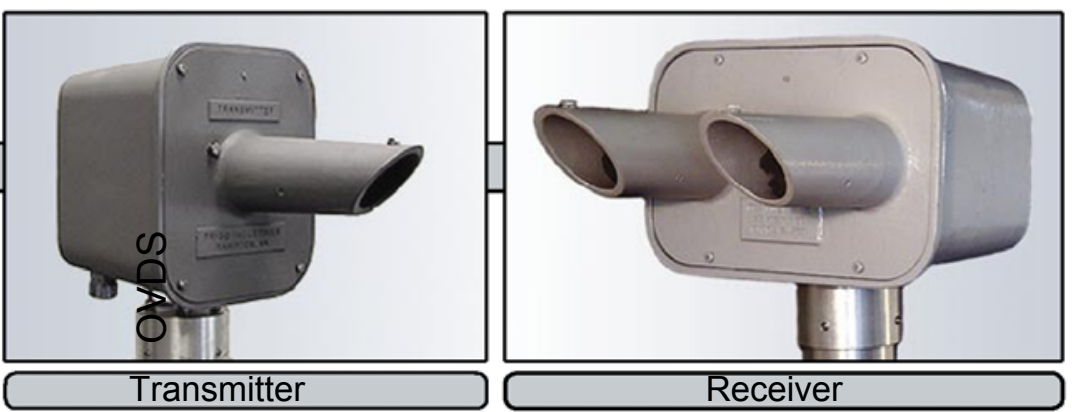

\begin{tabular}{ll}
\hline INPUT POWER & $\begin{array}{l}\text { 115VAC, +/- 10\%, 50/60HZ. Other options include 24VDC solar or 230VAC, +/-10\%, 50/60HZ } \\
\text { operation. }\end{array}$
\end{tabular}

OUTPUT

Form C, dry relay contact closure, contacts rated 115VAC 10A, protected by an $8 \mathrm{~A}$ circuit breaker. System switches to Single Eye Mode of operation upon loss of either detector.

FAULT REPORTING

Optional fault reporting output upon loss of power, transmitter failure or either eye blocked for more than 13 seconds. Single Eye mode of operation implemented.

ALARM TIME

Adjustable by customer from 1 to 30 seconds. Custom alarm times available.

ELECTRONICS

Sensors are NEMA 6P enclosure rated. Electronic printed circuits for years of reliable operation.

EFFECT OF AMBIENT LIGHT

DE-R/3110 - Sunlight immunity of 10,000 foot-candles.

DE-IR/3111 - Very high noise immunity.

MINIMUM RANGE

10 feet $(3 \mathrm{~m})$.

MAXIMUM RANGE

DE-R/3110 - 800 feet $(244 \mathrm{~m})$. Suggested maximum range 200 feet $(61 \mathrm{~m})$ to allow for bad weather and lens contamination.

DE-IR/3111 - 700 feet $(213 \mathrm{~m})$. Suggested maximum range 200 feet $(61 \mathrm{~m})$ to allow for bad weather and lens contamination.

DIRECTION SELECTION

Selection switch. No tools or adjustment required.

ALIGNMENT

Two LEDs and meter (GO-NOGO functions) provided for alignment. No special tools required.

REACTION SPEED

1 to $75 \mathrm{MPH}(1$ to $121 \mathrm{~km})$ for a 2 inch $(5 \mathrm{~cm})$ diameter object 1 inch $(3 \mathrm{~cm})$ above the detection height. Custom speed/size available.

COUNTER

Records the number of activations.

TEMPERATURE RANGE

ENVIRONMENTAL CONTROL

HOUSINGS $-40^{\circ}$ to $+135^{\circ} \mathrm{F}\left(-40^{\circ}\right.$ to $\left.+57^{\circ} \mathrm{C}\right)$.

Internal thermostat controls air flow which reduces moisture and maintains internal temperature during cold weather.

External housing is heavy ALMAG casting and sheet aluminum (not less than $1 / 8$ inch or $.318 \mathrm{~cm}$ thickness) for rugged durability and extended life. Cabinet design minimizes effects of vandalism and provides rigid mounting. The pole cap serves as a mounting bracket and sighting base with our poles. Meets NEMA 3R intent.

DIMENSIONS

Transmitter: $15 \frac{1}{2} \times 10 \times 8 \frac{3}{4}$ inches $(39 \times 2 \times 22 \mathrm{~cm})$.

Receiver: $12 \frac{3}{4} \times 16 \frac{1}{2} \times 81 / 2$ inches $(32 \times 42 \times 21.59 \mathrm{~cm})$. 


\section{Single Eye}

Visible Red or Infrared

\section{Model \#: SE-R/3310 or SE-IR/3311}

- Visible Red or Infrared systems

- Environmental control

- Fault protection and reporting

- Non-direction discerning

- Meets Nema 3R Intent
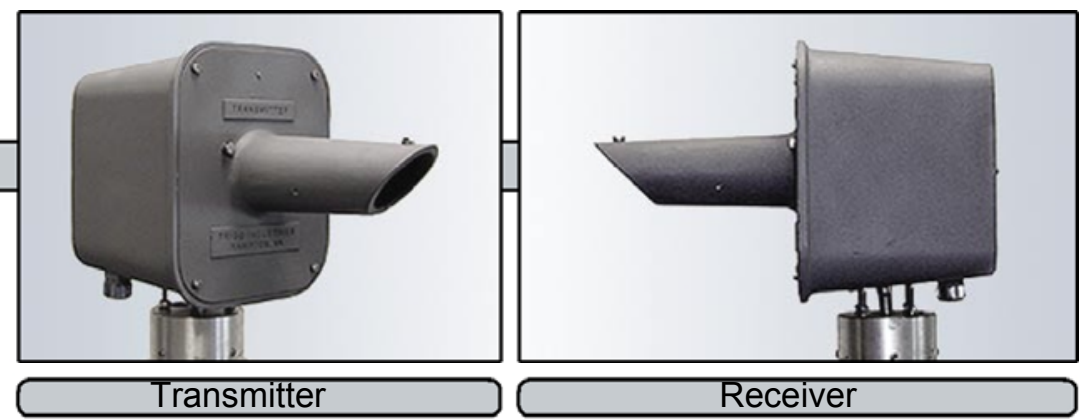

- Proprietary ALMAG cabinet design

\begin{tabular}{ll}
\hline INPUT POWER & $\begin{array}{l}115 \mathrm{VAC},+/-10 \%, 50 / 60 \mathrm{HZ} . \text { Other options include 24VDC solar or 230VAC, }+/-10 \%, 50 / 60 \mathrm{HZ} \\
\text { operation. }\end{array}$ \\
\hline OUTPUT & $\begin{array}{l}\text { Form C, dry relay contact closure, contacts rated 115VAC 10A, protected by an 8A circuit } \\
\text { breaker. }\end{array}$ \\
\hline FAULT REPORTING & $\begin{array}{l}\text { Optional fault reporting output upon loss of power, transmitter failure or either eye blocked for } \\
\text { more than 13 seconds. }\end{array}$
\end{tabular}

ALARM TIME

ELECTRONICS

EFFECT OF AMBIENT LIGHT

MINIMUM RANGE

MAXIMUM RANGE

ALIGNMENT

REACTION SPEED

COUNTER

TEMPERATURE RANGE

ENVIRONMENTAL CONTROL

HOUSINGS
Adjustable by customer from 1 to 30 seconds. Custom alarm times available.

Sensors are NEMA 6P enclosure rated. Electronic printed circuits for years of reliable operation.

SE-R/3110 - Sunlight immunity of 10,000 foot-candles.

SE-IR/3111 - Very high noise immunity.

6 feet $(2 \mathrm{~m})$.

SE-R/3110 - 800 feet $(244 \mathrm{~m})$. Suggested maximum range 200 feet $(61 \mathrm{~m})$ to allow for bad weather and lens contamination.

SE-IR/3111 - 700 feet $(213 \mathrm{~m})$. Suggested maximum range 200 feet $(61 \mathrm{~m})$ to allow for bad weather and lens contamination.

One LED and meter (GO-NOGO functions) provided for alignment. No special tools required.

1 to $75 \mathrm{MPH}$ ( 1 to $121 \mathrm{~km})$ for a 2 inch $(5 \mathrm{~cm})$ diameter object 1 inch $(3 \mathrm{~cm})$ above the detection height. Custom speed/size available.

Records the number of activations.

$-40^{\circ}$ to $+135^{\circ} \mathrm{F}\left(-40^{\circ}\right.$ to $\left.+57^{\circ} \mathrm{C}\right)$.

Internal thermostat controls air flow which reduces moisture and maintains internal temperature during cold weather.

External housing is heavy ALMAG casting and sheet aluminum (not less than $1 / 8$ inch or $.318 \mathrm{~cm}$ thickness) for rugged durability and extended life. Cabinet design minimizes effects of vandalism and provides rigid mounting. The pole cap serves as a mounting bracket and sighting base with our poles. Meets NEMA 3R intent. 


\section{Metro Economy}

Visible Red

Model \#: ME-R/301

Model \#: ME-R/305 or ME-R/310

- Visible Red system

- Nema 6P rating

- Light weight PVC cabinet

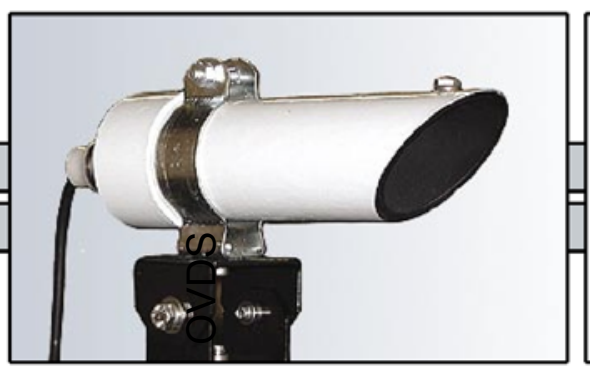

Transmitter

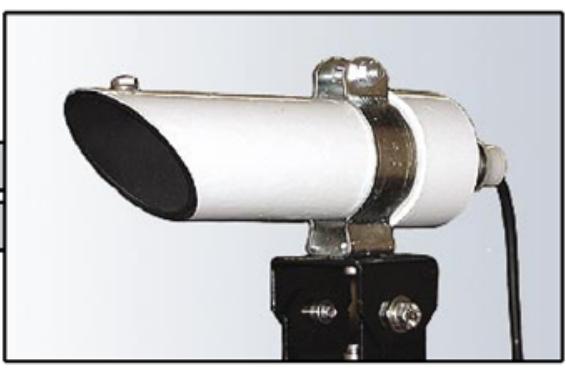

Receiver 
INPUT POWER

230VAC, $+/-10 \%$,

\section{OUTPUT}

protected by $5 \mathrm{~A}$ fuses.
115VAC, $+/-10 \%, 50 / 60 \mathrm{HZ}$. Other options include 12/24VDC solar or $50 / 60 \mathrm{HZ}$ operation.

Two form C dry relay contact closures. Contacts rated 115VAC 5A,

ME-R/301 \& ME-R/305 - Adjustable by customer from 2 to 30 seconds.

on request.

ME-R/310 - Duration equal to time beam is broken.

ELECTRONICS

Electronics use printed circuit
ME-R/301 \& ME-R/305 - Sensors are NEMA 6P enclosure rated.

board for reliable operation.

ME-R/310 - Sensors are NEMA 6 enclosure rated.

\section{EFFECT OF AMBIENT LIGHT Sunlight immunity of 10,000 foot candles.}

MINIMUM RANGE

MAXIMUM RANGE

feet to allow for bad

ALIGNMENT

required.
ME-R/301 - 6 feet $(2 \mathrm{~m})$.

ME-R/305 \& ME-R/310 - 1 foot (.3 m).

ME-R/301 - 800 feet (244 m). Suggested maximum range 200 (61 m)

weather and lens contamination.

ME-R/305 \& ME-R/310 - 80 feet $(24 \mathrm{~m})$. Suggested maximum range 40

$(13 \mathrm{~m})$ feet to

allow for bad weather and lens contamination.

GO-NOGO green LED indicator provided for alignment. No special tools

\section{REACTION SPEED object 1 inch $(3 \mathrm{~cm})$}

HOUSINGS
ME-R/301 - 1 to $75 \mathrm{MPH}$ ( 1 to $121 \mathrm{~km}$ ) for a 2 inch $(5 \mathrm{~cm})$ diameter

above the established height of detection.

ME-R/305 \& ME-R/310 - 1 to $11 \mathrm{MPH}$ ( 1 to $121 \mathrm{~km}$ ) for a 2 inch $(5 \mathrm{~cm})$

diameter object

1 inch $(3 \mathrm{~cm})$ above the established height of detection. 
APPENDIX B 


\begin{tabular}{|c|c|c|}
\hline Company & Phone Number & Fax Number \\
\hline $\begin{array}{c}\text { ASTI Transportation } \\
\text { Systems }\end{array}$ & $302-328-3220$ & $302-328-4051$ \\
\hline Autotron & $800-637-2546$ & $414-764-4296$ \\
\hline Banner Engineering & $322-456-0780$ & $322-456-0789$ \\
\hline Coeval Group & $(+) 441875-814555$ & $306-242-5599$ \\
\hline $\begin{array}{c}\text { Internaltional Road } \\
\text { Dynamics Inc. }\end{array}$ & $306-653-6600$ & $281-646-9565$ \\
\hline $\begin{array}{c}\text { Measurement Devices } \\
\text { Ltd. }\end{array}$ & $281-646-0050$ & $191-491-0799$ \\
\hline IDT & $191-491-0800$ & $(+) 492207-9677-80$ \\
\hline Peter Berghaus GmbH & $(+) 492207-9677-11$ & $(+) 49(0) 898402226$ \\
\hline Schuh \& Co. & $(+) 49(0) 89894131-0$ & $(+) 3130-6023-029$ \\
\hline TEC Traffic Systems & $(+) 3130-6023-000$ & $952-941-9287$ \\
\hline Sick Maihak & $952-941-6780$ & $323-845-9503$ \\
\hline Trigg Industries Inc. & $323-845-9390$ & \\
\hline
\end{tabular}


APPENDIX C 


\section{Proposed Solution to Limit \\ Over-height Bridge Impact}

Indianapolis, In
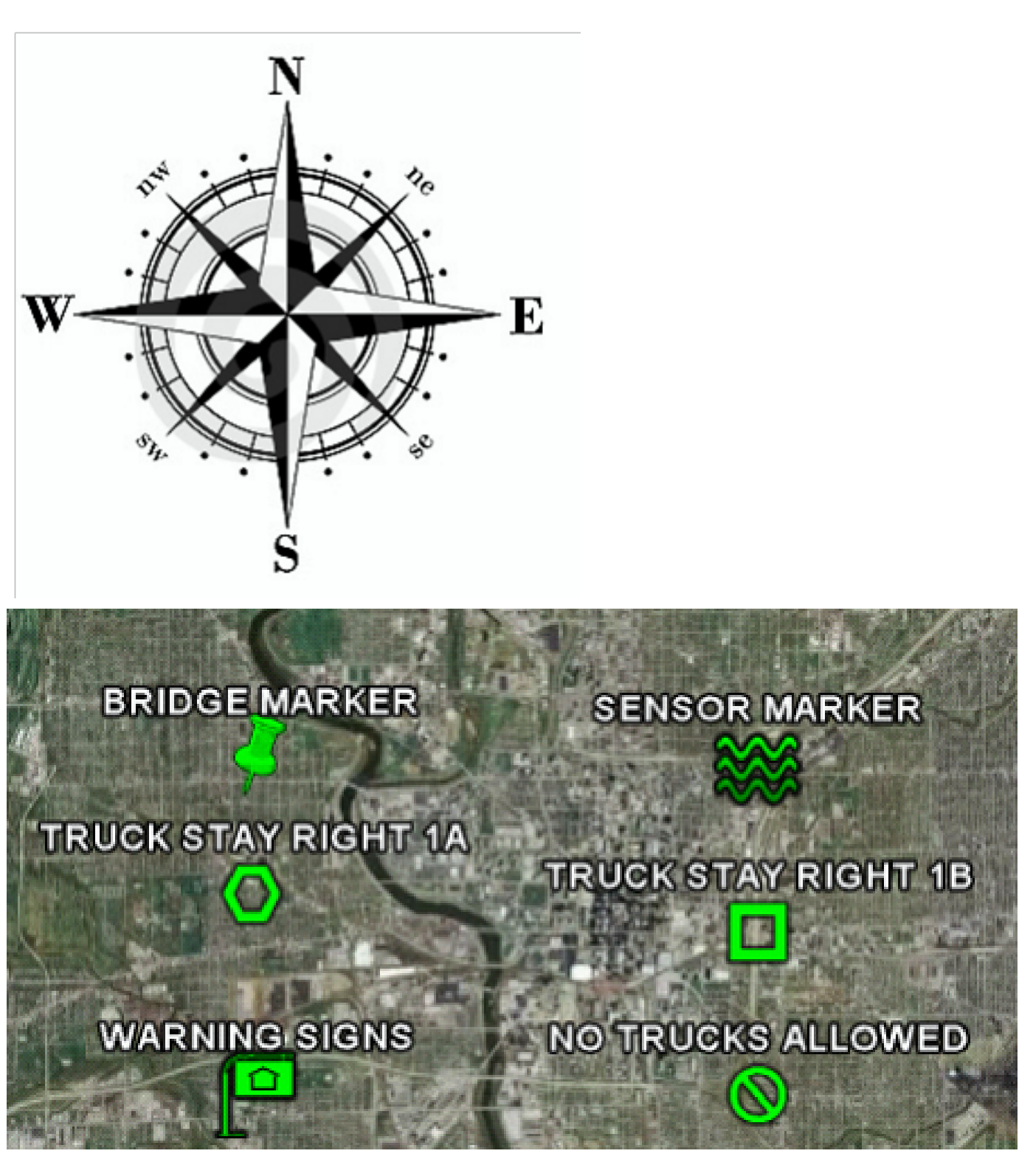

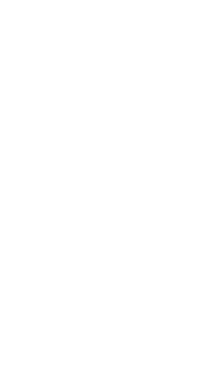

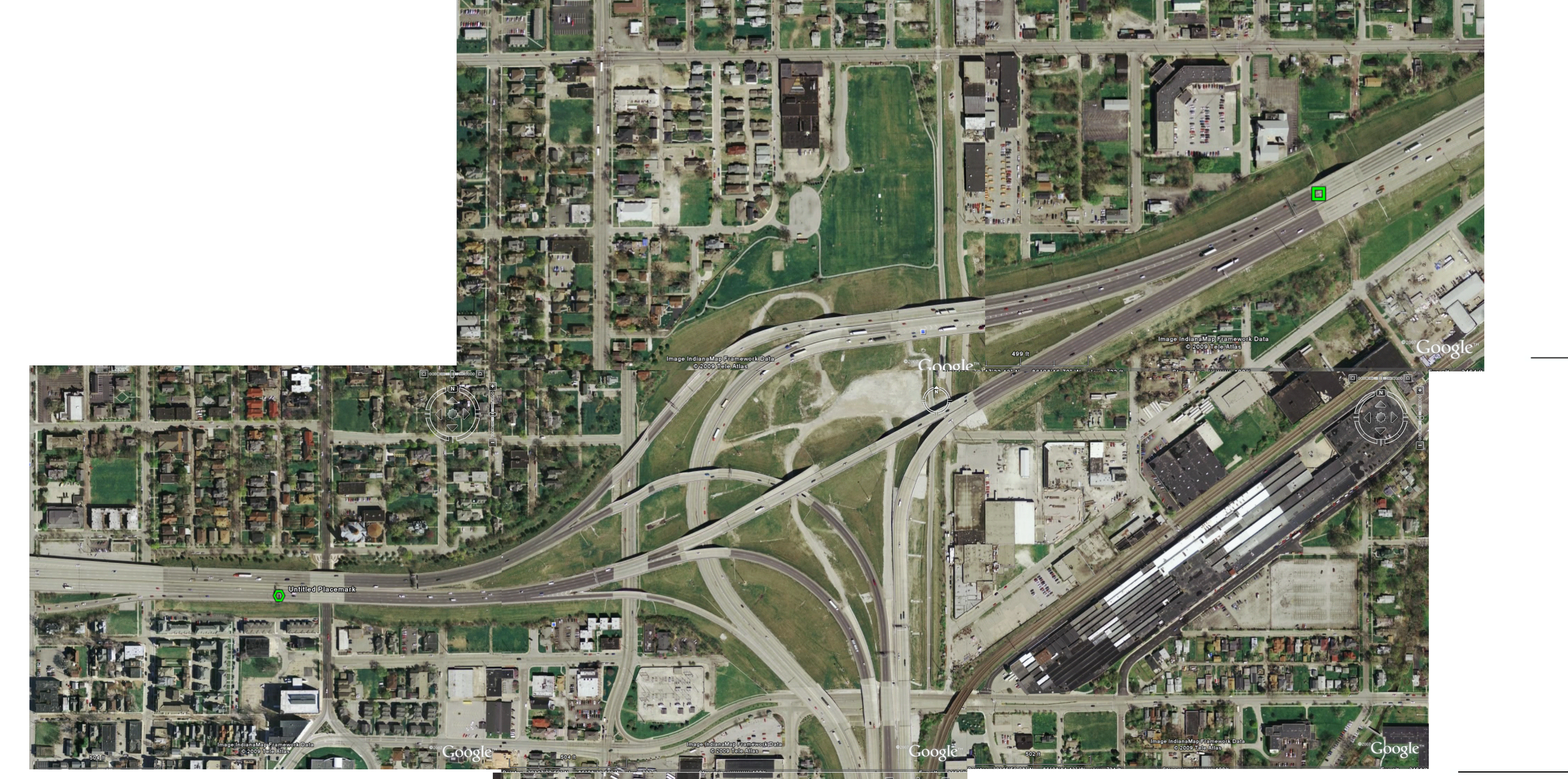

10

9
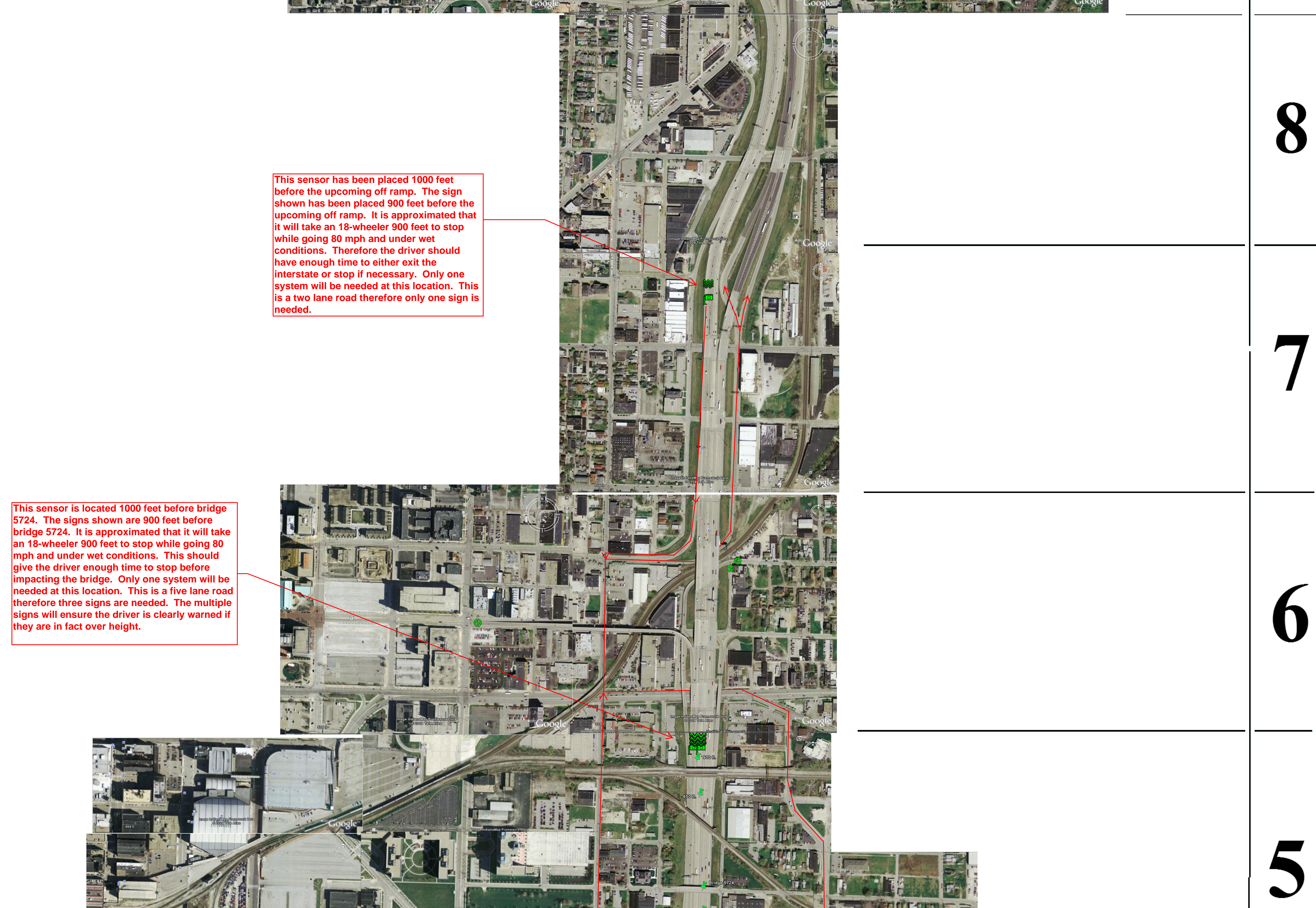

5

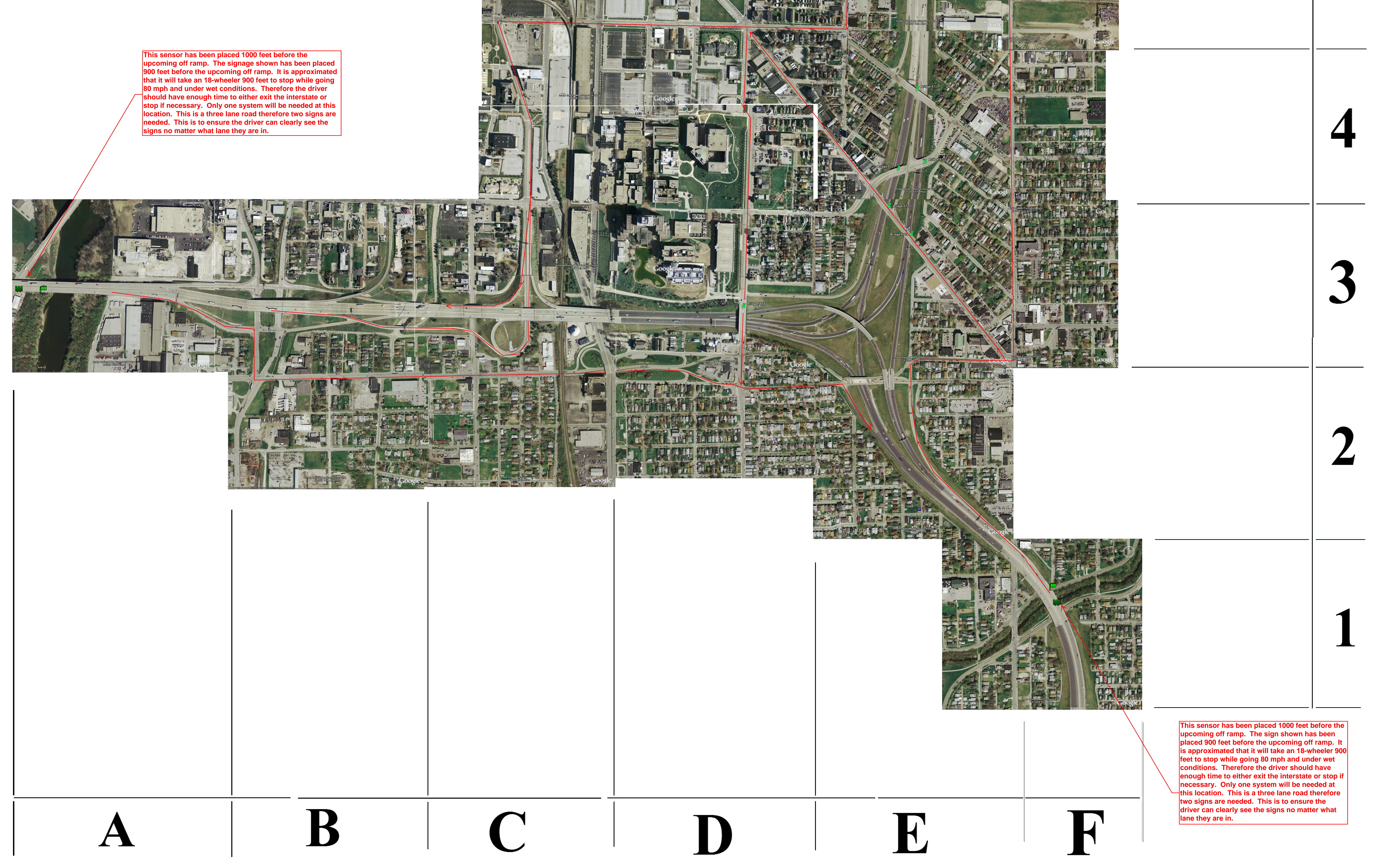

